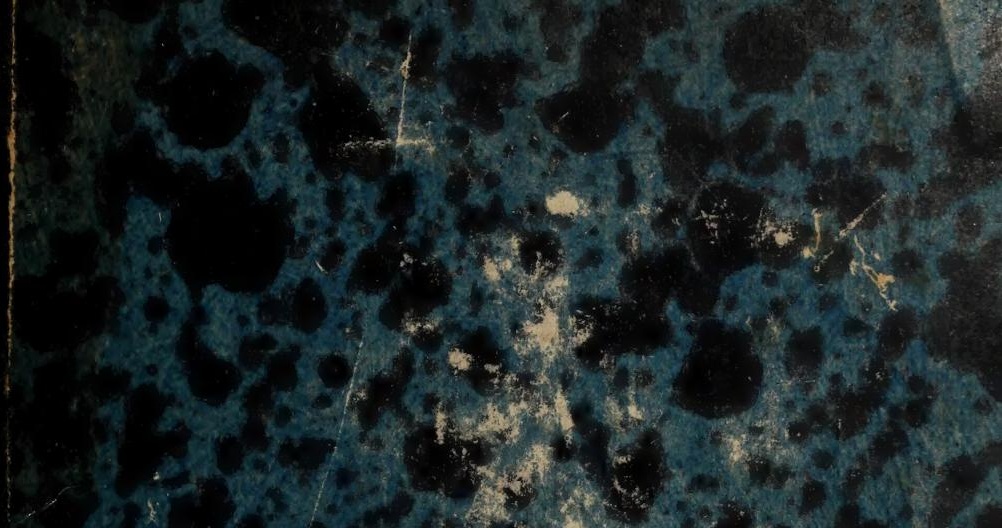

s

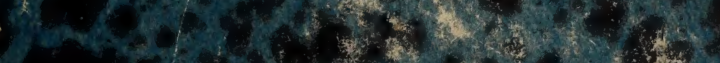

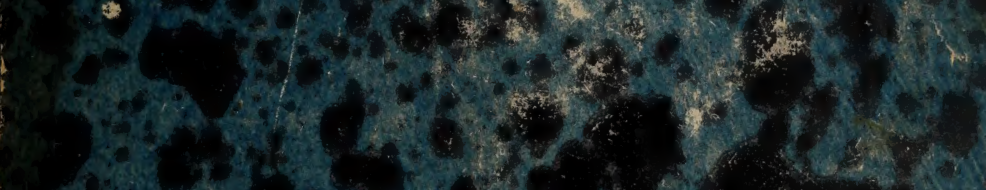
(5)

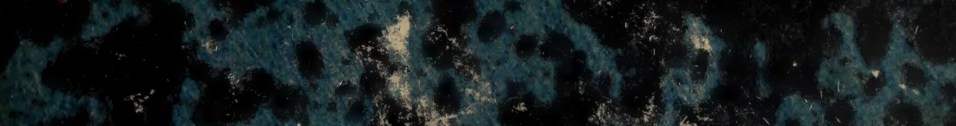

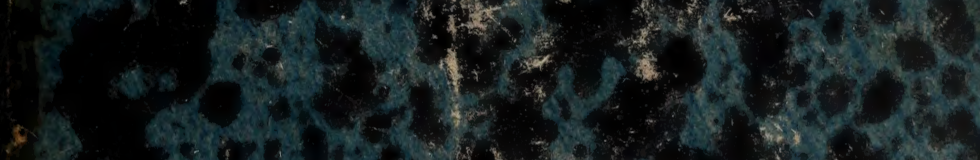
(5)

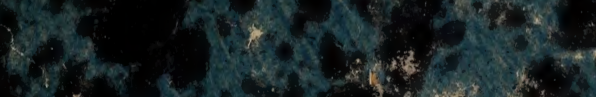

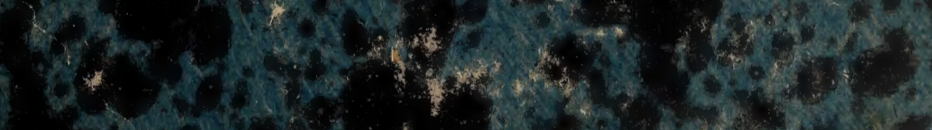
15.

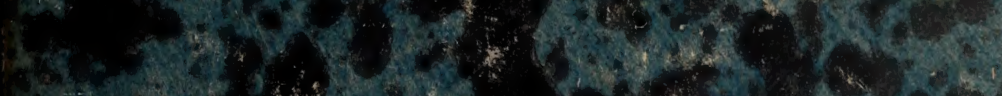

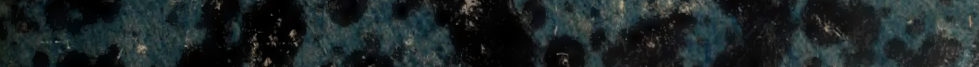

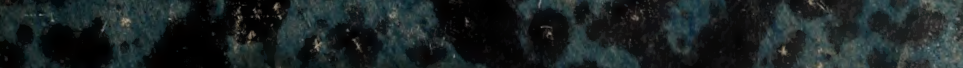
(6.60)

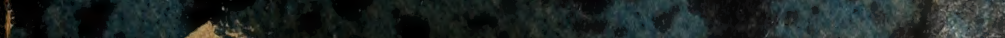


$\frac{N}{2}-2-35$
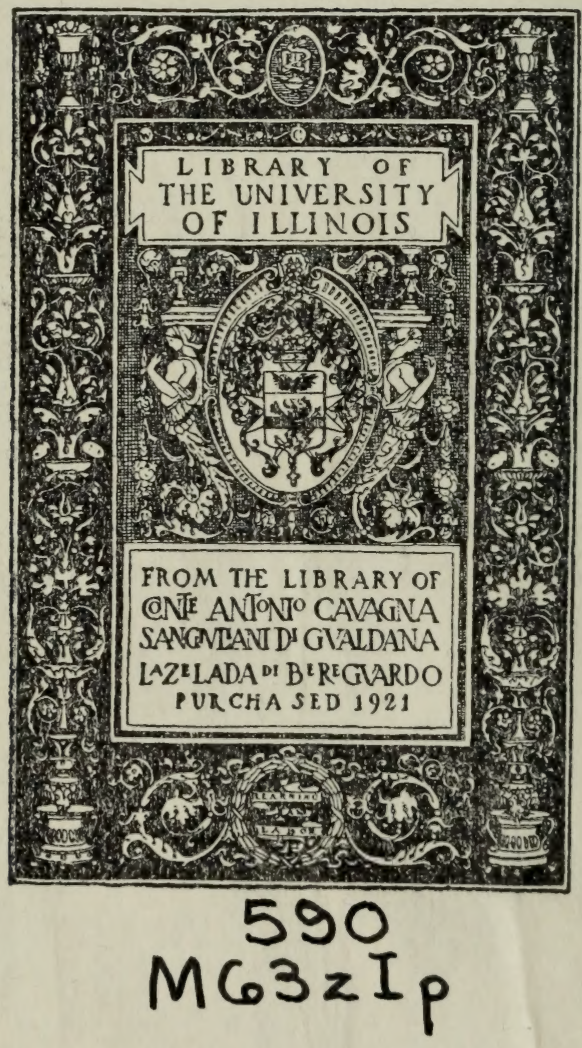


\section{sarpin}

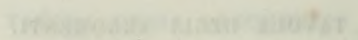
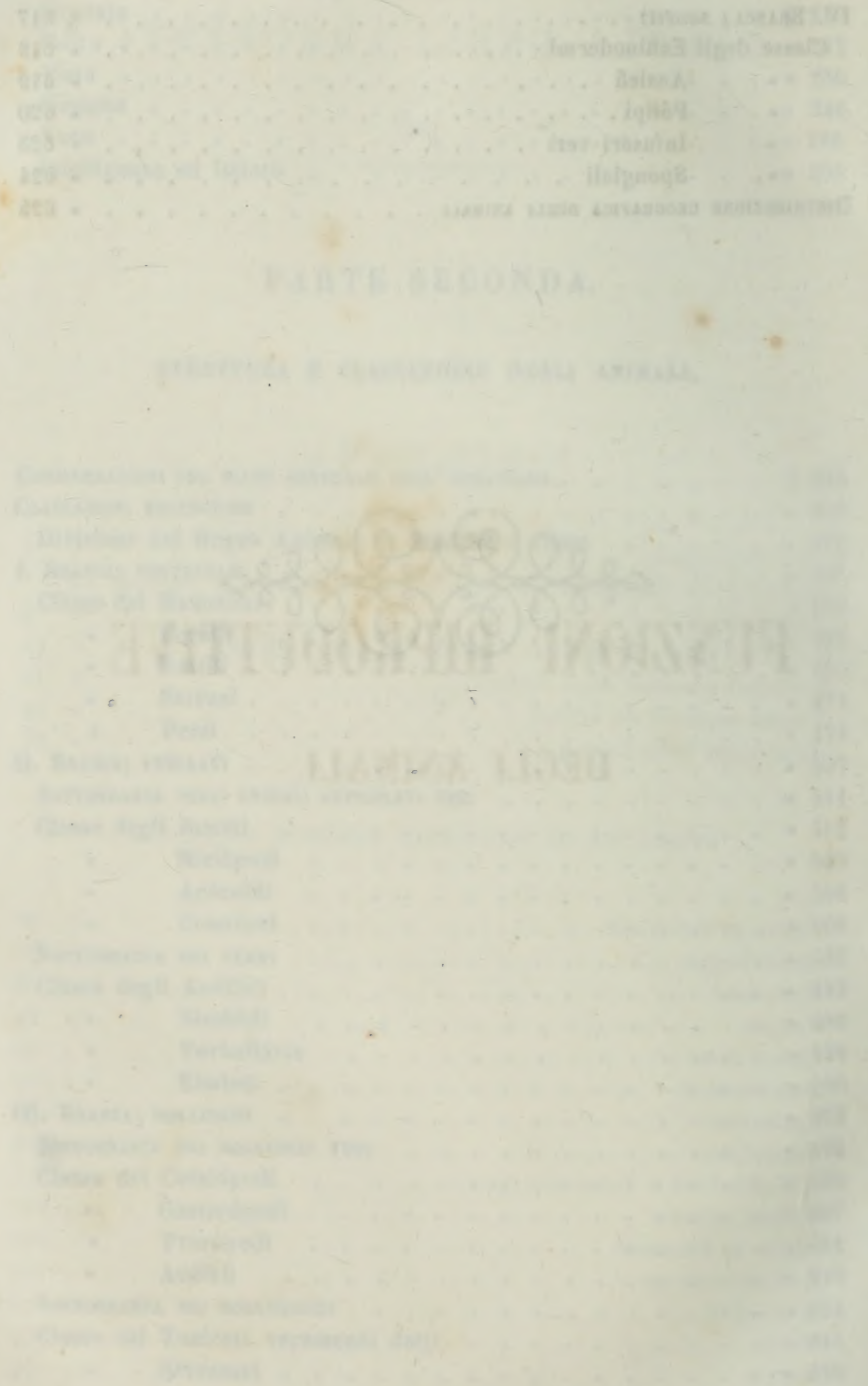
DELLE

\title{
FUNZIONI RIPRODUTTIVE
}

\author{
DEGLI ANIMALI.
}




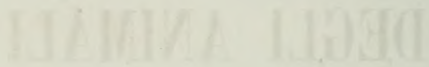

Digitized by the Internet Archive in 2012 with funding from

University of Illinois Urbana-Champaign

http://archive.org/details/dellefunzionirip00defi 


\section{INLLE \\ FUNZIONI RIPRODITTIVE DEGLI ANIMALI}

IN COMPLEMENTO ALLEDIZIONE ITALIANA

nEt.

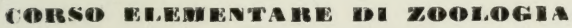

DEL SIGNOR MILNE EDWAROS

PER

\section{F. DE FILPPI}

D077. IK MFDIEINA E CHIREGIA, PROP. DI ZOOLOGIA KELIA R. UNIYERSITA" DI TORIVA, DIBETTORE DEI. R. BESEO ZOOLOGICO,

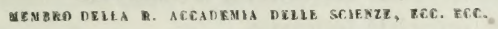

SFCOVOA EOTZTOSE RIELIRORITI GO ICCRESCIUTA

\section{A NO}

BOTS. FRAYEECD VALLARDI, THPOGRAFO-EOITORE

Contr. Blswesso a S. Alessassiro, N. 3950-B.

ksik. 
La presente pubblicazione è posta solto la tutela delle veglianti leggi e convenzioni dei Governi d'Italia, ehe concorsero a garantire le proprietà letterarie. 


\section{PREFAZIONE}

\section{ALLA PRIMA EDIZIONE}

Il signor Milne Edwards in quel suo prezioso Corso Elementare di Zoologia, che è ormai diffuso in quasi tutte le scuole d'Europa, ha creduto conveniente l'ommettere il trattato sugli organi e sulle funzioni della generazione. L'età e la classe degli studiosi ai quali è particolarmente consacrato il libro, esigevano questo riguardo, che nessuno può non approvare pienamente.

Ma la scarsità delle opere di Storia Naturale prestantisi all'educazione progressiva della gioventù in Italia, ha fatto si, che il libro del signor Milne Edwards vi si trovi anche fra le mani di persone più inoltrate e nell'età e nel senno e negli studj, che non gli alunni degli ordinarj Collegi e de'Licei. Per esse la lacuna espressamente lasciata dall'illustre professore di Parigi è dunque un vero difetto, cui l'editore italiano saggiamente pensò supplire con 
un trattatello apposito, del quale diede a me l' incarico.

Nell'accingermi a quest'impresa, ho ben veduto come le difficoltà del soggetto siano accresciute dal confronto coll' opera stessa del signor Milne Edwards; ma ho sperato che valesse appunto questa considerazione a meritarmi indulgenza presso il lettore.

Ho procurato eziandio, per quanto è possibile, evitare parole ed esempj che potessero solleticare una non lodevole curiosità. Già dissi a qual sorta di studiosi sia destinato questo trattatello; ho però lusinga che la sua inopportunità pe' giovanetti sia riconosciuta piuttosto nelle previe cognizioni occorrenti alla sua intelligenza, che nella natura stessa de' fatti esposti e degli argomenti discussi.

Torino, 31 Otlobre 1849. 


\section{PREF I\%IONE}

\section{A QUESTA SECONDA EDIZIONE}

Nel presentare ma seconda volta al Pubblico questo opuscolo che serve di appendice alla versione italiana del Corso Elementare del signor Milne Eduards, ho sentito la necessità di rielaborame alcune parti, secondo i progressi notabilissimi fatti dalla scienza nell'ora scorso lustro, specialmente nella storia genetica degli animali inferiori. Ho creduto però di non alterare il piano dell'operetta, non essendone in nulla mutato lo scopo. Fu quindi mia principal cura di mettere in evidenza le più importanti leggi che si manifestano nella generazione e nello sviluppo degli animali, servendomi di pochi ma scelti a parlanti esempj. 
trascorrendo su quelle molte particolarità morfologiche che non si lasciano comprendere sotto schemi o delineamenti generali, e che sarebbero riescite di interesse secondario. La mente umana si smarrisce nella varietì infinita delle forme di che fa pompa la natura, e non giunge che a stento ad afferrare in una serie di oggetti disparati un nesso comme. Io ho avuto intenzione di semplificare al lettore questo sforzo mentale. Rifletta egli alla difficoltà di un tale assunto, e si troverà inclinato all' indulgenza per tutto quanto non sembrasse conforme alla sua aspettazione, ed al mio stesso proposito.

Torino. 9 Ginenn 18:iti. 


\section{§ 1. Della fecondità degli animali.}

$\mathbf{L}$ facoltà che ne'due regni organici caratterizza gli esseri dotati di individualità propria, si è quella di riprodurre la sua specie, e mantenerne sulla faccia della terra in infinita sequela le generazioni. Ogni altra manifestazione della vita può essere oscura o sospesa, e questa tutt'ora vigente, talvolta anche con particolare energia, ultima a spegnersi.

Si danno invero esseri organizzati di così semplice struttura, che si direbbero quasi destituiti di una vera organizzazione, e non presentano altri fenomeni vitali se non quelli che tendono a soddisfare questo supremo scopo della riproduzione della specie. Pel contrario è noto come alcune parti staccate dell' organismo animale possano conservare, per un tempo più o meno lungo, non solo la propria organizzazione, ma ben anche alcune proprietà vitali, e la più illudente di tutte, il moto, fino ad assumere in tal caso l'apparenza di veri individui animati indipendenti; ma prive del requisito essenziale che sopra esponemmo, non essendo nè potendo mai diventar capaci a generare, non saranno per tradurre in inganno sulla vera loro natura. Dall' esempio volgarissimo che ci presta la coda delle lucerte, che staccata dal corpo si contorce e distende con rapida vicenda anche pel lasso di un certo tempo, siamo guidati ad altri meno generalmente conosciuti e più degni di menzione, come quelli che veramente furono causa di errori. Così i corpuscoli filiformi dell' umor seminale, dotati come sono di movimento, e dell'apparente figura di un corpicino munito di coda, furono

De Futrpr. Funzioni riproduttive. 
considerati come veri animali parassiti necessarj del testicolo; ma la circostanza che di essi tanti ve n'ha quanti nel testicolo stesso furono prodotti, nè in modo alcuno possono poi essi medesimi moltiplicarsi, vieta assolutamente che abbiano a considerarsi come vere e genuine specie animali. Lo stesso argomento può applicarsi a certe produzioni organizzate, di forma determinata e costante, dotate di manifesta vitalità, che nelle sepie e nei calamai servono di astuccio al seme. Dicasi lo stesso delle appendici peduncolate, bicornute, contrattili e decidue, portate sul dorso da quei gasteropodi eterobranchi che formano il genere delle tetidi, e considerate da alcuni naturalisti come veri animali parassiti esterni di que' molluschi (1).

La facoltà o presentanea o futura a procreare costituisce adunque il vero carattere dell' individuo vivente. L'epoca da cui questa facoltà è tradotta in atto distingue alla sua volta l' apogeo della vita dell' individuo stesso, trascorso il quale perduta, staremmo per dire, ogni ragione di più lunga esistenza, declina e muore. Come la natura sacrifichi la vita degli individui alla conservazione della specie, è dimostrato da mille fatti, e nel più evidente modo dalla carriera vitale degli insetti, i quali, siccome generalmente è noto, muojono subito dopo aver soddisfatto un' unica volta all'opera della generazione.

Il grado di questa facoltà propagativa, ossia la fecondità degli animali, è naturalmente espresso dal numero dei prodotti generati: ma nel modo di valutare questo grado, i naturalisti cadono soventi in errore. Cośi, per esempio, quando si decanta la maravigliosa prolificità degli infusorj, e si fanno le meraviglie perchè, secondo le asserzioni di Ehremberg, una sola vorticella può nel lasso di 24 ore generarne non meno di 140 bilioni, non si riflette che con altro più giusto ragionamento si dimostra essere la fecondità degli infusorj assai limitata; che in riguardo a questi animali la rapida comparsa in date condizioni di milioni e milioni di individui, è un fatto dipen. dente dalla rapidità di sviluppo, e conseguente brevità di carriera vitale degli individui stessi, i quali appena nati

(1) Carus ha fatto un genere apposito Needhamia degli astucci seminiferi (spermatofori), delle sepie; Otto un altro genere Vertumuns delte appendici decidue delle telidi. Vélrassi più avanti un caso analogo ed ancor più curioso a proposito dell' Ectocotyle. 
crescono, generano e muojono. Quando si contemplano in una goccia d'acqua miriadi d'infusorj della stessa specie, non si deve credere d'aver sott'occhio tanti individui di una stessa famiglia, legati fra di loro dall' istesso grado di parentela, tutti provenienti direttamente da una madre comune; ma piuttosto un assembramento di generazioni, per le quali i minuti contano come gli anni nelle generazioni umane. Quando un infusorio tosto nato si moltiplica, dividendosi, per esempio, in due, la sua individualità scompare, nè può nuovamente servire come elemento di calcolo nello stabilire il grado di fecondità della specie. Per lo contrario una cavalla non dà nel corso dell'anno che un solo prodotto, ma ripetendo i parti per otto o dieci anni di seguito, finisce per essere in realtà più feconda di quell'infusorio.

Qualora dunque s'intenda istituire un confronto tra varj animali in riguardo al rispettivo grado di fecondita, non si può far di meglio che limitarsi a calcolare il numero degli individui figliati direttamente da un solo progenitore. Si vedrà allora variar questo numero fra estremi molto fra loro distanti, e non trovarsi queste váriazioni in rapporti costanti e necessarj con altre condizioni fisiologiche degli animali presi in considerazione.

Appena in modo affatto generale, e con trascuranza di un numero più o meno grande di eccezioni si potrebbe stabilire che la prolificità degli animali è in rapporto

a) col grado di elevatezza nella scala organica. Nella grande divisione dei vertebrati si trova infatti che i pesci sono incomparabilmente più fecondi che non gli animali delle altre classi. Bloch si è divertito a calcolare il numero delle uova nelle ovaie mature di varj pesci, e ne ha trovato, per esempio:

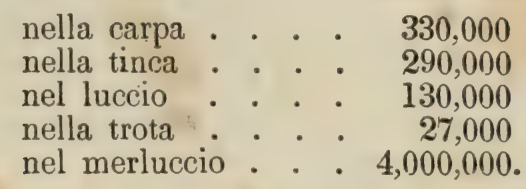

I rosicanti sono nella classe dei mammiferi i più fecondi. Il ratto delle chiaviche dà fino a 19 figli per parto, o rinnova questi fin 4 volte nell' anno; lo scojattolo pro- 
duce dai 3 ai 6 piccini per ognuno de' suoi due parti annuali, mentre fra i primati le stesse piccole specie glirifurmi, come gli ouistiti, non danno che un unico pro. dotto nel corso dell'anno.

b) colla qualità e quantità del nutrimento. Gli animali erbivori sono in generale più fecondi dei carnivori. Vediamo infatti tra gli uccelli i falchi e gli avvoltoj deporre un numero assai limitato di uova $(2-6)$; mentre i colombi, le quaglie e le pernici ne depongono fino a 24 e davantaggio in un anno. Gli squali e le razze, pesci tanto carnivori e voraci si distinguono nella loro classe pel piccolissimo numero dei loro prodotti annuali, di $8-32$.

La quantità del nutrimento spiega la maggior influenza nella fecondità degli animali. Perchè nell'organismo si sriluppino e funzionino attivamente gli organi riproduttori, si esige un precedente stato di normale nutrizione dell' organismo stesso, anzi, diremmo, di nutrizione esuberante. Non verificandosi questa condizione, può anche aver luogo un' assoluta sterílità. Un parlante esempio ci vien offerto a questo proposito dai ciprini dorati, i quali mantenuti come si accostuma per diletto in acqua limpida e pura entro vasi di cristallo, non producono giam. mai uova, mentre generano benissimo negli stagni artificiali dei giardini ove la natura lor presta abbondante nutrimento nelle alghe, nelle larre d'insetti, che si sviluppano e vivono in quelle acque.

c. col clima. Un certo grado di calore essendo necessario per lo sviluppo degli organi sessuali, è evidente che questo sviluppo non potrà raggiunger lo stesso grado in una medesima specie d'animali posta in climi fra loro molto diversi. Oltre di ciò la stagione ordinaria delle nozze essendo più o meno lunga secondo la posizione geografica dei varj paesi, ne viene di conseguenza che alcune specie possono durante la medesima replicare $\mathrm{i}$ parti in alcuni paesi, non già in altri. Ciò si verifica, per esempio, nella passera comune che nidifica fino 3 volte in un anno nell'Europa meridionale, e soltanto 2 ed anche una sola nelle regioni più settentrionali.

d) collo stato di libertà naturale o di domesticità, quando non si roglia trovare in questo genere di rapporti una combinazione dei due antecedenti. La maggior fecondità delle razze addomesticate in confronto degli individui della 
medesima specie viventi in istato di naturale libertà, è un fatto dei meglio riconosciuti. La femmina del cinghiale dà una sol volta all' anno da 4 a 6 prodotti, mentre la troja domestica ha due parti nell'anno di 6 a 12 piccini per ciascuno. Il coniglio selvatico produce da 2 a 3 volte all'anno e dai 2 a 5 piccoli per volta, mentre il domestico dà un doppio numero di parti e di prodotti. La comune anitra selvatica non depone che dalle 10 alle 15 uova in una sola nidiata durante l'anno, mentre la medesima specie ridotta allo stato di domesticità produce annualmerite fino a 50 uova. Una gallina comune può dare fino a 100 uova nell'anno, e più; ora per quanto poco si sappia della produttività di questa specie in istato di selvatichezza, si può presumere non oltrepassare essa la cifra di 30 uova nel corso di un anno. Le cause di queste differenze sono abbastanza evidenti. Agli animali domestici l'uomo stesso provvede in ogni epoca nna quanità di nutrimento sempre eccedente le esigenze del puro e semplice sviluppo normale dell' organismo, e tempera le condizioni contrarie di stagione o di clima; gli animali selvatici, per lo contrario, sono astretti a procacciarsi da sè medesimi il nutrimento; sostenere a questo fine frequenti lotte colla natura stessa, sottostare alle privazioni periodiche portate dalla vicenda delle stagioni ed alle accidentali cagionate dalla intemperie.

E però necessario il riflettere che altro è stato di dome. sticità, altro stato di schiavitù degli animali; che se tutte le specie possono subire quest'ultimo, assai poche relativamente sono quelle suscettibili di vero addomesticamento. L' uno stato accresce come vedemmo or ora la fecondità degli animali, l'altro invece sopprime in essi se non l'attitudine a procreare, almeno l'istinto, del che ci convince l'osservazione comune.

Ad una funzione di cosi suprema importanza quale si è quella della riproduzione della specie, la natura ha destinato organi appositi, più o meno complicati per forma, numero e posizione diversi, ma sempre destinati quali a produrre le uova, ossia le masse germinali dei novelli individui; quali a produrre il seme, ossia l'elemento com'pletivo e vivificatore dell' uovo. E noto generalmente come 1 primi costituiscano l'apparato femminile, i secondi l'apparato maschile. 
Nelle classi inferiori peraltro, nelle quali l'organizzazione degli animali si riduce alla massima semplicità, possono mancare anche gli organi sessuali, senza che sia for tolta per questo la facoltà che vedemmo tanto caratteristica degli esseri viventi. Come in simili animali, da chiamarsi con espressione assai propria agami, non possa mai aver luogo la distinzione di maschi e di femmine, è troppo evidente per sè.

La riproduzione delle specie adunque, o si compie senza apparati organici speciali, e mediante l'organizzazione di un unica sostanza plastica fondamentale (generazione agamica); o si compie col mezzo di due appositi apparati organici, e dal concorso di due diversi elementi plastici (generazione sessuale).

\section{§ 2. Della generaxione agamiea.}

\section{a) Per scissione.}

Gli animali hanno la facoltà di rigenerare alcune porzioni de'loro tessuti, anzi perfino alcune parti de loro organi, ed organi intieri. Questa facoltà, limitata nei quadrupedi e negli nccelli alle sole produzioni epiteliche 0 corriee, va guadagnando col discendere alle classi inferiori : e già vediamo le lucerte riprodurre la coda; la salamandra ripristinare le zampe amputate (Spallanzani); i crostacei le antenne e le gambe; le lumache il capo.

Se le attinie sono convenientemente tagliate in due o tre parti, ciascuna di queste ha la proprieta di riprodurre il mancante, e così si formano due o tre attinie da una sola. Le esperienze di Dicquemare a questo proposito sono state pienamente confermate da Contarini (1). Questa facoltà è ancor più meravigliosa nel polipo d'acqua dolce che ebbe il nome generico di idra, dal realizzare in sè quanto nella favola è detto dell' idra lernea. Le sperienze di 'Trembley su questo animaletto, istituite verso la meta del secolo scorso, fecero maravigliare l'Europa. Esse furono ripetute e verificate da molti naturalisti; e recentemente anche da Reichert (2). Il corpo dell' idra, composto di pura sostanza sarcodica, sia in qualunque direzione tagliato a

(1) Contarini. Trattato sulle Attinie. Venezia 1844, pag. 32.

(2) Die monogene Fortpflanzung. Dorpal 1852, pag. 46 e 81 . 
pezzi; ogni pezzo si riconvertirà in polipo; e già dopo il lasso di 24 ore uno di tali pezzi che sia di sufficiente grossezza sarà diventato un polipo capace ad inghiottire uno di que' minuti crostacei (dafnie) che sono l'ordinario pasto delle idre. Esperienze analoghe furono fatte da Dugés e ripetute anche da Reichert col medesimo successo sopra animali di ben più elevata organizzazione, quali sono le planarie. E dunque ben sicuro esservi animali che si possano moltiplicare per scissione o separazione di parti. La quistione si riduce a sapere se e dove questo modo di riproduzione è veramente naturale.

Pare che nell'ordine della natura gli esempii di vera scissione spontanea del corpo in due o più parti siano più limitati di quanto si crede generalmente. In molti casi questa scissione non è che apparente, e riducesi pintiosto alla separazione dal corpo materno di un giovane individuo novellamente prodotto nella continuità del corpo stesso, del che daremo esempii fra breve. In altri casi un processo che a primo sguardo può giudicarsi di scissione di un individuo in due, può essere invece un processo contrario, cioè la fusione incipiente di due individui in mno (1).

I casi in cui la scissiparità spontanea è bene avverata, non escono dalla cerchia delle infime classi di animali. I rizopodi, costituiti come sono da una polpa omogenea estensibile e contrattile, senza organi permanenti di sorta, dove lasciano un brano del corpo, lasciano materia per un nuovo individuo. La separazione naturale di un individuo in due affatto simili ha luogo frequentemente negli infusorj: Guanzati pel primo (1796), e molti anni più liardi Ehrenberg, la osservarono chiaramente ne' paramecj (fig.1); facile è il verificarla anche nelle vor-

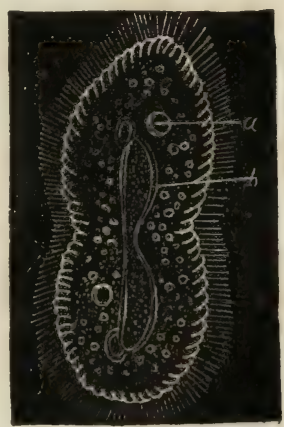

Fig. 1. Paramecio che sta scindendosi: da Stein (").

(1) C. Vogt (Bilder aus dem Thierleben, pag. 113) soggiunge: "il tempo non è forse lontano, in cui verrà ad essere dimostrato che la moltiplicazione per scissione che Ehremberg considera come caratteristica degli animali, non si verifica in questi menomamente, ma invece ne' soli vegetali : e che i fenomeni interpretati finora come una scissione, lungi dall' esser riferibili a questo processo, lo sono ad un processo contrario, la fusione".

(*) $a$ vacuolo che sparisce e compare alternativamente. $-b$ nucleo. 
ticelle (fig. 2). In tali casi è interessante il notare che se nell' infusorio è visibile un nucleo, la di-

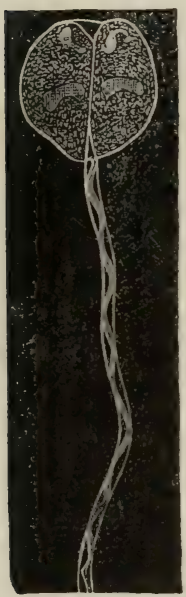

Fig. 2. Vorticella che si divide in due. visione di questo precede e sembra determinare quella del corpo, e la direzione del nucleo è perpendicolare a quella del solco di divisione.

Nelle idre e nelle attinie la moltiplicazione per scissione che vedemmo avvenire per causa violenta esterna, non ha luogo per processo naturale e spontaneo; nè di questo si troveranno numerosi esempj percorrendo la divisione dei raggiati. Però veggiamo alcune meduse giovani, allo stadio di polipo fisso, moltiplicarsi anche per scissione (Medusa aurita); e Koelliker ha veduto in una specie di medusa discofera (Stomobrachium), formarsi un solco diametrale che a poco a poco si approfonda fino ad una completa separazione del corpo in due.

Anche nell'immenso gruppo dei vermi non sono ancora ben chiari e sufficientemente appurati i casi di scissiparità, per quanto ne accennino gli autori. Questa maniera di moltiplicazione poi non si verifica affatto nelle classi superiori.

\section{b) Per gemme.}

Le vorticelle tra gli infusorj (fig. 3), le idre tra i polipi (fig. 4) che già vedemmo potersi moltiplicare quelle per scissione naturale, queste per taglio artificiale, si riproducono eziandio per un processo particolare che servi a stabilire una certa analogia fra questi animali ed i vegetabili. Su di una parte del corpo, per eccesso di nutrizione, spunta un bottone, una gemma, che a poco a poco prende la forma di un individuo simile alla madre che to sopporta; ed in seguito se ne distacca, per vivere di vita propria ed indipendente, e riprodurre alla sua volta altre gemme, e quindi altri individui. Una simile facolta è comune fra gli animali della classe de' polipi; se non che assai soventi i nuovi individui rimangono a permanenza congiunti col ceppo materno, e divenendo poi nel- 
l' istesso modo fecondi, contribuiscono ad accrescere la co-

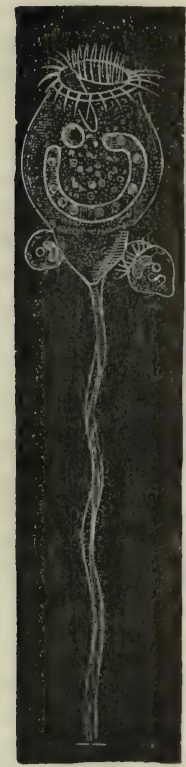

Fig. 3.

Vorticella con prole nata per gemmazione: da Stein.

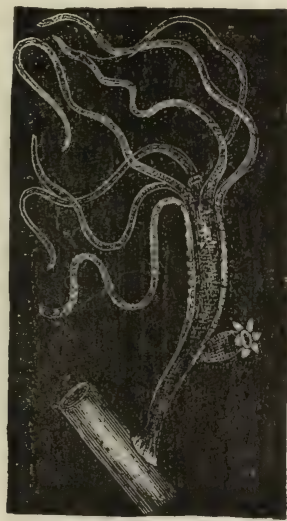

Fig. 4.

Idra con un piccino nato da una gemma. lonia i cui membri non solamente vivono vicini gli uni agli altri, ma veramente fra loro aggregati. E giusta e spontanea la qualificazione di gemmipari adcperata per questi animali.

Generalmente parlando queste gemme non sono prodotte da un organo prefisso del corpo materno; esse però sorgono sempre da tal parte del corpo dove accorre in sufficiente copia materia plastica: quindi dalla parete della cavità digerente, come per esempio nelle idre; o da quella del serbatoio del fluido nutritizio, come ne' polipi aggregati, o lungo il decorso o sulla terminazione de'vasi traducenti questo fluido, come in alcune meduse. Nelle salpe isolate, che, siccome è noto, producono per gemmazione interna una catena di individui aggregati, lo stolone gemmiparo può considerarsi come un'appendice del cuore, dal quale direttamente riceve il torrente sanguigno.

La moltiplicazione per gernme è assai più frequente di quella per scissione, ond'è che moltissimi esempii ne troviamo anche fuori della classe dei polipi. Ne riferiremo alcuni dei più singolari ed istruttivi osservati nella classe de'vermi.

O. F. Müller scoperse pel primo in un verme di mare della famiglia delle nereidi (Syllis prolifera), la formazione di un nuovo individuo all'ultimo segmento dell'estremità caudale, e la sua consecutiva separazione. Questo caso che fu interpretato come una vera scissione d'un individuo in 
due, si risolve invece nella formazione, all'estremità posteriore del corpo, di una gemma che rappresenta quasi in origine un segmento del corpo stesso, dalla qual gemma poi sviluppasi il nuovo individuo. In un altro genere affine (Myrianide) il signor Milne Edwards ha verificato la stessa cosa, colla differenza che non un individuo solo, ma una serie di molti si producono successivamente da questo verme; e di tal maniera, che il secondo individuo formato s' interpone fra il primo ed il corpo materno; il terzo tra questo ed il secondo individuo: e cosi di seguito. Da questa disposizione risulta una serie ed una catena di individui, quanto più adulti e sviluppati, quanto più discosti dalla madre gemmipara (fig. 5).

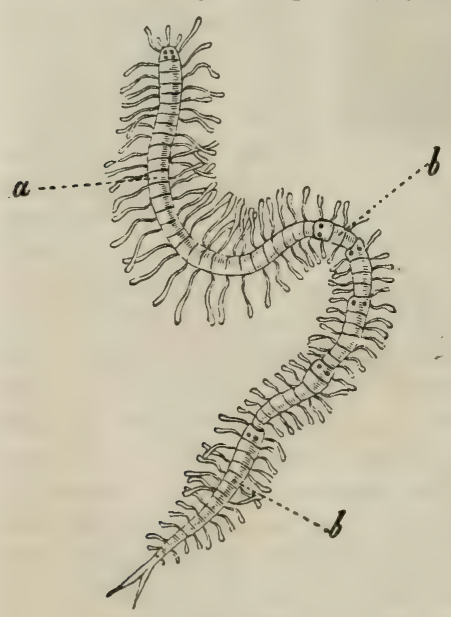

Fig. 5. Myrianide fasciata: da Nilne Edwards (").
Anche la Nais proboscidea, comune nelle acque dolci d'Europa, presenta un'aggregata di individui analogamente disposti, e tutti successivamente figliatidal primo individuo della serie; ma in questo caso speciale non sono affatto d'ac. cordo i naturalisti. Mentre Leuckart (1) vorrebbe veder in esso una ripetizione del processo di moltiplicazione delle Syllis e delle Myrianide, Schultze (2) ricondurrebbe il fatto ad una vera scissiparità, ammettendo che un segmento del corpo della naide materna divenga il fondamento organico (blastema) per la formazione del novello individuo; di modo che il numero di questi nuovi individui formati e disposti in serie, equivalga sempre al numero dei segmenti della Nais.

Non ha guari le tenie erano generalmente considerate come veri vermi anellati, come animali il cui corpo ri-

(1) Truschel. Archiv. für Naturgeschichte. 1851, p. I, pag. $13 \%$.

(2) Troschel. Archiv., ecc., 1852, p. I, pag. 3.

(") a Indiviluo generatore. - b Giovani prodotti per gemmazione. 
sulti di un capo, e di una serie di segmenti ; erano considerate, in altre parole, come specie monozoiche. Più giustamente invece si considerano oggi le tenie siccome specie polizoiche, cioè aggregati di animali esattamente paragonabili alle catene delle mirianidi, e come questi risultanti: $1.0^{\circ}$ di un individuo gemmiparo, col quale incomincia la serie, e che corrisponde a quella parte considerata, in addietro come la testa della tenia; $20^{\circ}$ di tanti individui ovi. pari quanti sono i segmenti che solevansi numerare nel corpo del verme. Questi individui non differiscono fra di loro che per l'ineguale sviluppo degli organi sessuali, ma assai differiscono dal primo, dal quale per gemmazione continua è prodotta la loro serie (1).

\section{c) Per spore.}

Negli animali inferiori, che in certi stadj almeno della loro vita, sono privi affatto di organi sessuali, la riproduzione della specie si effettua eziandio con un terzo processo ben differente dai due precedenti; cioè per una vera produzione interna di uno e d'ordinario più corpuscoli germinali, liberi fin dalla loro prima origine; i quali generalmente si sviluppano nella cavità viscerale dell' individuo materno, ed in pochi casi soltanto vengono emessi appena formati, e prima che incominci il loro sviluppo. La forma più semplice di questo processo può riscontrarsi nella produzione di cellule figliali in cellule materne, quale si verifica colla maggior chiarezza nello sviluppo di alcuni tessuti (il cartilagineo, per esempio) degli animali superiori. Gli animaletti che per la semplicita di loro organizzazione, possiamo considerare come cellule individualizzate, o come animaletti unicellulari presentano una ripetizione di questo processo.

I germi che si producono nella cavità del corpo degli animali inferiori, dal contenuto di questa cavita come da un rero blastema, stanno alle uova degli animali superiori come le spore delle piante crittogame, ai semi delle fanerogame; e potrebbero benissimo ricever questo nome

(1) E questo serve a dare ampia ragione di un fatto conosciutissimo da tutti $\mathrm{i}$ medici, non potersi una persona affetta da tenia riputarsi liberata compiutamente dal suo molesto ospite, se non quando insieme al lungo nasiro del verme non venga espulso il cosi detto capo. 
di spore anche nel linguaggio zoologico. Qualche volta sono essi costituiti di una parete, di un contenuto, e di una sorta di nucleo trasparente; e prendendo essi in tal caso l'aspetto di una cellula, sembrano accostarsi già alla natura di uova; ma sempre da queste si distingueranno per non essere il prodotto di un organo apposito, e per non richieder il concorso di un elemento estraneo, lo sperma, pel loro sviluppo.

Dicemmo già che questo processo di generazione si limita alle classi inferiori. Esso è frequentissimo negli infusorj, più ancora che non i due processi della gemmazione e della scissione; ed anzi in questi animali che non producono giammai vere uova, deve considerarsi come il processo riproduttivo fisiologicamente più elevato.

Generalmente parlando, gli infusorj che si apprestano a produrre nell' interno del corpo i germi della propria specie, si incistidano, ossia raccolgono il corpo a forma di sfera, e contemporaneamente trasudano un umore che si condensa in membrana periferica ora sottilissima e cedevole, or resistente ed elastica, formante un inviluppo destinato a rompersi o ad aprirsi al momento dell'emissione della prole (1). Soventi volte anzi l' individuo procreatore cosi incistidato si risolve in un inviluppo inerte della propria figliuolanza.

Dovendo noi limitarci a pochissimi esempj atti a servire di confronto pei varj casi che possono presentarsi all'os servazione, sceglieremo i seguenti.

Stein ha scoperto in una sola specie, che è la Vorticella microstoma, due diversi modi di generazione germipara. - In entrambi la vorticella perde la sua corona di cigli e si incistida, staccandosi più o meno presto dal suo stelo; ma in un caso il contenuto della cistide così formata si risolve in una sostanza trasparente gelatiniforme; il nucleo si scompone in particelle; compajono nuovi vacuali frammezzo a ripiegature saccate della parete propria della vorticella; ed in tale stato, rotta la cistide colla com. pressione, dà uscita ad una moltitudine di corpuscoli vivaci, simili a monadi, nuotanti in un umore denso gela-

(1) Anche il fatto dell'incistidamento degli infusorj, mezzo secolo prima che se ne rilevasse l'importanza e la generalita, fu chiaramente usservato e deseritto da un italiano, il Guanzati (Opuscoli scelti di Milano 1796. T. XIX). 
tinoso (fig. 6). Quei corpuscoli sono embrioni destinati a convertirsi col tempo in altrettante vorticelle.

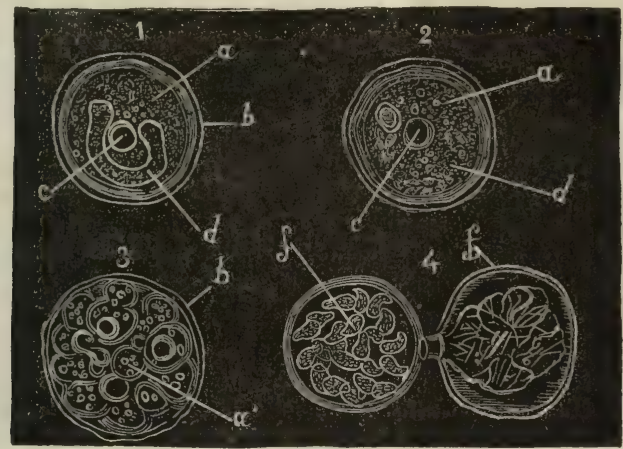

Fig. 6. Generazione della Vorticella microstoma: da Stein. (").

$\grave{\mathrm{E}}$ questo un modo di generazione germipara di cui si hanno frequenti esempj negli infusorj, e nel quale sono da notarsi queste condizioni: $10^{\circ}$ incistidamento completo dell' individuo materno: $2{ }^{\circ}$ morte di questo susseguente allo sviluppo della progenie: $3 .^{\circ}$ prole numerosa.

La stessa Vorticella microstoma fu veduta da Stein comportarsi altrimenti in un secondo caso. Dopo essersi rinchiusa in una cistide, come nell' esempio antecedente, ma di pareti più sottili e cedevoli, l'animaletto manda fuori tutt'all' ingiro e ritira con lentissima vicenda una moltitudine di filamenti jalini distribuiti a raggi, nel mentre che il suo corpo si estende in varie direzioni, od in una sola, prolungandosi in tal caso in un vero peduncolo. In questo periodo che Stein chiama di Acineta (1), il nucleo si trasforma in embrione, che si muove e si dimena nel

(') 1. La Vorticella di fresco incistidata. - 2. La stessa nella quale il nucleo si risolve in spore. - 3. La stessa colla prole gia sviluppata, che nella figura 4 per rottura della cistide, esce ravvolta in una sostanza gelatinosa. - $a$. Il corpo della Vorticella. - $b$. La membrana della cistide. c. Organo contrattile. - d. Nucleo. - $f$. Embrioni, - g. Sacco svuotato degli embrioni.

(1) Le vorticelle in questo stato furono gia deseritte come specie animali proprie e indipendenti, coi nomi generici di Acineta e Podophrya, se il loro corpo si prolunga in un pedunculo, Actinophrys se libero ed egualmente esteso in varie direzioni. 
corpo materno (fig. 7), ne esce quindi, e si sviluppa per proprio conto (1). Molti altri in-

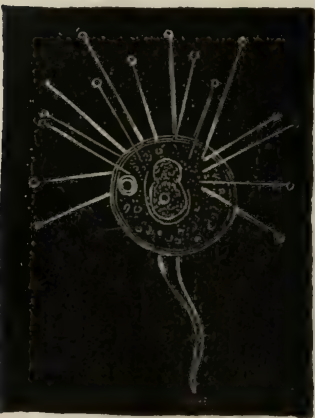

Fig. 7. Vorticella allo stato di acineta (Podophrya) con un embrione incluso: da Stein. fusorj vorticelliformi (gli Epistylis, le opercularie) pervengono ad uno stadio di acineta, raggiunto il quale generano dando origine ad un unico prodotto. Se e quanto ripetano queste generazioni, non è ancora ben noto; come non si è ancora ben in chiaro dei rapporti che questo secondo modo di generazione tiene col primo (2). Quantunque manchi negli infusorj ogni rudimento di organi appositi per la secrezione di questi corpuscoli riproduttori, come di ogni altro prodotto inserviente alla generazione, e non sia in essi possibile una distinzione di sessi, pure questo pro. cesso di generazione per spore o germi richiede talvolta una condizione analoga a quella che deve necessariamente aver luogo negli animali superiori muniti di distinti apparati sessuali: vale a dire un particolar modo di accoppiamento che fu designato col nome di zigosi.

A tale effetto due infusorj. della medesima specie, e più di raro tre o quattro, si avvicinano, si congiungono, e finiscono anche per saldarsi l'un l'altro, secernendo il più

(1) Questa derivazione dell'embrione del nucleo è esplicitamente asseverata da Stein nella sua prima Memoria (Siebold und Koelliker: Zeitschrift 3 Band); ma non più nella sua grande opera posteriormente pubblicata (Die Infusionsthiere. Leipzig 185\%), nella quale anzi figura varie acinete di Vorticella microstoma con un embrione e con un nucleo distinti. E questo un nucleo di nuova formazione destinato a convertirsi in nuovo embrione, nd è il nucleo primitivo, ed è in tal caso inesatto il dire che da esso si formi l'embrione?

(2) Possono aceadere negli infusorj tre casi assai diversi sotto una medesima apparenza. Uno o più corpuscoli, aventi l'aspetto di germi o di giovani individui, possono trovarsi rinchiusi nel corpo di un infusorio, $1 .{ }^{\circ}$ per esserne veramente generati, $\mathbf{2}^{\circ}$ per essere stati inghiottiti come alimento, $3 .^{\circ}$ per esservisi essi medesimi introdotti come parassiti, onde subirvi una metamorfosi. Il naturalista deve adunque mettersi in guardia contro l'illusione; od ogni qual volta abbia sott'occhio qualche cosa che rassomigli ad un infusorio pregnante, eliminare con apposite ricerche ogni sorta di duh bio sugli altri due casi. Viceversa puó accadere che la progenic di un infusorio sia presa per animaletti mangiati. 
delle volte, ma non sempre, una sostanza plastica, la quale condensandosi forma le pareti di una cistide comune (1).

Si può aver di questo processo un bellissimo esempio in quegli animaletti unicellulari che vivono parassiti nell' intestino di molti insetti e vermi, e formano pei naturalisti il genere delle gregarine. Essi sono liberi da principio, ma giunta l'epoca della propagazione si uniscono a due a due, ed ogni coppia resta a poco a poco inviluppata da una membrana di nuova formazione (fig. 8). Ciò avvenuto incomiricia nell' interno di ogni singolo individuo l'alterazione della sostanza e la consecutiva produ-

A

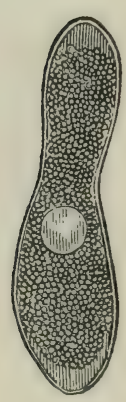

F

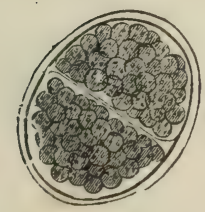

C

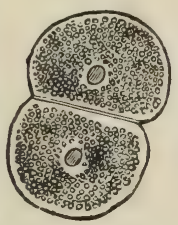

G

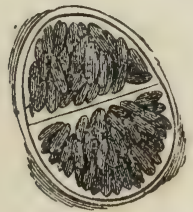

D
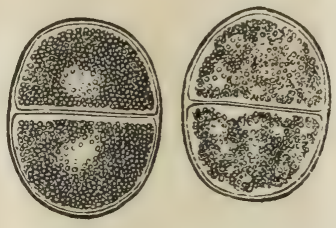

$\mathrm{H}$

$\mathrm{E}$

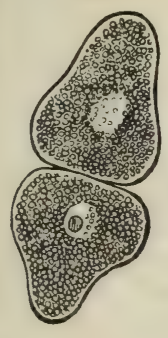


zione dei germi, i quali, allorchè sono completamente formati, presentano una forma che ricorda quella della spola dei tessitori, d'onde lor viene il nome di navicelle. Col tempo anche la parete particolare degli individui accoppiati sparisce, ed altro non resta che la cistide comune piena di navicelle.

Nelle acinete di vorticella colte al momento della zigosi, Stein ha fatto l' interessantissima osservazione che i due individui accoppiati non sono perfettamente simili, ma l'uno è più opaco dell'altro, in grazia di più numerosi e più grossi granuli del contenuto; circostanza che sembra accennare a qualche cosa di

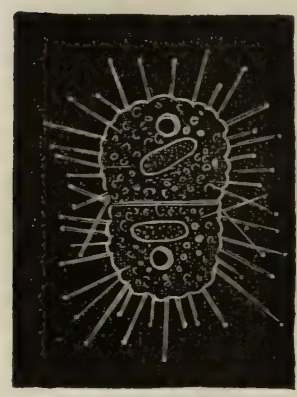

Fig. 9. Due vorticelle allo stato di acineta

(Actinophrys), ed accoppiate: da Stein. (") analogo ad una differenza sessuale (fig. 9):

La zigosi è un processo da lungo tempo conosciuto nei vegretabili più semplici, come nella conferve, e forse più generale di quanto comunemente si crede anche neglianimali; e soventi inavvertito, perchè in alcuni infusorj si compie in un modo più semplice. Gli individui qualche volta si uniscono senza se. cernere una cistide comune. E può accadere eziandio che due individui dopo essersi congiunti ed incistidati, di nuovo si svincolino, e poscia ciascuno separatamente dia luogo per interne spore alla formazione di una nuova progenie; di tal maniera in molti casi gli individui generatori isolati avrebbero già subita l'influenza dello stretto contatto con altri individui simili (1).

(") Si faccia attenzione che in questo caso il nucleo è quasi parallelo alla linea di congiunzione, circostanza che non permetterà di confondere due infusorj in istato di zigosi con un infusorio prossimo a scindersi in due.

(1) Questa supposizione trova il suo fondamento in un' osservazione che mi fu dato di fare nel modo più chiaro e preciso. Avendo sott'occhio una volta una moltitudine di infusorj affini alle Leucophrys, ma di una forma probabilmente non descritta, ne vidi un gran numero che stavano congiungendosi, ed altri gia congiunti e perfettamente incistidati. Alcuni giorni piu tardi trovai con sorpresa un gran numero di cistidi vuote, e molti di quegli infusorj ridatisi a liberta, per nulla mutati ne' primitivi caratteri ; e potei perfinn esser testimonio del momento in cus alcuni individui escivano nu(tvamente dalla loro cistide. 
I polipi e gli acalefi che vedemmo, in alcuni stadj almeno della loro vita, moltiplicarsi tanto per gemmazione come per scissione, non offrono alcun che di paragonabile ad una generazione per germi o spore. Di questa troviamo nuovamente chiarissimi esempj nella classe degli elminti. I giovani monostomi, distomi, anfistomi, nascono entro particolari sacchetti membranosi o sporocisti, ora semplici ed inerti, ora dotati di una bocca di un tubo intestinale, di vasi, e di movimenti vivaci e spontanei; e nascono da piccolissime vescichette libere fin dalla prima loro origine, e nuotanti nell'umore contenuto in quei sacchetti.Ciascuna vescichetta si trasforma a poco a poco in un ammasso di cellule nucleate, Je quali poscia si fondono in una sostanza omogenea che si organizza nel giovane elminto (figura 10).

Di alcuni problematici

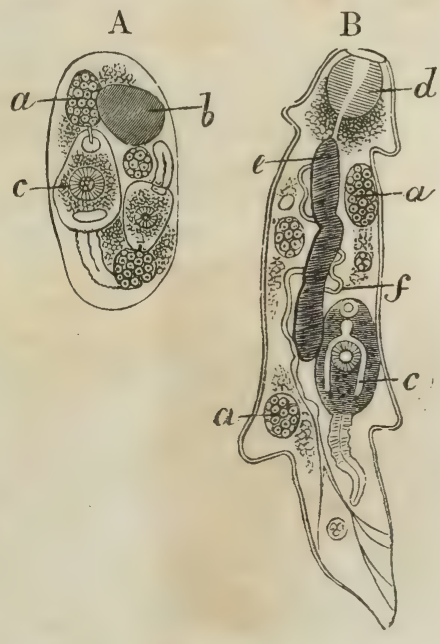

Fig. 10. Due sporocisti con inclusi germi e larve di distomi a vario grado di sviluppo (*). esernpj di questo modo di generazione, che, salendo nella scala organica, ci si presenterebbero nella grande divisione degli articolati, diremo a miglior occasione più avanti.

\section{$\S 3 .^{\circ}$ Della genemazione sessuale.}

a) Apparato maschile.

La parte veramente essenziale di questo apparato consiste in una o due o più glandole destinate a secernere

(*) A. Sporociste semplice. - B. Sporociste organizzata.

$a$. Germi nel primo stadio. - b. Germe nel secondo stadio. - $c$. Larve di distomi. - $d$. Faringe. - $\bullet$. Intestino. $-f$. Vasi.

DE FILIPPI. Funzioni riproduttive. 
un umore particolare detto seme o sperma. Questa glandola è il testicolo.

Tranne che nei polipi, negli acalefi, ed in alcuni echinedermi (crinoidi), ne' quali i testicoli, affatto rudimentali e ridotti a semplici capsulette sessili o peduncolate, si sviluppano all'esterno del corpo, questi organi sono collocati nella cavità viscerale. Nei mammiferi però essi trovansi in questo posto soltanto ne' primordi di loro formazione; e ben presto si fanno strada all'esterno per la via dei due canali inguinali.

I testicoli hanno la struttura generale delle glandole. Il prodotto della loro secrezione, cioè il seme o sperma, si spande direttamente all'esterno (polipi), o nella cavità addominale soltanto in rarissimi casi (alcuni vermi). In tutti gli altri animali esso è raccolto da un canale membranoso continuo col testicolo stesso, e per tal via riversato all' esterno. Questo canale, che dicesi condotto spermatico o deferente, parte in molti animali, da un' appendice del testicolo che è l'epididimo, e coll' ultima sua porzione detta

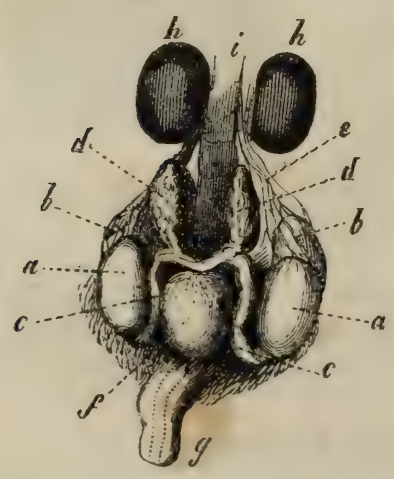

Fig. 11. Apparato sessuale maschile d'un pipistrello (Pteropus agyptiacus) (*). condotto ejaculatorio, termina sovente in un'appendice sporgente detta il pene (fig. 11) (1).

Nel tragitto più o meno lungo che il seme deve percorrere innanzi esser versato al di fuori, s'incontrano soventi sacchetti od espansioni del condotto deferente, ed appendici glandulose. Le prime destinate a serbatojo temporaneo del seme stesso, si chiamano vescicole seminali: tra le seconde annovereremo la prostata, le glandole di Cowper de' inammiferi. Le stesse vescicole seminali hanno soventi una strut-

(1) Per le varie condizioni e particolarita morfologiche degli apparati si maschili che femminili nelle varie classi di vertebrati, vedasi il bel lavoro di Lereboullet: Nuovi atti de' Curiosi della natura. Vol. 23, p. 1.

$\left(^{*}\right) a$. Testicoli. $-b$. Epididimo. $-c$. Condotto deferente. $-d$. Vescichette seminali. - e. Vasi sanguigni del testicolo. - $f$. Veseira orinaria rovesciata all'avanti. $-g$. Pene. $-h$. Reni. $-i$. Intestino retto. 
tura glandulosa, o, quando ne sono prive, accade talvolta che una porzione distinta del canal deferente prenda questa struttura, come si osserva ne' cavalli.

Il seme o sperma è un liquido più denso dell'acqua, di aspetto lattiginoso, dal qual carattere si può già travedere ciò che vien confermato dall'osservarlo ad un sufficiente ingrandimento col microscopio: cioé la sua composizione di una parte liquida e di una moltitudine di corpuscoli solidi in essa nuotanti. La forma di questi corpuscoli è d'ordinario quella di filamenti con una estremità ingrossata a guisa della capocchia di uno spillo; e soltanto nei crostacei ed in alcuni elminti nematoidi (negli ascaridi), presentano forme diverse che si allontanano da questo tipo (fig. 12).

Dominando il concetto che tendeva a far di questi corpuscoli altrettanti reri aninnali, parassiti necessarii del testicolo, la parte ingrossata di essi fu considerata come il coryo dell'animale, il filamento come la coda. Veniva in appoggio di questo concetto un fenomerio curiosissimo che presentano siffatti corpuscoli, che è quello di un movimerito anguillare assai vivace, che nel seme delle salamandre e di alcuni rospi è anche più complicato dalla rapida ondulazione di un finissimo lembo

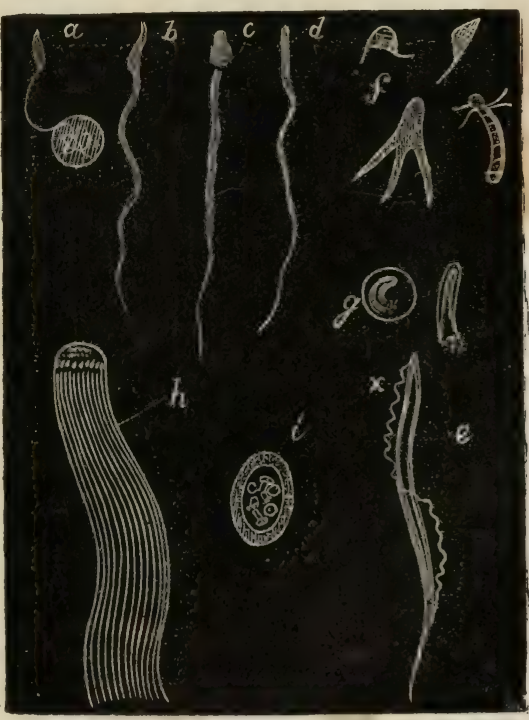

Fig. 12. Spermatozoidi ("). membranaceo. Da ciò son derivati i nomi di zoospermi

(*) a. Uno spermatozoide che esce dalla sua cellula. - b. Lo stesso reso libero. - c. Spermatozoidi di coniglio. - d. di rana. - e. di rospo, con membrana ondulante in $x_{0}-f$. di crostace $i$. $g$. di asearidi. $-h$. Faseio di spermatozoidi. $-i$. Spermatoforo di crostaceo. 
od animaletti spermatici che, da Leuwenoek, loro scopritore, in poi, ebbero questi corpuscoli: nomi sconvenienti, ai quali i moderni sostituirono quelli di flamenti spermatici o di spermatozoidi.

Giustamente poi è ora negata a questi corpuscoli la natura di veri individui animali; ed infatti essi non presentano a qualunque ingrandimento del microscopio alcuna traccia di organi interni; non si moltiplicano, ma tanti ve n' ha e rimangono, quanti furono prodotti nel testicolo; e la loro formazione si effettua nelle cellule di questa glandola, come si formano generalmente nelle cellule delle altre glandole i materiali essenziali delle secrezioni. Il loro movimento è un fenomeno vitale senza dubbio, e nello stato attuale della scienza affatto inesplicabile. Esso ha molta analogia con quello che si osserva nelle ciglia degli epitelii; ora, se le cellule staccate di queste, malgrado il morimento vibratorio che continua in esse per molto tempo, non possono essere considerate come individui animali, lo stesso ed a maggior ragione sarà de' filamenti spermatici (1).

Molto frequentemente gli spermatozoidi, osservati ancora nell' interno degli organi sessuali, si veggono radunati insieme, in vario numero, per lo più a fasci colle capocchie tutte riunite ad un' estremità, ed i fili distesi parallelamente come i crini della coda di un cavallo (fig. 12, $h$ ).

In molti animali lo sperma percorrendo il condotto deferente, si suddivide in porzioni distinte, inviluppate poscia da una essudazione di materia albuminosa che si condensa e forma una capsula allo sperma compreso. Di tali capsule, di forma ordinariamente allungata, si trovano in moltissime specie di insetti nella borsa copulatrice della femrnina depostevi del maschio. Se ne trovano del pari nel condotto deferente ne' crostacei decapodi, ne' quali si può seguire ancor più chiaramente la loro formazione (fig. $12, i$ ). A questi sacchetti contenenti lo sperma si è dato il nome di spermatofori.

Ne'cefalopodi questi sacchetti acquistano una struttura assai complicata. Incominciano già essi a formarsi nel con-

(1) Koelliker ha osservato recentemente che i movimenti arrestati da poen tempo negli spermatozoidi, si possono rieccitare per qualehe minuto coll'aggriunta di una leggier soluzione di polassa o di soda. Virchow avea sia fatto la stessit osservazione nelle ciglia degli cpitelii. 
dotto deferente, ma la loro organizzazione non si compie che in un organo glandolare (borsa di Needham) di cui è fornito l'apparato maschile di questi animali, e che sbocca nel condotto deferente presso la terminazione di questo. Gli spermatofori raccolti in questa borsa si presentano sotto l'aspetto di capsule allungate cilindriche (fig. 13), con una sorta di capocchia ad un'estremità, e nel loro interno contengono un budello, vero serbatoio dello sperma, che anteriormente è in continuità, median-

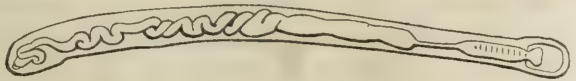

Fig. 13. Spermatoforo di eledone

(Milne Edw.).

te un esilissimo canaletto, con un apparecchio proiettatore, formato da un altro budello ricettante un filo spirale elastico. Allorquando questi spermatofori sono evacuati, pel contatto dell'acqua si rigonfiano, si aprono alla lor parte anteriore, e per l' elasticità del filo anzidetto tutto il tubo proiettatore e poscia il sacco stesso dello sperma vengono spinti fuori. Nell'atto della copula, i maschi de' cefalopodi non fanno che abbandonar gli spermatofori nel corpo della femmina (1).

\section{h) Apparato femmineo.}

La parte caratteristica e veramente essenziale di questo apparato è l'ovario, ossia la glandola produttrice delle uova. Nell'organismo delle femmine esso corrisponde esattamente per numero e per disposizione al testicolo de' maschi. Esso trovasi del pari al massimo grado di semplicità ne' polipi idriformi e nelle meduse a ombrello, risultando in questi di semplici capsule ovigene che si sviluppano, crescono e si aprono all'esterno del corpo. In tutti gli altri casi esso è collocato nella cavità addominale. La sua forma è di. versa ne'varii animali; ora si presenta esso coll' aspetto di una glandola a grappolo, ed è questo il caso più generale, glandola che nella massima sua semplicità sarebbe

(1) Questi singolari corpi, che racchiudono lo sperma ne'cefalopodi, erano già conosciuti da Redi che li considerú come animali parassiti. Needham pel primo vi riconobbe la vera natura del contenuto. Carus li consideró come giganteschi animaletti spermatici; e ne fece un genere particolare di parassiti col nome di Needhamia expulsoria. 
rappresentata da un solo acino: ora consta di tubi membranosi varii per numero e disposizione, come negli insetti. Ne' pesci si presenta sotto forma di ripiegature membranose: ne' mammiferi sotto quella di piccole masse subrotonde costituite d'un tessuto compatto (stroma). D'ordinario le uova, che all'epoca della maturità si distaccano dall' ovario, sono tradotte all'esterno col mezzo di un canale membranoso od ovidutto che corrisponde al canal deferente de'maschi; oppure sono prese da un particolar canale membranoso, terminante nella cavità addominale con estremità libera ed espansa a guisa di tromba, d'onde appunto il nome

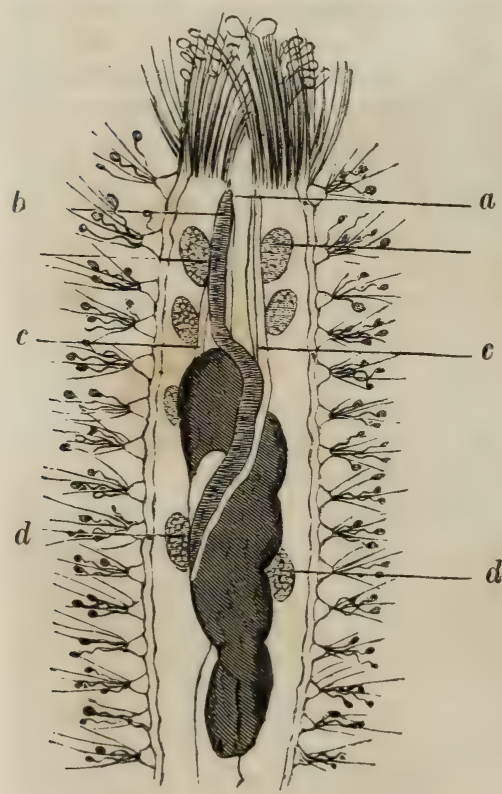

Fig. 14. Parte anteriore del corpo di una clorema ("). di tuba che ha ricevuto (alcuni pesci, rettili, uccelli, mammiferi). In pochi casi manca ogni sorta di canale, e le uova cadono direttamente nella cavità addominale, come in alcuni pesci (trote, cheppie) ed in molti vermi (cloreme, fig. 14). Quando vi hanno,

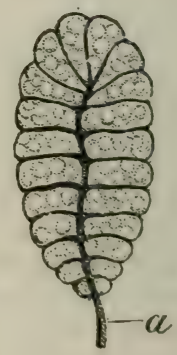

Fig. 14 bis. Una glimd'la sessuale di clorema ("*).

(*) a. Esofago, - b. Vaso pulsante. $-c$. Glandole salivati. $-d$. Glandole sessuali.

(“) Questa glandola è rappresentata ancora allo stato indifferente: ció non ancora promunciata o come testicolo o come ovario; il suo jenduncolo a è un vaso sanguigno. 
come per esempio, nei mammiferi, due o più ovidutti o tube, corrispondenti ad altrettanti ovarj, questi canali non si aprono direttamente all' esterno, ma indirettamente, col mezzo di un canale unico al quale confluiscono, e cui si dà generalmente il nome di vagina. In varj animali si osserva o lungo il tragitto degli ovidutti o delle tube, oppure alla confluenza di questi canali, un'espansione destinata a ricettar le uova per un tempo più o meno lungo, tanto da permettere loro uno sviluppo più o meno inoltrato: quest'espansione è ciò che suol dirsi utero (fig. 15).

A queste parti che più generalmente costituiscono l'apparato femmineo degli animali, si aggiungono, secondo i casi, organi accessorii destinati a secrezioni particolari. Cosi, per esempio, negli insetti, oltre le parti testè designate vi ha una borsetta apposita (borsa copulatrice) che riceve il pene del maschio durante l' accoppiamen-

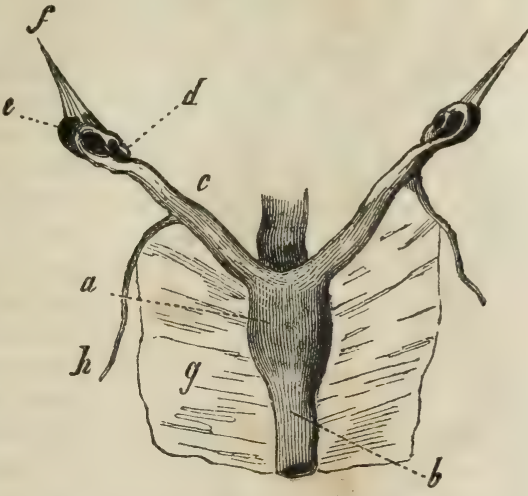

Fig. 15. Apparato sessuals femminile d'un pipistrello

(Pteropus ægyptiacus) (").

to, una vescichetta che riceve e conserva il seme da questo versato (ricettacolo del seme), ed in fine apposite glan. dole che si aprono nella vagina, ed aggiungono all'esterno dell' novo una vernice appiccaticcia (glandola del glutine) (fig. 16).

Quanto alla loro natura ed al modo di formazione, le uova si possono considerare in generale come grandi cellule, le quali in luogo di rompersi e versare il loro contenuto, come accade delle cellule secernenti delle altre glandole, si distaccano dal tessuto proprio dell'ovario, e vengono emesse intiere.

(") $a$. Utero. - b. Vagina. - c. Ovidutti o tube falloppiane. - $d$. Apertura delle tube. - e. Ovario. - $f, g, h$. Legamenti (f. Legamento terete. $g$. Legamento largo. $-h$. Legamento rotondo). 
La composizione dell' uovo negli animali è lungi però

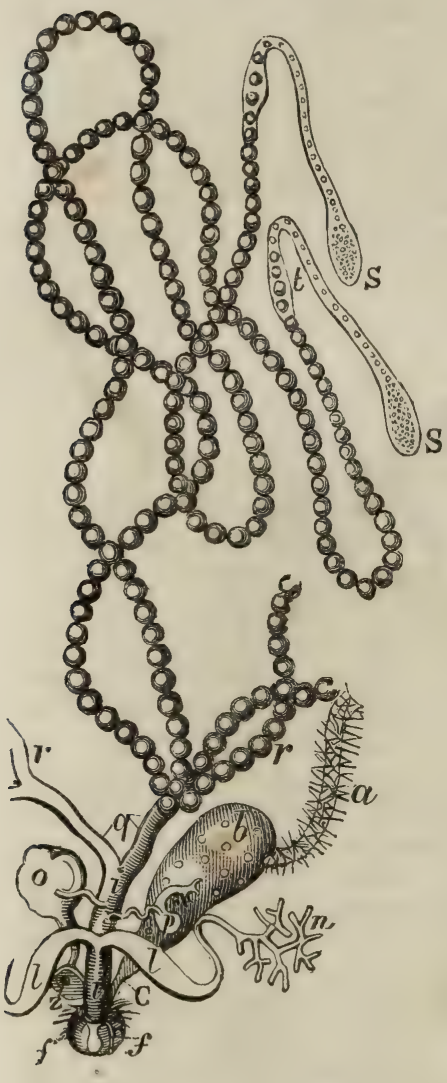

Fig. 16. Apparato femminile del bombice del gelso (*). dall'essere sempre identica. Volendo nullameno abbracciare, per quanto è possibile in poche parole, la generalità di un soggetto così im. portante, noteremo le cose seguenti.

Nella pluralità degli animali, e precisamente in tutti quelli delle infime classi, si distingue nell'uovo: da prima una membrana esterna, da molti autori chiamata chorion, da altri membrana testacea: essa costituisce la parete di una capsula per lo più di forma che s'accosta alla sferica, ed entro la quale vi ha la parte veramente essenziale dell' uovo, ossia il tuorlo, o vitellus de'latini. Consta questo di un umore denso, torbido, coagulabile pel calore, contenuto soventi ma non sempre in una membrana finissima anista (cioè senza struttura) detta membrana vitellina; e contiene entro di sè, per lo più in posizione eccentrica, una vescichetta trasparente che, dalla parte che prende alla formazione dell'embrione, è detta vescicola germinativa ed. anche vescicola di Purkinje,

(*) Devo questa figura al mio amico Emilio Cornalia.

a. Termine dell'intestino. $-b$. Cieco. $-c$. Suo condotto $-f$. Aperture esterne e distinte dell' intestino e del canal comune degli ovilulti. - I. Recipiente del glutine. - $n$. Glandola del glutine. - o. Borsa copulatrice. $p$. Borsa accessoria. - $q$. Ovidutti. - $r, s, t$. Diverse parti dellovario. z. Apertura per la quale entra il pene nella copula. 
dal rome di chi ne fece rilevare pel primo la grande importanza fisiologica. La vescicola germinativa contiene alla sua volta uno o più corpuscoli che sono le macchiette germinative o corpuscoli di Wagner (fig. 17). L'uovo in tal condizione fu paragonato ad una cellula, di cui la membrana vitellina è la parete, il tuorlo è il contenuto, la vescichetta germinativa il nucleo, le macchiette germinative i nucleoli.

Delle due membrane anzidette

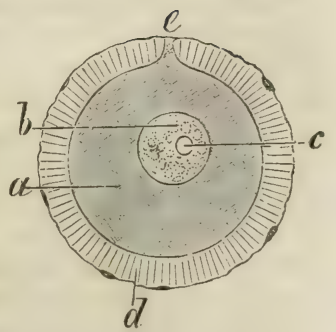

Fig. 17. Uovo di Oloturia: da G. Müller (").

la prima a formarsi è l'esterna o la testacea: essa distinguesi ordinariamente per una struttura particolare, come fosse costituita di tanti piccoli prismi, o trapassata da tanti minutissimi canaletti disposti nella direzione de'raggi che suppongansi parti dal centro dell'uovo. Negli insetti questa membrana si fa molto densa, opaca e resistente.

Il tuorlo è costituito da acqua, alcuni sali disciolti, molta albumina, tenente in sospensione granuli solidi analoghi a quelli del pigmento, e globuli di grasso; i quali tendono a radunarsi all' ingiro della vescicola germinativa ed a nasconderla. La membrana del tuorlo, o vitellina, si forma più tardi; in alcuni animali assai tardi, e quando l'uovo è già in corso di sviluppo; in altri riesce perfino difficile il constatarne l'esistenza.

La vescicola germinativa precede la formazione del tuorlo, come si può desumere dall'apparir essa relativamente tanto píu grande e più distinta quanto meno le uova sono prossime alla maturità.

E meritevole di particolare attenzione un piccol foro della membrana testaeea, cui corrisponde ordinariamente un infundibolo od un canaletto che guida nell' interno dell'uovo, e situato in corrispondenza del punto pel quale in origine l'uovo stesso aderiva al tessuto dell'ovario. Questo foro, pel confronto giustissimo con quanto si osserva nell' embrione de' vegetali fanerogami, fu detto micropilo. Esso fu osservato ben chiaramente nelle uova di un gran numero di animali, e va mano mano scoprendosi in altre nelle quali

(") a. Tuorlo. - b. Vescica germinativa. - c. Macchia germinativa. d. Membrana testacea. - e. Micropilo. 
non erasi veduto da prima. Nell'uovo degli insetti, in luogo di un semplice foro, ve ne hanno molti, disposti in modo da formar una specie di rosetta assai distinta sulla superficie dell'uovo. Più tardi faremo rilevare la somma importanza fisiologica di questo micropilo.

In alcuni animali l'uovo è più complesso, per l'aggiunta di altri inviluppi ed altri umori: tale è il caso dell' uovo degli uccelli, che fino a questi ultini tempi, con danno piuttosto che con vantaggio della scienza, fu preso per l'uovo tipo. In questo si distingue principalmente il rosso, o tuorlo, sulla cui superficie spicca una macchietta circolare bianca che è la cicatricola; esso è contenuto in una membrana assai distinta, cui per la prima volta si applicò il nome di membrana vitellina. Due filamenti spirali (chalazae) formati da albumina addensata, partono da due poli opposti del rosso, nella direzione dell' asse longitudinale dell'uovo. Il rosso è tutto inviluppato dall' albume disposto a strati, di cui i più densi son quelli che direttamente involgono il rosso medesimo. L'albume è contenuto in una membrana bianca, quella che primaniente fu chiamata membrana testacea, che all'estrernità ottusa dell'uovo si dimostra formata da due lamine, entro le quali, col progresso del tempo, si aduna dell'aria, d'onde ha origine la così detta camera d'aria. Infine a questa membrana bianca si trova applicato il guscio (fig. 18).

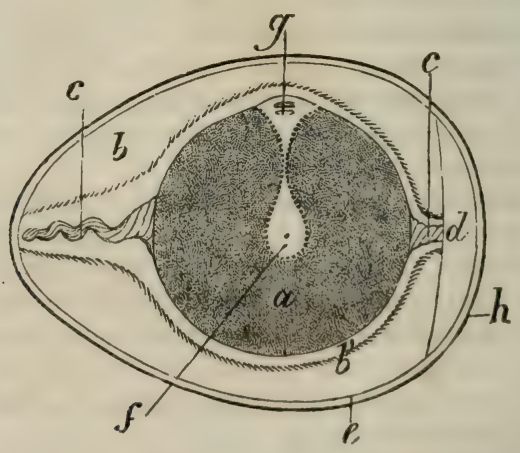

Fig. 18. Uovo di gallina (*).

(`) a. Tuorlo. $-b$. Albume più denso in $b^{\prime} .-c$. Calaze. $-d$. Camera 
Tutte queste parti non si formano contemporaneamente. L'ovario della gallina (fig. 19) si presenta come un grappolo formato da una riunione di capsule membranose pedunco. late, ricche di vasi sanguigni, ed a diverso grado di sviluppo. In quelle di maggior diametro si osserva una fascia equatoriale (stigma) di color pallido per esser priva di vasi. E nella direzione di questa fascia che si apre la capsula, risultandone allora un calice, che lascia sfuggire il suo contenuto, ossia il rosso dell' uovo colla sua membrana. Scendendo per lé ripiegature dell'ovidutto, o meglio tuba, e con moto rotatorio

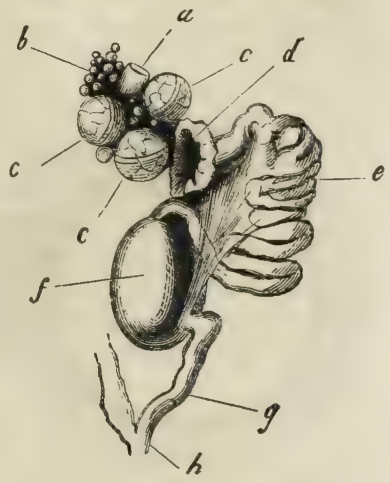

Fig. 19. Ovario di gallina ("). sul proprio asse, il tuorlo si involge dell'albume densissimo secreto nelle prime porzioni della tuba, ed in grazia dell'anzidetto moto si formano le calaze. L'albume sempre meno denso continua a sovrapporsi al tuorlo per tutto il resto del tragitto; nella parte inferiore della tuba si forma la membrana testacea; e per ultimo a questa si sovrappone il guscio.

Dall' uovo degli uccelli poco differisce quello de' rettili e de' pesci; se non che in questi ultimi non vi ha un vero alburne, al cui posto v' ha dell' acqua penetrata pe' canaletti della membrana testacea. Ben diverso è l'uovo dei mammiferi, la cui scoperta, dovuta all'ancor vivente e celeberrimo Baer, segna un' epoca della fisiologia. Molti autori, e Graaf prima d'ogni altro, avean già fatta conoscere la struttura dell'ovario di questi animali, consistente in un tessuto compatto o stroma, entro il quale si sviluppano, crescono, e maturano successivamente tarite vescichette,

d'aria. - $e$. Membrana testacea. - f. Parte interna più fluida del tuorlo. - g. Cicatricola. - h. Guscio.

(') a. Calice abbandonato dall'uovo. - $b$. Uova immature. - $c$. Uova mature ancora nell ovario. - $d$. Apertura dell'ovidutto. - e. Ovidutto. f. Uovo col guscio gia formato, e che discende per la continuazione dell'ovidutto $g_{0}-h$. Cloaca. 
che furono considerate insino a questi ultimi anni siccome le vere uova. Esse ricevono ora la denominazione di follicoli di Graaf, e contiensi in ciascuna il vero uo.

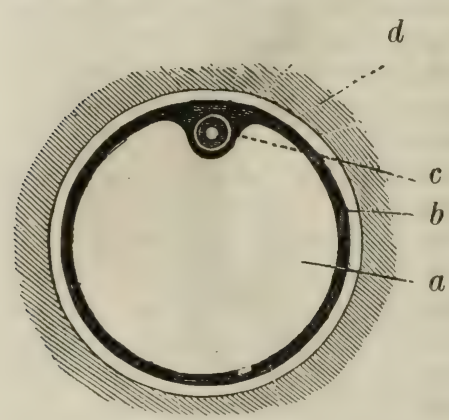

Fıg. 20. Fullicolo di Graaf (*). vicino, tanto microscopico che appena misura $1 / 10$ di linea in diametro.

Un follicolo Graafiano maturo (fig. 20) consta di una vescichetta membranosa, racchiudente un umore albuminoso, ed intonacato internaménte da uno strato di cellule e granuli (membrana granulosa), che in un punto della periferia del follicolo formano un cumulo distinto. Entro questo cumulo sta l'uovicino, il quale isolato, ed esaminato al microscopio si vede constare: di una membrana esterna relativamente grossa, trasparente, in modo da presentare un doppio contorno (zona pellucida); di un tuorlo che tutto riempie lo spazio limitato dall'anzidetta membrana; di una vescichetta germinativa, che contiene una o più macchie germinative. Collo scoppio di un follicolo Graafiano, resosi per maturità sporgente alla superficie dell'ovario, l'uovicino vien preso della corrispondente tuba, e segue il suo destino. Il follicolo sunnotato presenta poscia in corrispondenza della sua apertura una specie di verruca, e nell'interno un piccol grumo di sangue, circondato da una sostanza gialla; dando così origine ad uno de' cosi detti corpi lutei, il quale pure col tempo diminuisce e scompare (fig. 21). Allorquando si ta-
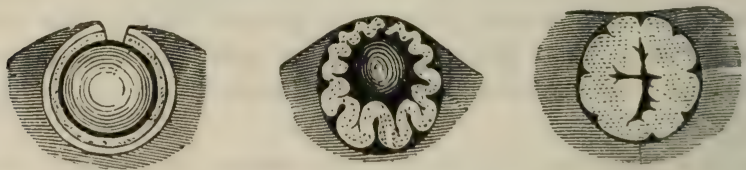

Fig. 21. Corpi lutei in diversi periodi.

(') a. Interno del follicoln. - b. Membrana granulosa. - c. Uovicino. d. Stroma dell'ovario. V. Wagner-Eeker. Icones physiologice. 
glia un ovario di mammifero si incontrano disseminati nello stroma, follicoli di Graaf a diversi gradi di maturanza, e corpi lutei di varie epoche.

Una distinzione che importa far qui subito, ma che verrà più ampiamente dimostrata in seguito si è questa : in alcuni animali, come nell' intiera serie degfi invertebrati (esclusi i cefalopodi), ne'batracii, ne' mammiferi, tutto il tuorlo si converte in embrione; mentre ne' cefalopodi, ne' pesci, ne' rettili squammosi, negli uccelli, l'embrione si forma alla superficie di quel globo che dicesi comunemente il tuorlo, e questo rimane distinto come un'appendice esterna del giovane individuo fino ad epoca assai inoltrata, fino al momento in cui egli si appresta a rom. pere il guscio dell' uovo (1).

\section{c) Caratteri esterni del sesso.}

I condotti del seme e quello delle uova sboccano frequentemente (come ne' batracii, ne' rettili e negli uccelli) in una cavità detta cloaca, comune all' intestino retto ed agli ureteri, e che versa tutto all' esterno per la via dell'ano; ma ancor più di sovente l'apertura esterna degli organi sessuali è distinta da quella dell'ano; ed è specialmente in quest'ultimo caso che l'apparato sessuale si complica per l'aggiunta di organi esterni destinati all'atto materiale della fecondazione, od a conservar le uova, od a collocarle in luogo sicuro pel sostentamento della prole che sarà per dischiudersene. Queste appendici esterne servono appunto di principale mezzo, nella pluralità de' casi, per distinguere a primo sguardo il sesso degli animali. $\mathrm{Si}$ presentano esse più o meno complicate, e così varie quanto alla struitura, alla forma, alla posizione, al meccanismo, da non prestarsi menomamente ad essere rappresentate con formule generali.

(1) Il confronto esatto delle diverse parti dell'uovo ne' varii animali riesce del più grande interesse; ma è ancora soggetto a molte difficoltà. Già fin d'ora si puó asserire che le parti chiamate nel linguaggio usuale e nelle varie uova colle denominazioni di membrana testacea, membrana vitellina, tuorlo, vescicola germinativa, non si corrispondouo sempre. Il tuorlo nei mammiferi corrisponde alla sola vescicola germinativa dell' uovo degli uccelli, de' reltili squammosi, de' pesci ; il tuorlo di questi corrisponde al contenuto del follicolo Graafiano de' mammiferi. La zona pellucida dell' uovo de' mammiferi, la membrana vitellina degli uccelli, la membrana testacea dell' uovo de' pesci, si corrispondono pure reciprocamente. 
Una grandissima varietà di forma presentano queste ap. pendici anche nella sola classe degli insetti; ove ne'maschi si rende più o meno palese alla parte posteriore del corpo un pene protetto da due piastre cornee laterali, ed in alcuni anche da un astuccio parimenti corneo; mentre le femmine si distinguono ora per una vagina tubo: losa e retrattile, ora per uno strumento di due o tre pezzi

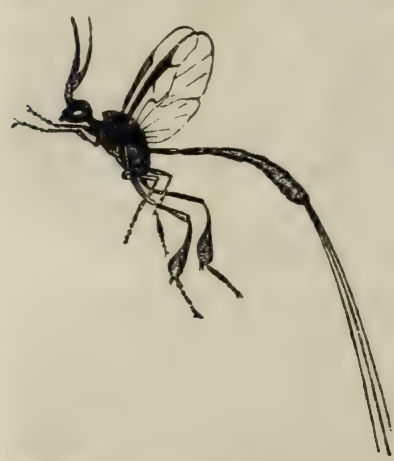

Fig. 22. Imenottero coll'oriscatto. o valve rigide, più o meno prolungato all'estremità dell'addome, e destinato per lo più ad aprire una nicchia alle uova ed a collocarvele, d'onde il nome che ha preso di ovopositore od oviscatto (fig. 22). In alcuni insetti imenotteri, come nelle api e nelle vespe, questo strumento cambia ufficio, e diventa un organo velenifero.

In alcuni animali e specialmente ne'crostacei, le femmine portano seco le uova appese alla parte posteriore del corpo, ora collocate fra loro in modo da formar due grappoli laterali, ora contenute in cavità o borse particolari. Anche tra i pesci i lofobranchi si distinguono per una grande fessura ovigera posta sotto la porzione caudale; ma per caso affatto eccezionale questo organo è proprio de'maschi, i quali perciò vi ricerono e conservano le uova depostevi dalla femmina.

L'apparato copulatore maschile è posto generalmente nella continuità del condotto seminale, ma in alcuni animali ne è distante. Nelle libellule è posto sul davanti dell' addome, al 2. ${ }^{\circ}$ anello, mentre l' apertura del condotio seminale è al $9 .{ }^{\circ}$ segmento; e per siffatta combinazione il maschio dere versar il seme nell' organo copulatore, innanzi che la femmina gli si congiunga. Ne maschi dei ragni gli organi copulatori sono i palpi, il cui ultimo articolo, carico dello sperma raccolto dall' apertura sessuale posta sotto l' addome, viene poscia applicato all'ovidutto della femmina. Nella classe de' crostacei gli arguli posseggono pure un organo copulatore separato che consiste in due fossette al penultimo pajo di arti, che l'animale ap- 
plica una dopo l'altra al foro genitale unico mediano, finchè sian piene di sperma, e che poscia appone alle corrispondenti due aperture del ricettacolo del seme della fem. mina (1).

Una particolarità maravigliosa circa il modo e l'apparato con cui si compie l'atto della copula, ci venne offerto da alcuni cefalopodi, quali sono gli argonauti ed i polpi del genere moderno Tremoctopus (2).

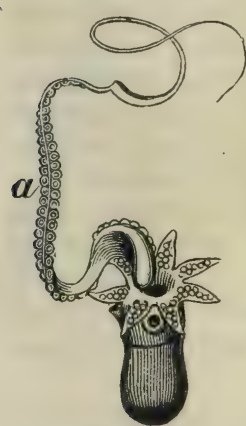

Fig. 23. Argonauta maschio : da E. Müller (").

In questi l'organo copulatore (fig. 23) è un braccio deciduo e riproducentesi, modificato nella sua forma ed organizzazione, in conformità dell' ufficio speciale cui è destinato. Esso è più grosso delle altre braccia, sparso di un maggior numero di ventose; e porta alla sua base una borsa che a suo tempo si riempie di spermatofori. Il maschio incontrata una femmina lascia su questa il braccio copulatore, il quale vi conserva a lungo la propria vitalità, al punto da apparir come un individuo animale indipendente. E tale fu realmente per lunghi anni considerato anche dallo stesso Cuvier, che gli assegnò un posto nella classe de'vermi intestinali, sotto il nome generico di Ectocotyle (3).

Nei vertebrati l'apparato copulatore si limita generalmente ad un pene, erettile in grazia di una particolar disposizione de' vasi sanguigni che vi si distribuiscono. Ne sono però affatto privi i pesci ed i batracj; mentre che ne' saurj e negli ofidj quest'organo è doppio, e posto ai due lati della cloaca, e ne' chelonj, ne' coccodrilli, in tutti gli uccelli esso è unico, e situato alla parete anteriore della cloaca. Ne' mammiferi giunge al massimo sviluppo, ed è affatto esterno, ma generalmente contenuto in una guaina cutanea, e non libero e pendente, come nella specie umana, se non ne' chirotteri e ne' quadrumani.

(1) Leydig (Siebold und Koelliker Zeitschrift, vol. 2).

(2) Polpi aventi alla regione cefalica due aperture che guidano in un sistema acquifero.

(*) a. Braceio copulatore deciduo (ectocotile).

(3) Vedi Vogt e Verany. Annales des sciences naturell's. 3. me serie, Vol.17. Leuckart. Zoologische Untersuchungen $3 .^{\circ}$ fascicolo. 
La distinzione de' sessi è facile nella maggior parte degli animali che cadono comunemente sotto la nostra osservazione, anche senza l' ispezione anatomica degli organi essenziali della generazione, che sono nella massima parte nascosti; perchè in molti casi si connettono coll'apparato generatore propriamente detto alcune appendici esterne che fanno subito riconoscere il sesso. Tali sono, per esempio, negli squali e nelle razze gli organi coadiuturi della copula, connessi alle pinne ventrali, e sporgenti in modo da rappresentar quasi un paio di gambe posteriori ; ed al lato interno de'quali trovasi eziandio un apparato glanidoloso particolare. E noto poi come negli uccelli e ne mammiferi varj caratteri di statura, di colori, d'ornamenti accompagnino spesso le essenziali differenze sessuali e le facciano riconoscere anche volgarmente. Ma in alcune classi di animali queste differenze sono ben più rilevanti, e tali da esser causa de'più grandi errori nelle classificazioni, poichè sono portate fino ad abolire ogni rassomiglianza fra il maschio e la femmina d' una medesima specie. Eccone alcuni esempj.

Tra i crostacei dell'ordine de'succhiatori o parassiti, vi hanno alcune specie componenti la famiglia delle lerneidi, delle quali per lungo tempo non si conobbe il maschio, tanta è la disparità di forma di volume e di abitudini che regna tra esso e la femmina. Questa vive aderente per lo più alle branchie de' pesci, succhiandone gli umori ed in: grossando a dismisura per lo sviluppo delle ova, delle quali porta ripieni due sacchetti dietro l'addome; non ha vere gambe articolate come gli altri crostacei, e piuttosto direbbesi rassomigliante ad un verme. Il maschio invece presenta i caratteri di crostaceo ben riconoscibili, ha gambe articolate, non è parassito, e solo all' epoca della generazione si fissa in prossimità dell'orifizio sessuale della femmina e la feconda. Ma ciò che v'ha di più singolare si è la enorme sproporzione di volume fra il maschio e la femmina, che nel massimo stato di rigonfiamento di questa, si fa salire da qualcheautore fino al rapporto di $1: 4600$. Non dobbiamo ommettere però che questa femmina nello stato di gioventù ha subíto, quanto alle forme, le stesse metamorfosi del maschio; ma nel mentre questo si è arrestato a un dato periodo, essa continuò fino a trasmutarsi in una sorta di verme, scendendo di grado, per così dire, nella scala gerarchica animale (fig. 24). 


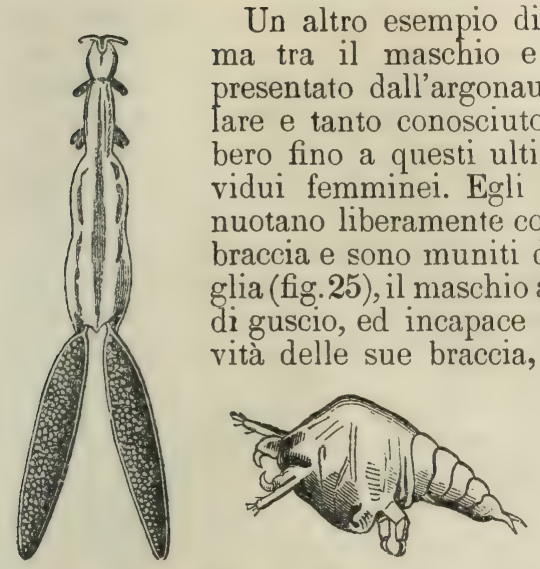

Fig. 24. Lernaea cornuta Linn. (Chondracanthus cornutus Nordm.) (").

zioni di storia naturale queste distinzioni di sesso, i naturalisti hanno scelto per convenzione il simbolo $\delta \vec{d}$ (Marte) pel maschio; e quello $q$ (Venere) per la femmina.

\section{d) Ermafroditi.}

Gli individui che portano riuniti gli organi maschili e femminili, si chiamano ermafroditi o monoici. Sebbene questi casi occorrano frequentemente e per legge normale nelle classi inferiori, pure le osservazioni accurate de' moderni ne hanno ristretto il numero, dimostrando in molti animali dianzi giudicati ermafroditi, la completa separazione de' sessi. Non ha molto un distinto naturalista danese, il signor Steenstrup, trascorse ad un altro eccesso, negando perfino la realtà dell'ermafroditismo in natıra, appoggiandosi particolarmente sulle molte cause di errore che possono illudere $\mathrm{i}$ naturalisti intorno alla precisa determinazione de'sessi e su false premesse di teoria. Que-

(*) A. Individuo femmina ingrandito.

R. Individuo maschio ingrandito assai più.

(Nordmann. - Mikrographische Beiträge, ecc.).

DE Filippr. Funzioni riproduttive. 


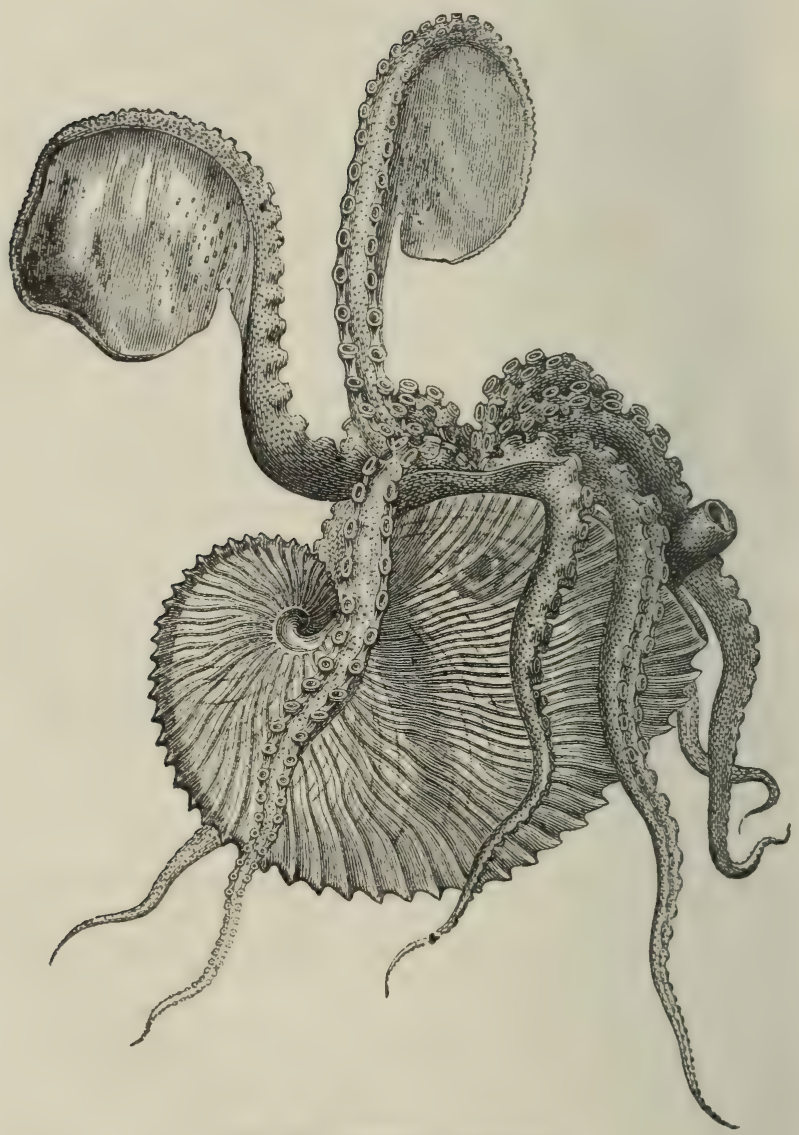

Fig. 25. Argonauta femmina.

sto sforzo d'ingegno non ottenne però il risultato che si era proposto. Esistono in natura veri e reali ermafroditi, presentanti nel medesimo tempo non solamente gli organi de' due sessi, ma i prodotti caratteristici di entrambi.

Perfetta corrispondenza esiste fra le parti sessuali del maschio e quelle della femmina, in modo da rappresen- 
tarsi reciprocamente (1). Le une e le altre provengono dai medesimi organi rudimentali dell'embrione, i quali si sviluppano in un modo o nell'altro, secondo che, per cause finora ignote, si dere più tardi pronunciare il sesso. Negli insetti si è persino osservato qualche volta lo sviluppo abnorme di organi femminili da un lato, di maschili dall'altro; e pretendesi che il medesimo caso, sebbene assai più raramente, sia occorso in individui delle classi de'crostacei e de' pesci. In questo ermafroditismo laterale si è anche notato che le parti femminili sono ordinariamente a sinistra; la qual circostanza è in rapporto collo sviluppo

(1) L'ovario della femmina corrisponde sempre ed esattamente al testicolo de' maschi : si corrispondono pure il canal deferente e l'ovidutto nelle specie in cui questo è continuo coll'ovario, non peró in quelle in cui l'ovidutto prende la forma di tuba. Questa è una parte distinta, ed il canale che nella femmina rappresenta il condnito deferente, esiste ancle in tal caso, ma solo nell'embrione, od appena si mantiene atrofico per tulta la vita in alcune pochissime specie.

La vescicola prostatica ne' mammiferi corrisponde all' utero della femmina, ed ha preso percio la denominazione di utero mascolino. Il professor E. E. Weber di Lipsia, fece pel primo questa osservazione nel castoro, ove essendo doppio l'utero della femmina, doppia del pari è la vescicola prostatica del maschio. Altri la confermarono con nuovi esempj.

$\mathrm{Ne}$ primi periodi dello sviluppo dell'embrione, quando il sesso non è ancora determinato, veggonsi nella caviti del ventre, ai lati della colonna vertebrale, ed all' esterno de' reni, due corpi simmetrici, molto pronunciati, e che descritti per la prima volta da Wolff, da lui prendono il nome. Essi constano di una glandola indifferente $d$ (fig, 26), che si trasformerà più tardi od in ovario od in testicolo; di molti canaletti $a$, i quali per la massima parte diventeranno l'epididimo nel maschio, od il corrispondente parovario (organo di Rosenmüller) nella femmina; di un condotto escretore $b$

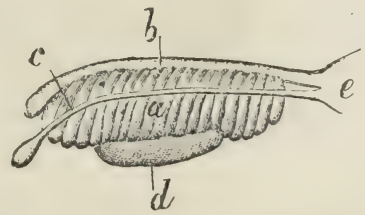
che resterà come canal deferente nel maschio, e sparira più o meno com- Fig. 26. Curpo di Wolff: da Kobeil ("). piutamente nella femmina. I cosi

detti canali di Gartner, che ne' majali e ne'ruminanti vanno direttamente dall' ovajo alla vagina, ne sono•un residuo permanente.

Lungo questo condotto vi ha un altro filimento (filamento di Müller), che termina alla sua estremitá libera con una capocchia, ed il quale subisce una sorte inversa; cioe scompare e si atrotizza ben presto nell' embrione maschio, mentre nella femmina si sviluppa sempre jiù e si trasforma in tuba.

(') $a$. Canaletti cicelf - b. Condutto escretore - c. Filamento di Xüller. - $d$. Glandola sessuale indifierente. - $e$. Caviti uru-ggenitale. 
normale ed esclusivo dell' ovario sinistro negli uccelli. Giammai però in questi casi entrambi gli apparati sessuali sono capaci delle rispettive funzioni: sovente anzi vi ha sterilità completa d'ambe le parti.

Negli animali della divisione de'vertebrati sono rarissimi e reramente eccezionali i casi di ermafroditismo, cioè di presenza contemporanea di ovaja o di testicoli capaci a funzionare in uno stesso individuo (1). Anzi, propriamente parlando, per quanto è noto fino ad ora, si riducono ad un solo presentato da alcuni pesci del genere de'sciarrani (Serranusr sciba e S. cabrilla), e già fatto osservare da Ari-

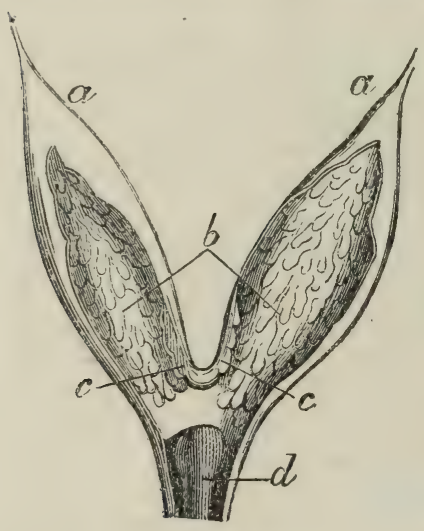

Fig. 27. Organi sessuali di sciarrano (*). stotile. In questi animali l'apparato sessuale consta di due sacchi oblunghi con molte pieghe interne formate dal tessuto proprio della glandola sessuale che secerne le uova quasi per tutta la sua estensione, tranre che in una assai circoscritta parte, al lato inferiore interno di ogni sacco, presso la loro confluenza nella vagina, ove si secerne invece lo sperma (2) (fig. 27).

Anche nella suddivisione degli artropodi la separazione de'sessi è legge costante, dalla quale appena si discostano gli ermafroditi cirripedi nella classe de'crostacei. Nella sud-

(1) I casi che non infrequentemente si riferiscono di ermafroditi nella classe de' mammiferi, non consistono che in semplici alterazioni di forma degli organi sessuali per cui de'maschi presentino de'caratteri di femmina e viceversa; o nella permanenza o sviluppo anormale di parti che dovrebbero invece esser sparite nello svilupparsi dell'embrione. La persistenza dei condotti escretori de'corpi di Wolff (sotto forma di canali di Gartner) nella femmina de' ruminanti, è una ragione dell'esser in questi animali più che in altri frequenti $\mathrm{i}$ casi di pseudo-ermafroditismo.

Jacobson ha trovato frequentemente ne' rospi associarsi agli organi maschili sviluppati e funzionanti, rudimenti di ovario e di ovidutto. Bidder, per altro, dà a queste parti una diversa significazione.

(2) Tra i pesci ermafruditi non sono da annoverarsi le anguille, come generalmente e per tanti secoli si è creduto. Ciù che vi ha di strano in questi pesci si è che tutti gli individui fin qui esaminati sono femminei.

(") a. Ovarj. - b Pieghe interne nelle quali propriamente si secernono le uova. - $c$. Follicoli maschili. $-d$. Papilla uro-genitale. 
divisione de'vermi l'unisessualità si verifica negli anellidi branchiati, ne'rotiferi, e negli elminti nematoidi : l'ermafroditismo invece, con pochissime eccezioni, negli anellidi abranchi, ne' turbellarj e negli elminti parenchimatosi.

Nella divisione de'molluschi s'incontrano ancora ne' cefalopodi i sessi perfettamente separati: ma ne' gasteropodi e negli acefali, predominando sempre le specie unisessuali, suno frequenti i casi di normale riunione de' sessi; anzi in una medesima famiglia e perfino in un medesimo genere si incontrano specie ermafrodite e specie uuisessuali; e secondo un autore moderno, qualche specie (il Pecten glaber, per esempio) presenterebbe indifferentemente individui nell'una e nell'altra condizione.

I sessi sono costantemente riuniti ne' tunicati (salpe, ascidie).

L'unisessualità è di nuovo prevalente negli animali della divisione de' raggiati, e si verifica come legge costante negli echinodermi, nelle meduse discofore, nella pluralità de'polipi. La riunione de'sessi ha luogo soltanto nelle meduse costate (beroe, callianire), ed in alcuni polipi (idra).

Non è sempre possibile il decidere se nelle specie ermafrodite gli individui possano bastare da sè alla fecondazione delle uova (ermafroditi autogami), oppure se debbano accoppiarsi per esser fecondati (ermafroditi eterogami). Pochissimi in ogni modo sarebbero nel primo caso, ed appena limitati a quelle specie le quali, come gli sciarrani ermafroditi, e le ascidie, presentano contemporaneamente sviluppati le ovaje ed i testicoli, ed emettono ad un tempo. uova e seme in modo che l'unione di questi due elementi riproduttori della specie abbia luogo immediatamente, fuori del corpo materno.

L' accoppiamento è una necessità per la maggior parte dagli ermafroditi, come vediamo accadere nelle lumache; ed in tal caso nasce di nuovo la quistione, se durante questo atto ambo gli individui siano fecondati, oppure un solo. A tale quistione non si può rispondere aricora cor assoluta certezza. $\mathrm{E}$ un fatto che in molti animali ermafroditi la maturazione delle uova e quella dello sperma rion sono contemporanee, sicchè sembrino in essi alternanti le funzioni di maschio e di femmina. $\mathrm{O}$ più esattamente diremo, che la capacità a funzionar come maschio dura più a lungo, e si rinnova a più brevi intervalli, mentre la maturazione 
delle uova non ha luogo che a più distanti periodi, e si compie rapidamente; e fatte esse mature vengono tosto emesse. E legge generale che gli spermatozoidi si formino più precocemente delle uora, e più a lungo si conservino ne' meandri dell'organo sessuale, come in attesa dell'opportunità fugace per fecondar le uova della femmina.

Ma in alcune specie ermafrodrite si effettua ben più che

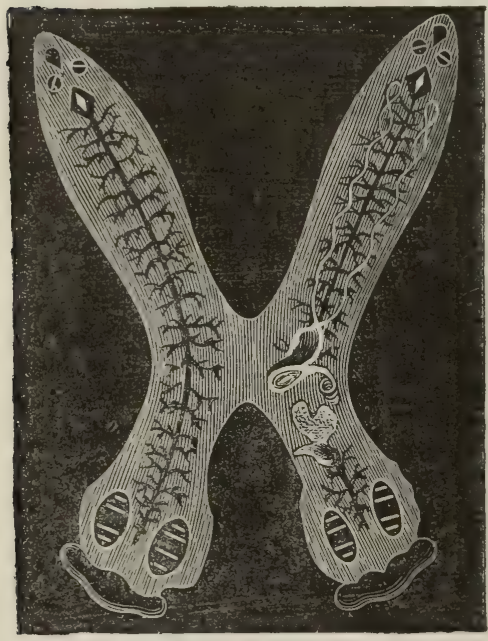

Fig. 28. Diplozoon. un semplice accoppiamento; un'intima unione, una conjugazione di due individui per una parte del loro corpo, analogamente a quanto vedemmo aver luogo negli infusorj. Quel curioso animaletto che vive parassito sulle branchie de'pesci d'acqua dolce, e che fu descritto da Nordmann col nome di Diplozoon (doppio animale) (fig. 28), rappresenta appunto una coppia di individui insieme coniugati, in ciascun de' quali riconosconsi benissimo sviluppati gli orgarii de' due sessi. I medesimi individui, nello

stato anteriore di isolamento, si distinguono per la presenza di un succhiatojo ventrale, pel quale si salderanno più tardi i due corpi e per l'assenza di organi generatori, lo sviluppo de' quali non ha luogo se non consecutivamente alla conjugazione (1).

Il processo della conjugazione è diverso adunque da

(1) Gia più sopra abbiamo considerato le tenie come agrogrogati. dienmu che ogni segmento (nel linguagorio antien) di questi vermi, rappresenta un inclivilue crmafrodito. Ora io credo che si debloa ravisare un arereazione più complirala in quelle specie che presentano due apemure sessuali at

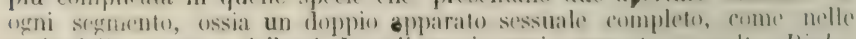

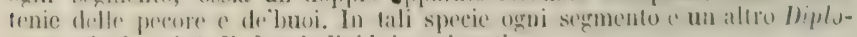
zoon, risulta cioś di due individui conjugati. 
quello della copula anche per ciò, che mentre questo non tende che a determinar il contatto dello sperma colle uova già prodotte da organi sessuali preesistenti, quello ha per iscopo di determinare lo sviluppo di tali organi.

E d uopo fare altra importante distinzione nelle specie ermafrodite o monoiche. In alcune cioè, come nelle sanguisughe (fig. 29) ne'distomi, ecc. gli organi sessuali maschili e femmili sono affatto distinti, e non si riuniscono che in prossimità del loro sbocco: in altri, come in molti molluschi, una medesima glandola, in follicoli separati però, secerne i materiali dell'uovo e del seme. Questa glandola, la quale non è nè ovario nè testicolo, ma l'uno e l'altro ad un tempo, dicesi glandola ermafroditica. Nella lumaca comune e ne' generi affini, il follicolo del seme è contenuto entro quello delle uova come un dito in un guanto; e tal rapporto si mantiene anche per gran tratto de' rispettivi condotti escretori. In altri e più rari casi invece, una medesima glandola fatta a grappolo porta acini distinti, de'quali gli uni sono maschili, gli altri femminili (fig. 30).

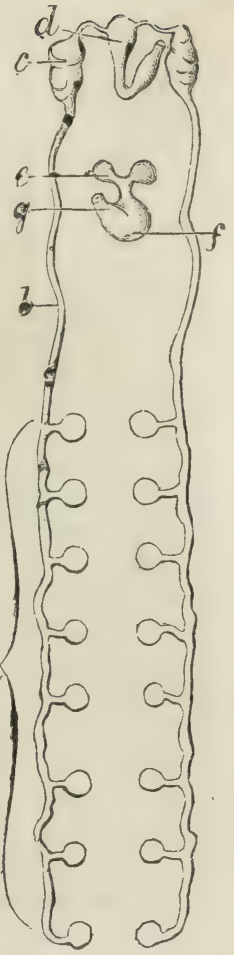

Fig. 29. Organi sessuali di sanguisuga (").

\section{e) Neutri.}

Nella pluralità de'casi i giovani individui, quelli stessi che devono subire una metamorfosi, come le rane, le salamandre, gli insetti, hanno già rudimenti ben distinti degli organi della generazione: solamente questi organi non entreranno in funzione che tardi, ad epoca prefissa e sicura. Nelle classi infime del regno animale invece, i giovani

(*) $a$. Testicoli. $-b$. Condotto deferente. $-c$. Vescicole seminali. d. Borsa da cui diparte il pene. - e. Ovaja. - $f$. Utero. - g. Vagina. 

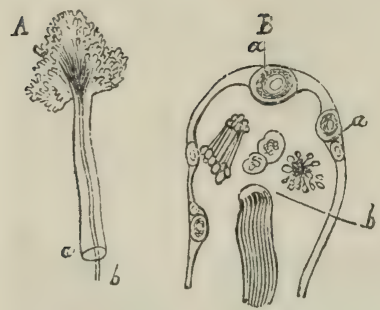

Fig. 30. Glandola ermafrodita di Lumaca : $d a$ E. Meckel (*).

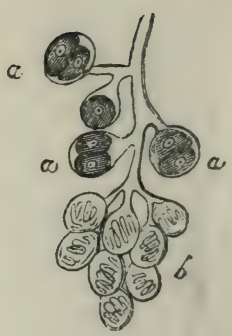

Fig. 30 bis. Glandola ermafroditica, di Rhodope: da Koelliker ("*).

appena dischiusi dall'uovo sono assolutamente agami, e lo sviluppo degli organi sessuali è in essi vincolato a certe condizioni, mancardo le quali potrà quello sviluppo ritardarsi fino ad epoca indefinita, o non esser mai raggiunto. Sono in tal caso gli elminti, o vermi intestinali, così detti perchè la loro sede ordinaria è l'intestino degli animali, particolarmente di quelli spettanti alla divisione de'vertebrati. In questa sede soltanto pervengono gli elminti al termine della loro carriera, e gli organi della riproduzione si sviluppano in essi completamente. In altre sedi, civè fuori della cavità intestinale anzidetta, oppure nel corpo degli animali delle classi inferiori, gli elminti restano ordinariamente agami, e non cambiano questo stato se non dopo una trasmigrazione, la quale, essendo quasi sempre passiva per parte loro, è in gran parte opera del caso.

Di tutto questo dà ragione la legge costante, che l'attività del processo nutritivo deve precedere e preparare quella del processo riproduttivo; come già ebbimo occasione di osservare altrove ( pag. 4), e come meglio si rileva dal. l'esempio seguente. In molte specie di imenotteri si distin. guono individui maschi, individui femmine, ed individui che si dicono neutri, perchè non appartengono nè all'uno nè all'altro sesso. Or questi sono veramente agami, quan.

(") A. La glandola. - a. Ovidutto. - b. Canal deferente.

B. Un follicolo della glandola ingrandito al microscopio. $-a$. Uova a diversi gradi di sviluppo. - b. Spermatozoidi e cellule che li producono.

(") a. Acini femminili. - b. Acini maschili. 
tunque abbiano già raggiunta l' epoca nella quale avreb. bero dovuto svilupparsi gli organi sessuali. E destino della natura che tali abbiano a rimanere per tutto il resto della vita. Le api operaje, di cui son noti ed i maravigliosi istinti ed i provvidi ufficj nell'alveare, snno individui neutri : più esattamente però si devono considerare come femmine nelle quali gli organi essenziali del sesso non si sono svi. luppati, e di femmina altro non posseggono se non l'aculeo velenifero, che è una trasformazione dell'oviscatto. Or bene in nessun caso, come in una società di api, è resa marifesta l'influenza grandissima del nutrimento sullo sviluppo degli organi sessuali ; poichè in esse è appunto la qualità e quantità del nutrimento che determina il sesso o lo stato neutrale. La larva destinata a diventar una vera femmina è allevata in una cella apposita, e nutrita non già col pol. line che serve a pasto delle future neutre, ma con un cibo più succoso e più abbondante, colla così detta gelatina reale. Ora se la femmina dell'alveare muore e nell'arnia non trovisi una larva già predestinata a diventar una femmina, le api neutre si adoperano con sollecitudine attorno ad una larva della loro categoria, e ne ingrandiscono la cella, e vi arrecano gelatina reale in copia sufficiente; per le quali cure l'insetto alato in cui si deve trasmutare quella larva, non sarà più un individuo neutro, ma una femmina atta a procreare, e che tosto nata riceve gli omaggi di regina.

Verrà detto in seguito come in molte specie di animali delle infime classi le funzioni principali della vita siano affidate non già ad organi, ma ad individui distinti succedenti l'uno all'altro; ed anche in questi casi non verrà mai smentita la legge sopraenunciata, e sempre gli individui nutritivi si vedranno precedere gli individui pro. creatori.

\section{f) Fecondazione dell'uovo.}

L'uovo maturo è un prodotto inutile se non viene fecondato (1); ed esso ne perde l'attitudine in ragione del

(1) Un' eccezione a questa, che pure direbbesi legge costante e rigorosa, fu gia a quest'ora verificata, sebbene in casi relativamente rari, in varie specie di farfalle. Furono cioè vedute femmine, perfettamente isolate fin dal precedente stato di larva o di crisalide, deporre uova, e da queste na- 
tempo che trascorre dopo il suo distacco dall' ovario. La natura ha però disposto con varj e mirabili artifizj che ad ogni epoca di maturanza delle uova, mentre la femmina è pressata dal bisogno di deporle, non manchi mai il concorso del seme del maschio.

Generalmente parlando la fecondazione delle uova accade nell' atto stesso della copula, o pochi momenti dopo; ma in alcuni casi questi due atti sono affatto distanti e separati da un lungo intervallo di tempo. Così accade negli insetti, ove il maschio si limita a riempir dell'umor prolifico il ricettacolo del seme della femmina, e le uova di questa sono fecondate più tardi, al momento della loro emissione. In alcune specie perfino, come Siebold ha constatato nelle vespe, l' accoppiamento arviene in autunno, poscia il maschio muore, e la femmina sola sverna per emettere le uova nella successiva primavera.

Riguardo all'atto esterno della fecondazione, ossia all'accoppiamento, esso ha luogo in due modi diversi. Nella maggior parte de'pesci, nelle rane, nei rospi, la femmina partorisce le uova che rengono immediatamente dopo fecondate dal maschio. Nella pluralità degli altri animali, il maschio, o col mezzo di un organo copulatore apposito, o contrapponendo la sua apertura sessuale a quella della femmina, injetta nella vagina di questa l'umor seminale, che ascende verso le uova. La fecondazione è quindi esterna od interna. Può essere interna anche senza vero accoppiamento, mercè l'epitelio vibratile di cui è guernito in varie parti il corpo degli animali, ed il quale determina alcune correnti nella direzione che più torna opportuna alle funzioni varie. Una di queste correnti dirige l'umor seminale versato in prossimità dell'organo sessuale femmineo entro quest'organo stesso: ed è in questa maniera che ha luogo la fecondazione in molti molluschi acefali, ne'polipi, negli acalefi, ne' quali la facoltà locomotiva è assai limitata, od anche nulla nelle specie che vivono sempre aderenti.

Il moto vibratile della superficie interna delle cavità

scere in seguito altrettanti bruchi. Simili casi di feconcliti in femmine vergini (Lucina sine concubitu, o Partemogenesis, secondo l'espressione elegante di Owen) si possono paragonare a quello delle ripelute generazioni vivipare degli afidi; colla differenza che quello e un caso normale e costante e questi si dabbono considerare come abnormi ed accidentali, finche non siano conosciute le leggi sotto le quali occorrono. 
sessuali della femmina, è pure una delle cause dell'ascensione dello sperma verso l⿳ovario, anche negli animali superiori ne'quali ha lıogo un vero accoppiamento; effettuandosi appunto la fecondazione o nell'ovario stesso o nelle prime porzioni della corrispondente tuba, ove non potrebbe giungere lo sperma per la sola spinta riceruta nell'emissione.

Ci si offrono a questo punto alcune quistioni di grave momento: quale delle due sostanze di cui si compone lo sperma, la parte liquida cioè, e la parte rappresentata dagli spermatozoidi, sia attiva nella fecondazione: ed in che cosa consista questo processo?

Alla prima quistione si può rispondere completamente. Dalla costanza degli spermatozoidi nel seme di tutti gli animali, dalla loro prevalenza sovra la parte liquida, si può già dedurre che in essi debba risiedere la virtù fecondante. L'esperienza poi che facilmente si può istituire sulle rane, dimostra esser la parte liquida del seme passata attraverso un filtro, inattiva sulle uova, mentre si riesce a fecondar queste colla parte che rimane trattenuta sul filtro.

Alla seconda quistione non si può dare che una soluzione parziale. Prévost e Dumas già da molti anni avevano emessa l'opinione che $\mathrm{i}$ cosi detti animalculi spermatici entrino a far parte materiale del nuovo embrione; ma non avendo essi data prova alcuna di questa asserzione, avendo anzi oltrepassato il confine concesso alle ipotesi col sostenere che in ogni uovo un zoosperma vada a costituire l'asse cerebro-spinale dell'embrione stesso, l'ipotesi cadde, trascinando seco quanto più tardi dovea esser dimostrato vero. Riconoscendo sempre che la parte efficace dello sperma consiste ne' suoi corpuscoli solidi, tutti i fisiologi convennero nell'ammettere che questi corpuscoli non entrino materialmente a far parte dell'uovo, e non esercitino su di esse altra azione se non una simile a quella che $\mathrm{i}$ chimici dicono asione di contatto. Recentissime ed esatte osservazioni, ripetute e moltiplicate a sufficienza, ci obbligano nuovamente a riconoscere che gli spermatozoidi penetrano effettivamente e per attività foro propria nell'uovo (1). Quel foro di cui si fè cenno più sopra e che

(1) Veggansi diverse pubblicazioni dell'ora decorso anno, per parte di Barry, Nelson, Keber, Bischoff, Leuckart e Meissner; e specialmente uno scritio di quest'ultimo autore nel giornale di Siebold e Koelliker (Zeitschrift der wissenschaft. Zoologie. Vol. vi, Fase. II). 
dicemmo micropilo, è la via ordinaria che gli spermatozoidi tengono onde giunger fino nell' interno del tuorlo, ove essi, a quanto pare, finiscono per decomporsi, subendo la metamorfosi pinguedinosa, e riducendosi in granuli di sostanza grassa che si immischiano con quelli proprj dell'uoro stesso. In qualche specie (negli ascaridi e nel lombrico di terra, per esempio), entrano essi nella sostanza del tuorlo prima che si formi attorno a questa la mem. brana vitellina.

L'uovo fecondato e posto in opportune condizioni, percorre una serie di fasi, delle quali diremo qualche parola più tardi (1).

\section{g) Epoca degli amori.}

L'attività e lo sviluppo degli organi sessuali non sono costanti in ogni tempo dell'anno; ma ricorrono a periodi determinati e varj a norma delle specie. $\dot{E}$ universalmente salutata la primavera come la stagione delle nozze, sia per le piante, come per la maggior parte degli animali che popolano le nostre campagne; e in vero possono considerarsi quasi come un'eccezione le specie che vanno in amore o sotto le brume autunnali, o ne' rigori del verno, come per esempio il lupo fra i mammiferi, i salmoni fra i pesci; e nella classe degli uccelli $\mathrm{i}$ becc' in croce, che possono nidificare in tutte le stagioni, anche nel cuore dell'inverno.

Non solamente queste epoche sono contrassegnate da un grande sviluppo di uova o di spermatozoidi negli organi ciò destinati; ma anche dal manifestarsi di nuovi caratteri consensuali, quali sono per esempio lo sviluppo di

(1) Spallanzani, il primo che abbia dimostrato sperimentalmente la necessita del contatto materiale dello sperma colle uova, ed annullata cosi l'ipotesi di un' aura seminale fecondante, è il primo del pari che abbia tentato in varj animali, ma specialmente nelle rane, la fecondazione artificiale.

Erede del suo genio, Rusconi si valse pur di questo mezzo per giungere ad importantissime scoperte in quella parte della fisiologia che tratta della formazione e sviluppo degli embrioni. Egli insegnù il modo assai facile, spedito, suggerito dalla natura stessa, per fecondar le uova dei pesci, spremendule dal ventre della femmina, e poscia versando su queste il seme spremuto da' maschi. Questo semplice sperimento, che ha servito dapprima ail uno scopo puramente scientifico, si svolse in un vero procedimento industriale, e divenne un mezzo per diffondere e moltiplicare nelle acyue le più utili specie di pesci, coll'istessa sicurezza ed importanza di prodotto che si ottiene nella seminagione del grano sulla terra. 
certe ghiandole cutanee sovente odorifere ne'mammiferi, il maggior lusso delle piume negli uccelli, le creste dorsali de'tritoni, le spine sulle scaglie di alcune lasche, ecc. In generale questi caratteri secondarj sono tanto più appariscenti, quanto più lungo è l'intervallo fra l'una e l'altra epoca nuziale; quindi più negli animali che generano una sol volta all'anno, che in quelli che s'accoppiano più volte. Fanno maraviglia a questo riguardo gli insetti per l'enorme differenza tra le forme della larva e quelle che presentano dopo subite le metamorfosi. In quest' ultimo loro stadio passano una vita brevissima ed appena sufficiente all'opera della propagazione, opera che essi non rinnovano mai, per la morte che li colpisce appena vi hanno adempiuto un'unica volta. Da tutto ciò si vedrà con quanto fondamento i naturalisti prescelgano di studiare i caratteri degli animali alla stagione in cui questi caratteri sono maggiormente spiegati e l' organismo è, per così dire, più completo: la quale stagione è appunto quella degli amori.

Essa è contrassegnata anche da un cambiamento notevole nel morale e nelle abitudini degli animali. Alcuni che d'ordinario sono d'indole tranquilla e pacifica, diventano irrequieti e furibondi pel possedimento delle femmine che difendono o contrastano perfino con pugne accanite. Molti pesci abbandonano i profondi recessi del mare per salire lungo le correnti de'fiumi, e depositarvi il frutto de' loro apatici amori ; alcuni insetti, abbandonata la loro dimora terrestre od aquatica, spiegano le ali nelle libere vie dell'aria.

Per tutti gli animali, senza distinzione veruna, l'attitudine a procreare ricorre a periodi determinati, più o meno distanti l' uno dell' altro. La nedesima specie umana non si sottrae a questa legge, per quanto volgarmente si creda il contrario.

Questa periodicità si rende in generale meglio palese nelle femmine che ne' maschi. In tutte le specie, senza eccezione, le uova giungono spontaneamente a maturità, si distaccano dall'ovario, e sono emesse. Ne'mammiferi la maturanza di un uovicino, la tumescenza e la consecutiva rottura di un follicolo di Graaf, sono accompagnate da un particolare orgasmo da uno straordinario afflusso di sangue a tutto il sistema generatore. Il quale afflusso si manifesta in vari gradi: in alcuni, come ne'conigli, ne' majali, con una semplice essudazione di poco muco sanguinolento 
nella cavità dell'utero: in altri con un vero scolo più o meno copioso di sangue nella vagina, quale si vede non raramente nelle vacche, e ricorre a regolari e determinati periodi ne' mammiferi superiori, come nelle scimmie. $\dot{\mathrm{E}}$ questo il principal carattere che contraddistingue l'epoca del calore ne'mammiferi. La stessa mestruazione della donna non ha altra causa; essa è del pari un effetto della periodica maturazione di un follicolo di Graaf e del conseguente distacco di un uovicino.

\section{\$ $4 .^{0}$ I lorridi.}

Uno dei più sicuri dati che servono di fondamento all'idea della specie, è quello dell'accoppiamento spontaneo produttore di una prole illimitatamente feconda. La natura è cosi gelosa conservatrice dei tipi primitivi della specie, che ha infuso in tutti gli animali una ripugnanza decisa a congiungersi in connubio con specie differenti.

L' unione sessuale di due individui di specie diversa arviene tuttavia abbastanza di frequente negli animali che per la domesticità e per la schiavitù sono in parte sottratti alle leggi ed alle libertà naturali: sempre però si richiede che $i$ due individui appartengano a specie assai affini. I prodotti che ne nascono si dicono ibridi, o meticci. Basta non di raro che un solo degli individui stipiti sia allo stato di schiavitù per dar luogo a questa deviazione del piano della natura. Così vediamo, per esempio, le anitre selvatiche scendere talvolta sui laghetti delle nostre ville, a congiungersi coll' anitra muschiata domestica. In qualche rarissimo caso soltanto non è necessaria que. sta circostanza, e possono due individui veramente liberi e di specie differenti, ma affini, incontrarsi per via e congiungersi in amore. E ormai sicuro che il tetraone medio non sia una vera specie, ma solo fondata su individui derivanti dall' urogallo maschio e dalla femmina del comun gallo di monte. Anche in questo caso però bisogna scorgere la lontana influenza dell' uomo, che inseguendo alla caccia una selvaggina cosi ricercata, ha potuto costringere ad uno stato di isolamento dalla loro famiglia legittima $\mathrm{i}$ due individui di questa coppia, e forzare il maschio, salace e forte come in tutte le specie poliganc, a sfogar listinto amoroso su di una femmina che non gli appartiene. 
Da alcuni casi si è perfino indotti a conchiudere che lo stato di schiavitù non solo porti a congiungersi fra loro i due individui di specie diverse, ma perverta siffattamente gli istinti nativi, da rendere una simile unione più facile che non fra due individui della medesima specie. I casi di accoppiamento fra leone e leonessa nei serragli sono assai più rari che non quelli del leone colla tigre.

Tutti sanno come si provochi ad arte l'incrociamento fra alcune specie di animali domestici; fra la cavalla e l'asino onde averne il mulo, l'asina ed il cavallo onde averne il bardotto. La natura, quasi volesse punire ne' figli la colpa de' genitori, e sempre nell' intento della stabilità delle specie, ha fatto si che gli ibridi siano generalmente sterili ed infecondi. La vera causa di ciò non è ancora ben conosciuta. Non v' ha differenza alcuna tra gli organi sessuali de' cavalli o degli asini e quelli de' muli. Stando ad alcune osservazioni, ripetute e confermate anche recentemente da De Martino, pare si debba riconoscere questa causa nella mancanza di spermatozoidi nel seme del mulo. In qualche caso raro ed anormale si sono però avuti ibridi fecondi. Or fa appena qualehe anno, il prof. De Nanzio di Napoli ha raccolto il parto di una mula che era stata coperta da un cavallo; ed altri esempj simili bene accertati, sebben sempre assai rari, furono esposti dai fisiologi in varie epoche. Si è trovato che $\mathrm{i}$ nati dall' accoppiamento dello stambecco colla capra sono fecondi: che del pari lo sono quelli che provengono dal montone e dalla capra, oppure dal becco e dalla pecora. Da ciò si è voluto dedurre che la definizione della specie, quale è generalmente ammessa dai naturalisti, non è esatta; che a tırto si considerano le tante e sì varie razze del cane famigliare come provenienti da un ceppo unico pel fatto che dai ripetuti loro incrociamenti si ha costantemente una prole feconda. E trasferendo questa argomentazione ad una quistione di ben più alta importanza, si è ripetuto ancora recentemente che l'uomo istesso non appartiene ad un' unica specie, ma a tante diverse specie originarie, quante sono le principali razze o varietà che se ne distinguono.

Ognun si persuade agevolmente che, stando in questi termini, la quistione minaccia di risolversi in un giuoco di parole, se prima non si stabilisce chiaramente cosa 
debba intendersi per specie. Non essendo possibile fissare in modo preciso ed assoluto i limiti di variabilità nei ca. ratteri esterni in animali evidentemente spettanti ad una medesima serie genealogica, ue viene di conseguenza che il carattere più sicuro della specie non possa riscontrarsi altrove che nella fecondità perdurante della prole nata da un connubio spontanco. I casi riferiti di ibridi fecondi, perdono ogni valor d'opposizione quando si consideri: $1 .^{\circ}$ che l'accoppiamento fra $\mathrm{i}$ genitori di quegli ibridi non ha avuto luogo in condizioni affatto naturali, ma sempre sotto la diretta o indiretta influenza dell' uomo; $20^{\circ}$ che sempre e puramente que' casi rari ed eccezionali si risolvono nel parto di femmine ibride fecondate da un maschio di una delle specie stipiti; $3 .^{\circ}$ che anche la fecondità di tali femmine ibride si estingue dopo poche generazioni.

\section{Sviluppo dell' uovo e formazione dell' embrione.}

L' uovo non racchiude già un embrione in miniatura, che l'atto della fecondazione risvegli e faccia ingrandire, come sino al principio di questo secolo fu creduto, ma contiene i soli materiali primi per la sua formazione. I tessuti di questo embrione non si formano neppure pel ravvicinamento di molecole nervee, musculari, membranose, ossee, ecc., preesistenti nell' uovo; ma hanno origine da cellule di nuova formazione, che da principio sono tutte omogenee, ma vanno successivamente differenziandosi. Queste cellule elementari, ordinariamente non visibili che ai maggiori ingrandimenti del microscopio, constano di un sacchetto od otricello sferico, contenente un liquido denso e più o meno trasparente, nel quale è immerso in posizione eccentrica un secondo otricello più piccolo che dicesi nucleo, contenente alla sua volta uno o più nucleoli. Talvolta varie di queste cellule sono contenute in un sacco comune, formato esso pure da una membrana semplice, senza struttura, e che ha preso il nome di cellula madre.

Torra opportuno il rammentar qui le parti costituenti dell' uovo, ed il considerarlo per un istante siccome una cellula, di cui la vescicola germinativa è il nucleo, le macchie germinative sono i nucleoli. Questa cellula non racchiude ancora le cellule embrionali, ma le deve produrre; 
al quale atto eminentemente vitale prende una parte im. portante la vescicola germinativa stessa.

Il processo embriogenico si può dividere in due grandi periodi. Il primo incomincia dalla fecondazione dell uovo o dal suo distacco dell'ovario, e finisce colla sua riduzione totale o parziale in un aggregato di cellule embrionali omogenee: il secondo, più complesso, più lungo, divisibile in stadj secondarj, incomincia dal differenziamento delle cellule embrionali, e finisce colla completa organizzazione del nuovo individuo.

Nel primo periodo si presenta un fenomeno assai interessante, comune a tutti gli animali: la segmentazione, il solcamento del tuorlo. Per farcene una prima idea, supponiamo una sola grande cellula, una sfera vitellina; e che per uno stringimento o sulco equatoriale si divida essa in due parti uguali : ciascuna di queste metà venga suddivisa similmente da un secondo solco perpendicolare al primo; sopravvenga poscia altro solco in ciascuna delle quattro parti cosi risultanti del tuorlo, e via di seguito; di tal maniera che il tuorlo si dirida da prima in 2 parti, poscia in 4 , quindi in 8 , in 16 in 32 , in 64, ecc. Queste parti sono dette lobi e lobuli di solcamento. Il tuorlo sarà infine ridotto in un aggregato di lobuli minuti che non si solcheranno più, e ciascuno con una membranella, un contenuto, un nucleo; sarà questo un aggregato di cellule embrionali (1).

La vescichetta germinativa inclusa nel tuorlo ha preso parte a queste divisioni e suddivisioni, ed infatti ogni lobo ed ogni lobulo contiene nel suo interno un nucleo trasparente. Da alcune osservazioni sembra anzi potersi stabilire che la divisione della vescicola germinativa

(1) In questo modo, cioè dal solcamento del tuorlo, si formano le cellule embrionali in tutti gli animali, dai polipi ai mammiferi. Sultanto in alcune specie della classe degli elminti, le dette cellule si formano entro il tuorlo senza sua diretta partecipazione; esse lo assimilano a poco a poco (vedi Koelliker Müllers Archiv. 1843).

Un fatto maraviglioso che dovrebbe essere assoggettato a nuova critica è quello osservato da Koren e Danielssen nel buccino ondato (Arnales des Sciences naturelles, Vol. 18, 19, 3. ${ }^{\mathrm{a}}$ serie). L'embrione in questa specie sembra formarsi piuttosto che dalla segmentazione del tuorlo, da una riunione di molti tuorli distinti. La nota apposta dal signor Milne Edwarils (vol. 18, pag. 260) mette assai ragionevolmente in dubbio la giustezza dell'interpretazione data da que' due autori al fatto che sarebbe loro caduto sott' occhio. 
sia quella che preceda e trascini con sè quella del tuorlo (1).

Or fa d'uopo avvertire che queste solcature sono totali o parziali: interessano, cioè ora l'intiera massa del tuarlo, ora una sola parte di esso, anzi una parte che non spetta propriamente al tuorlo, ma vi è incastonata. Le solcature totali si osservano nell' uovo dei marnmiferi, dei batracj, dei gasteropodi, degli acefali, dei vermi, di alcuni artico. lati, dei raggiati.

Le solcature parziali invece di quelle degli uccelli, dei rettili, dei pesci, dei cefalopodi, della maggior parte degli articolati. Ognun vede perciò che non si potrebbe stabilire una divisione naturale degli animali in due scompartimenti, su questo dato delle solcature dell' uovo piuttosto parziali che totali. La causa di questa differenza è inerente alla diversa composizione originaria dell' uovo, di cui fu brevemente accennato a pag. 29.

Per meglio comprendere in cosa consista questo fenomeno, sceglieremo i due esempi che seguono.

Nell'uovo dei pesci ossei, appena deposto e fecondato, il tuorlo è sferico e senza rialzo di sorta alcuna alla sua superficie. La vescichetta germinativa è sparita ed in sua vece trovasi alla periferia del tuorlo un' areola poco distinta, nella quale però sussistono i corpicciuoli che formavano le macchiette germinative; nessun dubbio adunque che la materia di cui essa è formata sia la stessa della cosi detta vescicola di Purkinje. Nello spazio di alcuni minuti, in corrispondenza di questa areola, si forma un rialzo, che poco dopo, sopravvenuto un primo solco, è diviso in due, poi da un secondo solco tagliante il primo ad angolo retto in quattro (fig. 31): quindi in otto, in sedici, in trentadue, e cosi progredendo sempre in ragione geometrica, il rialzo diventa un ammasso di cellule em. brionali omogenee. Il tuorlo non ha preso parte alla seg. mentazione. L'embrione che si forma alla sua superficie a poco a poco lo investe e lo ritira nella cavita addominale, ove col tempo è assorbito.

(1) Si è disputato con animosita portata quasi ai confini del ridieolu, se questi lobuli abbiano o no una membranella circumambiente. In tesi ge nerale si puo dire che tosto o tardi una tal membranella si forma : ma l'epora precisa di questa formazione è da determinarsi nei singoli casi. Cii che vi ha di certo si è che ne vanno sempre muniti i minuti lobuli risultanti dall'ultima divisione. 
Per darci una ragione di questo fatto, si parte dal dato che quella parte da noi ora chiamata rescicola di Purkinje non corrisponda esattamente alla parte di egual nome nelle uova in cui la segmentazione è totale, ma consti essa medesima di un piccolo tuorlo speciale che diremo tuorlo di evoluzione, distinto dal tuorlo comunemente detto, che sarà invece un tuorlo di nutrizione, come in questa figura schematica (fig. 32).

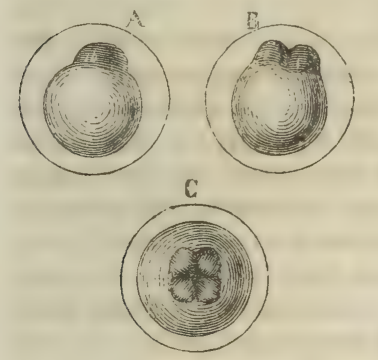

Fig. 31. Uova di cheppia (Clupea) (").

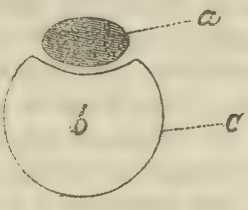

Fig. $32\left({ }^{* *}\right)$

Si esaminino ora di quelle uora nelle quali l'embrione si formi per segmentazione totale del tuorlo, per esempin le uova che si trovano accumulate nell'ovidutto tubolare dell' ascaride parassito del polmone della rana (1) (fig. 33).
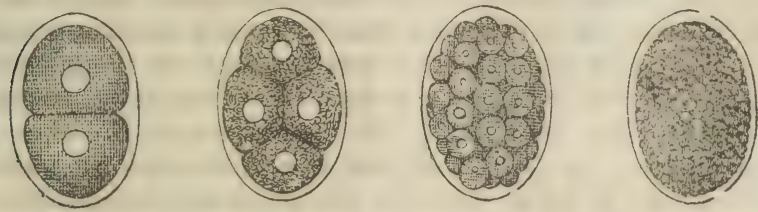

Fig. 33. Uova di un Ascaride a varj gradi di sviluppo.

(") A. Mezzora dopo la fecondazione. Prima formazıone del grerme.

B. Un'ora dopo la stessa. Divisione del germe in due.

C. Un'ora e mezza dopo la stessa. Divisione del germe in quattro.

(*) a. Tuorlo di evoluzione privo di membrana propria.

$b$. Tuorlo di nutrizione, racchiuso in una membranella $c$.

(1) Per una dimnstrazione facile e spedita del processo di segmentazione dell' uovo, convengono assai certe specie di clminti nematoidi, e fra queste la maggior parte degli ascaridi, in quanto che si possono rinvenire d'un tratto, in un soggetto solo, uova a tutti i periodi di segmentazıone. 
In questo il solcamento procede come fu esposto più sopra: qui non vi ha che un solo tuorlo, ossia le due sostanze che vedemmo dirise nell' uoro dei pesci sono confuse assieme. La vescicola germinativa si suddivide col tuorlo, e forma un nucleo ad ogni lobulo di solcamento. La sola differenza che sarà da osservarsi nei varj animali in cui la segmentazione del tuorlo procede in questo modo, consiste nella maggiore o minore regolarita della segmentazione. In alcuni casi, come nell' uovo delle salamandre, i solchi si tagliano con tal ordine che i lobuli risultanti sono uguali, e si suddividono contemporaneamente; in altri, come nelle rane, i lobuli stessi sono disuguali; alcuni cioè sono più grandi, altri più piccoli; e questa disuguaglianza giunge in alcuni casi al punto, che una parte del tuorlo si divide prestamente in piccoli lobuli, e nella rimanente porzione il solcamento resta incompleto.

Per tal modo si stabilisce quasi un passaggio della seç: mentazione totale alla parziale. - Si ha un esempio di questo nei gasteropodi, ma specialmente nei pteropodi, nei quali la regolarità del solcamento non va oltre la divisione del tuorlo in quattro lobi, e tocco questo periodo, uno dei lobi soltanto si suddivide ulteriormente fino a ridursi in un aggregato di cellule embrionali, stando ancora immutati gli altri tre. Anzi le cellule di quell'aggre. gato si differenziano rapidamente, e quindi si dispongono
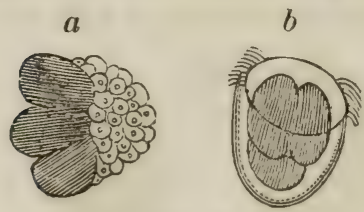

Fig. 34. Uova di Hyaloea: da Gegenbaur ("). tosto in uno strato periferico che inviluppa $\mathrm{i}$ lobi residui, e sul quale non tarda a comparire una zona di lunghe ciglia vibratili che corrisponde ad un organo dell'embrione, al così detto velo (fig. 34).

Non ci è possibile estenderci nell'esposizione di quel mirabile processo in virtù del quale un uovo si trasforma in un essere animato, e di complicazione organica cosi varia, quanto appare arche dall' esame comparativo dei soli principali tipi di animali. Queste ricerche formano

(') a. Uova in principio delle solealure. Un lobo è gia suddiviso e ridotte in un aggregato di cellule trasparenti.

Questo aggregrato format gria 11 b un inviluppo il cui margine ciliato rappresenta il velo del futuro embrione. 
oggetto d'un ramo particolare della filosofia zoologica, l'embriologia, che ha raggiunto in questi ultimi anni un grande sviluppo. Per altro, onde non lasciare a questo posto una troppo grande lacuna, riassumeremo in brevi parole $\mathrm{i}$ fatti più importanti; e violando l'ordine che ci sarebbe prefisso, incominceremo dalla formazione del pulcino nell' uovo di gallina, che è il campo prediletto degli embriologi da Malpighi ai giorni nostri.

L' uovo fecondato nell'ovario o nella porzione superiore della tuba, discende per questo canale, e nel mentre si aggiunge l'albume attorno al tuorlo, si compie la formazione della cicatricola. Come questa abbia luogo non è ancora ben chiaro, però l'analogia grandissima fra l'uoro degli nccelli e quello dei pesci, fra la struttura della cicatricola in quello e l'aggregato di cellule embrionali in questo, ci fa credere che la cicatricola sia già il risultato di una segmentazione avvenuta nascostamente forse nell'ovario stesso, o nel tragitto per la tuba. Poche ore dopo l'espulsione dell' uovo, e sotto l'influenza di una ternperatura dai $28^{\circ}$ ai $32^{\circ} \mathrm{R}$. la cicatricola, detta anche disco proligero, si estende, ed in questo mentre si divide in due strati, l'uno superiore chiamato foglietto sieroso od animale, l'altro inferiore più grande, foglietto mucoso o vegetativo; e fra l'uno e l'altro si rende distinta una regione centrale da prima elittica ed alquanto trasparente, chiamata perciò areola pellucida (fig. 35). Questi due foglietti in cui per un primo differenziamento si riduce la cicatricola, constano di una riunione di cellule nucleate; e ciascuno di essi col tempo successivo si differenzierà alla

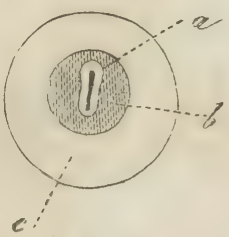

Fig. 33. Tuorlo d'novo di galline colla sua areola pellucida, dopo 36 ore di incubazione ("). sua volta per dar origine, il loglietto sieroso ai varj apparati del senso e del moto (cute, asse cerebro-spinale, organi dei sensi, scheletro, muscoli degli arti e del tronco), il foglietto mucoso ai sistemi della rita regetativa (pol-

(*) $a$. Areola pellucida. - b. Foglio vascolare in cui appajono wia $\mathrm{H}^{*}$ isole sanguigne. $-\epsilon$. Membrana vitellina. 
moni, apparato digerente, organi sessuali). L' areola pellucida consta di cellule più trasparenti senza nucleo, ed appartiene alla parte inferiore del foglietto sieroso od animale. Una terza lamina intermedia, che fu chiamata foglietto vascolare, si forma ben tosto; e contemporaneamente il sottoposto foglietto mucoso s'estende sempre più, fino a costituire un sacco chiuso che racchiude il tuorlo.

Ora i più importanti cambiamenti si veggono in corrispondenza dell' area pellucida. Questa si allunga e prende la forma di un biscotto; e nella direzione del suo asse, che è perpendicolare all' asse maggiore dell' uovo, si manifesta una lineetta o striscia primitiva. Ai lati di questa striscia, come per comprenderla in mezzo, compajono

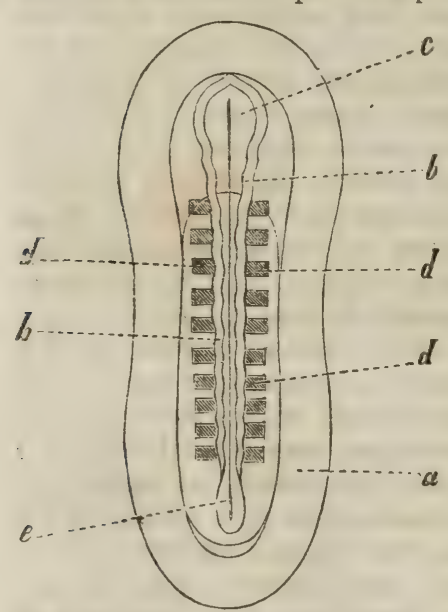

Fis. 36. Lareola pellucida della fiyura precedente molto ingrandila (figura teorica) ("). due rilievi o lamine di sostan. za assai molle, che si congiungono, per formare un tutto continuo, alle due estremità, ove, e specialmente all'estremità anteriore, prima di congiungersi si divaricano. Sono queste le così dette lamine dorsali, e rappresentano già il primo abbozzo del corpo dell' embrione. Le due divaricazioni terminali corrispondono l'anteriore al rigonfiamento cefalico, la posteriore al seno romboidale del midollo spinale (fig. 36 ).

Al di sotto, nella precisa direzione della striscia primitiva, si forma un'altra importantissima parte dell'embrione, la cosi detta corda dorsale, avente l'aspetto di un bastoncino di sostanza gelatiniforme, e che guardato al nicroscopio si palesa formato di cellule particolari assai trasparenti. Essa rappresenta l'asse provvisorio della futura colonna vertebrale. Però è da notarsi fin d'ora che la

(") a. Areola. - b. Lamine dorsali. - c. Cavita dove si svilupperanno 1. vesciche cerebrali. $-d$. Lamine rudimentali delle vertebre. $-c$. Spazio rorrispondente al seno romboidale. 
corda dorsale non prende parte alcuna alla formazione delle vertebre; queste si formano attorno alla corda, dai suoi inviluppi, e col loro successivo progresso la comprendono in modo che ne determinano la totale scomparsa. La corda dorsale è dunque nel pulcino un organo provvisorio, un organo embrionale.

In questo frattempo, ai lati delle lamine anzidette e della corda dorsale compajono tanti corpicciuoli subprismatici, disposti in due serie simmetriche, ed il cui numero, assai ristretto da prima, va gradatamente aumentando. Corrispondono essi ai veri rudimenti delle vertebre. L'embrione, che da questo momento è abbozzato, si incurva a falce nella sua regione ventrale, e specialmente alla estremità anteriore o cefalica. I margini delle lamine dorsali si sono ravvicinati e quindi saldati, in modo da costituire un canale, il cui interno è rivestito di un sottile dilicatissimo strato di sostanza trasparente che forma le pareti di un' ampolla a lungo collo, di cui la parte espansa corrisponde al futuro cervello, il collo al midollo spinale. L' ampolla cerebrale è scompartita da due stringimenti incompleti in tre vesciche secondarie, corrispondenti ciascuna ad una parte particolare della massa encefalica: con questo però che la vôlta della vescica posteriore non è chiusa come nelle altre due, ma aperta, atteso che in questa parte i due lembi delle lamine formative, non si riuniscono. Ciascuna di queste vesciche corrisponde ad un apparato sensitivo speciale, alla cui formazione essa contribuisce. La vescica anteriore, o prosencefalo, corrisponde all'organo olfattorio; la vescica media, o mesencefalo, agli occhi; la vescica posteriore, od epencefalo, agli organi uditivi.

Mentre hanno luogo questi cambiamenti, altri importanti si rilevano nel foglietto vascolare. Alla periferia di esso manifestansi a guisa di tante isolette sparse, piccole ramificazioni sanguigne, che tendono a formar una rete fra loro, ed a spingere più grossi rami verso la parte centrale, dove il ouore, sotto forma d' un piccolo canale flessuoso e rilevato (punctum saliens) incomincia con ritmo lento e regolare le sue pulsazioni, assai distintamente visibili fin del terzo giorno dell'incubazione.

Il foglietto sieroso a poco a poco si separa al suo lembo in due lamine, la superiore delle quali, ripiegandosi tutt'all' ingiro sul dorso, forma un sacco il cui margine gra- 
datamente si chiude (fig. 37 ). In tal modo ha origine il sac-

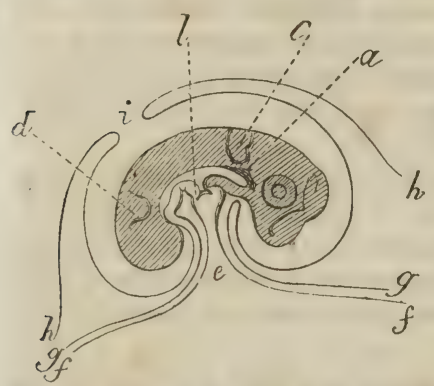

Fig. 37. Figura teorica d'un pulcino in corso di sviluppo ("). co dell'amnios, contenente un liquido nel quale sta immerso il corpo dell'embrione. La lamina inferiore dello stesso foglietto col successivo differenziarsi delle sue cel. lule alimentari forma le pareti dell'addome edel tronco, e gli organi più importanti della vita animale.

Il foglio mucoso forma il canale alimentare da principio breve, diritto, le cui tonache si continuano colla parete della vescica racchiudente il tuorlo, ma che in progresso di tempo si isola sempre più da questa vescica, di tal maniera che la sua comunicazione con questa si riduce ad un sottile peduncolo (condotto vitello-intestinale). Si formano pure da questo foglietto tutti i visceri della digestione. - E mentre avvengono questi cambiamenti, la circolazione sanguigna va sempre più sviluppandosi.

Durante l'organizzazione del pulcino, una parte del li. quido dell' uovo si evapora, specialmente dalla estremità ottusa dell' uovo; ed aumenta per conseguenza la densità dell'albume. Questa evaporazione è indipendente dallo sviluppo dell' embrione, e si effettua del pari nelle uova non fecondate. Un effetto di essa è la formazione della così detta camera d'aria al polo ottuso dell' uovo.

In sei giorni l'embrione ha già acquistato la forma di un pulcino: il capo è molto voluminoso, con due grandissimi occhi, e nel mezzo il rudimento del becco. Incominciano prima a comparire le estremità anteriori, e quindi le posteriori, sotto forma di palette che in seguito si dividono in dita. In questo stato il pulcino è affatto distinto dal tuorlo, al quale non aderisce che per un piccolo peduncolo comunicante coll'intestino. Una grossa vena ed

(*) a. Cuore. - b. Intestino. - c. Rudimenti delle estremiti anteriori. d. lidem delle posteriori. - e. Condotto fra il tuorlo e lintestino (ductus: vitello-intestinalis). - $f$. Foylio mucoso. - g. Foglio vaseolare. - h. Foglio sieroso, $-i$. Apertura che va chiudendusi def sacen dell' amnios. i. Tuorlo. (Pander. - Isis 1818). 
una minore arteria (vasi onfalo-mesenterici) rispettivamente diramata dai vasi del mesenterio, formano una rete sanguigna alla superficie del tuorlo. La sostanza propria di questo, il rosso dell' uovo, passando in parte nell' intestino, per la via del condotto intestinale è digerita; in più gran parte è assorbita dalle vene serpeggianti nel globo vitellino, e per esse viene portata al fegato, ove probabilmente ¿̀ utilizzata alla formazione del sangue. Il bianco od albume viene a poco a poco assorbito nel tuorlo. Il globo vitellino sparisce infine, rientrando tutto nella cavitì addominale, il che non arviene che assai tardi, quando il pulcino è prossimo a sbucciare.

Oltre al sacco vitellino ed a quello dell'amnios, se ne forma ben tosto un terzo, l'allantoide da una srolta dell'estremita inferiore dell'intestino. Questa srolta sviluppasi rapidamente in una grande rescica che involge l'embrione alla parte corrispondente alla camera d'aria. Due arterie dell' embrione provenienti dalle iliache (che sono i due rami in cui dividesi l'aorta ventrale), si distribuiscono nell' allantoide e traducono nelle numerose loro diramazioni un sangue atro e renoso: i rasellini renosi, per lo contrario, si riuniscono in una grossa rena, la vena ombellicale, che si dirige al fecato, e traduce sangue arterioso. Da questa circostanza chiaro apparisce la funzione dell'allantoide, che è quella di serrir alla respirazione dell'embrione; ed infatti se distendesi un intonaco di rernice sul guscio dell' uovo, ed anche semplicemente in corrispondenza della sua estremità ottusa, l'embrione muore per l'intercettato contatto dell' aria.

Dopo rentun giorni di incubazione il pulcino è sriluppato completamente, rompe il guscio dell' uovo ed esce alla luce del giorno. Il globo vitellino è tutto rientrato nell' addome, e de' materiali che hanno servito alla completa formazione del pulcino, cioè del tuorlo di nutrizione e dell' albume, non rimane più traccia.

Presso a poco identico è il processo erolutiro dei rettili squammosi e dei pesci (fig. 38) se non che in questi ultimi non si sviluppa l'allantoide; e nella maggior parte i vasi che serpeggiano sul globo vitellino non sono più i vasi onfalo-mesenterici, ma i vasi del fegato, cioè l'arteria epatica, la rena epatica e la rena porta, ed il tuorlo non passa neppure in piccola proporzione nell' intestino, 
ma viene tutto assorbito direttamente dalle diramazioni

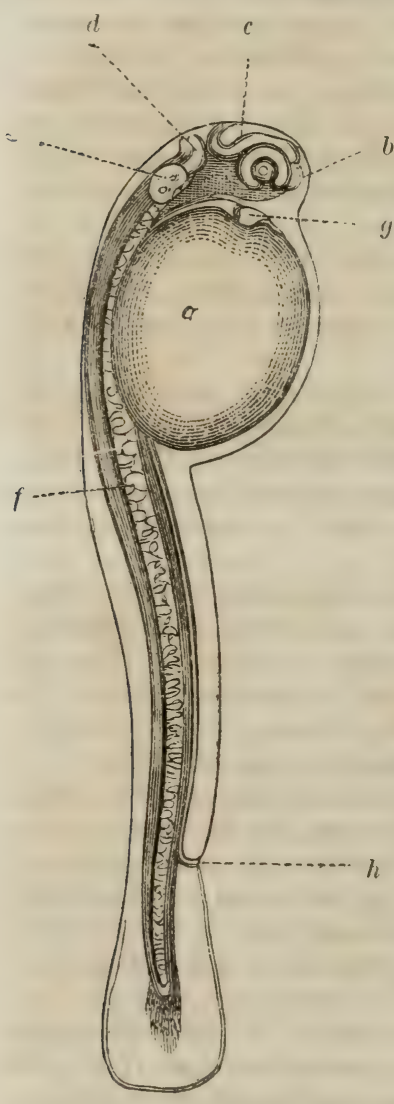

Fig. 38. Embrione di un pesce (Cheppia) ("). della vena epatica. Nei soli selacj (squali, razze), il globo vitellino comunica col tubo intestinale, ed ha un sistema vascolare suo proprio come negli uccelli.

Nei mammiferi il piano generale di sviluppo siegue pres. s'a poco le stesse fasi, se non che grandi differenze intervengono in grazia della mancanza di un tuorlo di nutrizione, e della consecutiva necessità per l'embrione di ricavare i suoi materiali di sviluppo dalla madre.

Il piccolo uovicino dei mam. miferi subisce, come già fu detto, una segmentazione totale, che si compie nel suo tragitto per le tube. Ridotto ad un aggregato di cellule embrionali omogenee, it primo cambiamento che in lui si manifesta, è l'accumulamento di alquanto liquido nel suo interno, e la disposizione delle cellule verso la periferia come per formare le pareti di una vescichetta. L'uovicino cosi rigonfiandosi distende anche la zona pellucida, e la riduce in una mem. brananella finissima. In un punto di questa vescichetta si distingue un piccolo cumulo di cellule meno trasparenti delle altre; è in questo cumulo rhe appajono i prini rudimenti dell' embrione come nulla ricatricola degli uccelli, e nel modo che fu detto.

(') a. Tuorlo. - b. Prosencefalo. - c. Mesencefalo. - d. Epencefalo. 1. Veseica uditiva, - i. Corda dorsale, - y. Cuore, - h. Ano. 
FUNZIONI RIPRODUTTIVE.

La zona pellucida assottigliata, essendo l'uovo già disceso nell' utero, prenderà d'ora in poi il nome di corion. La sua superficie si copre di una moltitudine di villi, i quali si intromettono negli interstizj di una membrana formatasi contemporaneamente nell' utero, e chiamata decidua, da ciò che deve presto scomparire. Per questa via affluisce all' uovo una certa quantità di umore, ed esso aumenta in diametro.

Collo sviluppo del foglietto vascolare, in una o più parti del corion si accumulano diramazioni sanguigne provenienti da quel medesimo sistema che nel pulcino vedemmo spettare all'allantoide. In questo modo si formano alla superficie del corion una o più placente, costituite da grandi fiocchi di minute anse vascolari: pel restante la superficie di questa membrana si fa liscia. Colla formazione della placenta scimpare la decidua. L'embrione è già disegnato in tutte le sue parti, e dicesi da questo momento il feto.

In perfetta corrispondenza colla placenta spettante al feto, si forma alla superficie interna dell'utero una placenta uterina; le anse delle due placente si applicano l'una all'altra senza inoscularsi. La materia essudata dalla placenta materna è assorbita dalla placenta fetale, e supplisce al difetto del tuorlo di nutrizione (fig. 39, 40).

Del resto la forma e la distribuzione della placenta varia nei mammiferi. Essa è unica, grossa, ha la forma di una focaccia carnosa nella specie umana e ne' quadrumani; è annulare nei carnivori; divisa in tanti lobi sparsi, o cotiledoni, ne'ruminanti cornuti ; diffusa sotto l'aspetto di un velluto vascolare, su tutta la superficie del corion, nei cavalli e nei ruminanti privi di corna.

La yescica dell'allantoide nei mammiferi è sempre priva di vasi, poichè quelli che le spetterebbero servono alla formazione della placenta : essa in generale si atrofizza e scompare ben presto, non restandone più che un residuo sotto forma di un legamento (l'uraco) fra l'omhellico e la vescica orinaria. In alcuni però, come nei cavalli, l'allantoide è molto sviluppata e persiste sotto forma di un grande sacco pieno di liquido, fino al termine della gestazione (fig. 41, V. pag. 61).

Si forma nei mammiferi assai per tempo, per scomparire del pari prestissimo, una vescichetta ombellicale che corrisponde al globo vitellino dell' uovo degli uccelli. 
Un ordine intiero di questi animali, l'ordine dei mar-

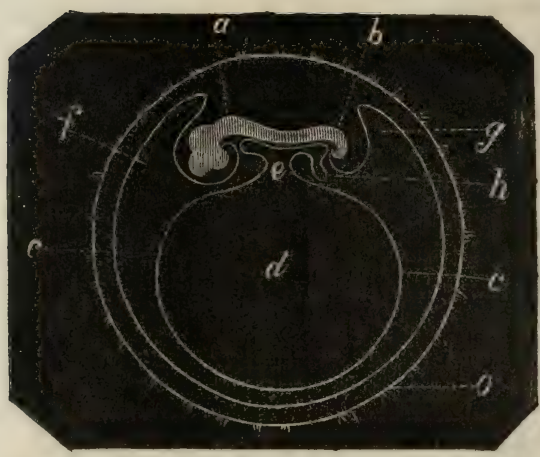

Fig. 39. Embrione di mammifero colle sue dipendenze: (figura schematica).

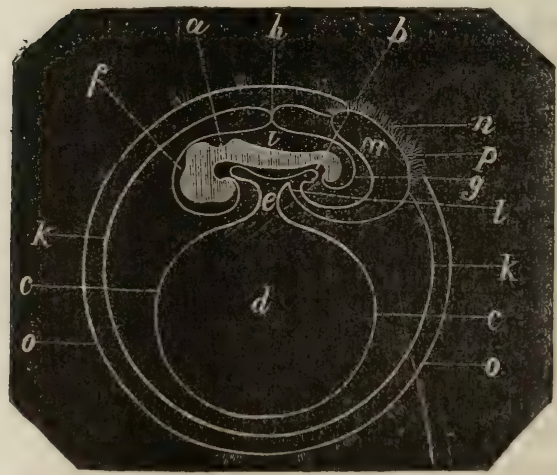

Fig. 40. Lo stesso alquanto piiu inoltrats nello sviluppo ("). supiali, si distingue per una singolare eccezione, che il corion rimane sempre liscio, e non vi si forma placenta. L'uinore che redemmo essere assorbito dall'uovo,e bastare ai primordi del suo sviluppo finchè non sia stabilita la comunicazione fra la madre e il feto, è il solo materiale di nutrizione per gli embrioni di questi animali. Molto sviluppata però è in essi la vescichetta ombellicale coi suoi vasi onfalomesenterici, everso la fine della breve vita uterina, anche l'allantoide co' suoi vasi om. bellicali. I feti vengono partoriti in uno stato assai immaturo, e raccolti dalla madre in una borsa ventrale, ove si attaccano ai capezzoli, e ricevono dalle mammelle $i$ materiali pel loro suc-

cessivo e completo sviluppo.

(*) a. Parte cefalica dellembrione, $-b$. Parte caudale. $-c$. Vescichetta ombellieale. - $e$. Suo peduneolo communicante coll'intestino. - $-(-y$. Sareo sieroso dell'amnios le cui ripiegature sono ancora molto distanti nella fig. 39. es gia si toecano nella $400^{\circ}$ in h. - La membrana esterna, $k$. (amnio spurio)) sparsise ben presto, mentre s'aduna sempre margior quantulit di liequido

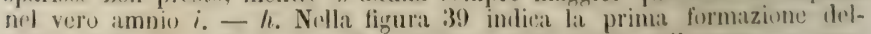

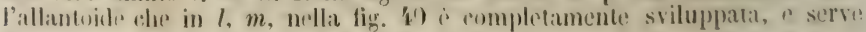
alla formazione della placenta $n,-0$. Corion. 
In tutti gli altri vertebrati, in quelli stessi nei quali le uova si dischiudono gia nell'ovidutto, bastando, siccome fu detto, il tuorlo di nutrizione allo sviluppo del nuovo individuo, non si forma placenta. Però, si incontrano qui pure alcune eccezioni. Il prof. Studiati di Pisa ha scoperto nei Seps una connessione fra gli inviluppi fetali e la parete dell'ovidutto, una vera placenta allantoidea; e già era noto ad Aristotele che un pesce della famiglia degli squali, il pesce palombo ( $\boldsymbol{M} u$ stelus) è viviparo non solo,

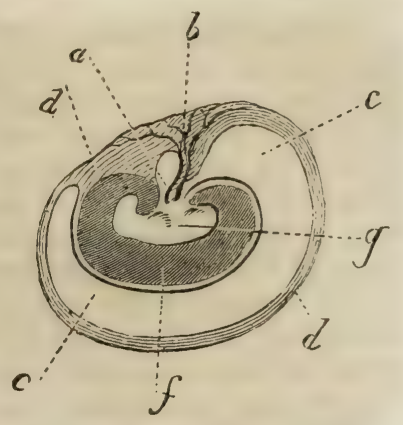

Fig. 41. Embrione di covallo co' suoi inviluppi (").

ma veramente placentario. I vasi però che in questo pescee formano la placenta, sono i vasi onfalo-masenterici, mancando esso, come i pesci tutti, dell'allantoide (1).

Nel suo complesso, malgrado le differenze che ci occorre notare, il processo embriogenico nei vertebrati siegue un piano uniforme, e pone il suggello alle tante affinità che fanno di questi animali una divisione assai naturale. Ora sarebbe del maggior interesse il seguir nell'embrioue di questi animali lo sviluppo dei singoli sistemi organici, ma ciò non essendo consentaneo alla natura ed allo scopo di questa operetta, ci limniteremo ad un breve cenno intorno alla formazione di due fra $\mathrm{i}$ principali di essi sistemi, ed a mettere in evidenza alcuni pochi fatti applicabili ad alte quistioni di filosofia zoologica.

'Tutto l' asse cerebro-spinale dell' embrione è caro; ma

(*) $a$. Vescicola ombellicale. -- b. Vasi onfalo-mesenterici. - c. Allantoide. - $d$. Corion. - $f$. Sacco dell'amnios. - $g$. Embrione.

(Bojanus. - Isis 1818).

(1) Questa osservazione di Aristotele, ripetuta anche da Stenone, rimase presso che dimenticata fino a questi ultimi anni, in cui il celebre fisiologo di Berlino, G. Müller, ebbe a porla nuovamente in piena luce, ed a completarla. Prima di Müller peró Cavolini l'avea pienamente eonfermata, ma le sue osservazioni su questo argomento sono rimaste inedite fino al $\mathbf{1 8 0 0 3}$ (vedi Cavolini, Memorie postume, pubblicate da S. Delle Chiaje. Benevento 1853 , pag. 182 e seg. 
co successivo sviluppo delle varie parti che lo compongono, in alcuna di queste la cavità originaria si ristringe od anche si ostruisce, e ciò in varia proporzione secondo l'elevatezza organica della specie cui spetta l'embrione. I così detti ventricoli cerebrali sono residui della cavità embrionale. Ora nei pesci tutti le diverse parti della massa encefalica rimangono cave, mentre nei mammiferi i lobi ottici ed il cervelletto si fanno compatti; e ristretto pure è lo spazio dei due ventricoli laterali degli emisferi, del terzo e del quarto ventricolo. Esiste nella quasi totalità dei vertebrati, e fin in molti mammiferi, come nel bue, un canale mediano del midollo spinale, residuo esso pure della cavità embrionale; ma questo canale è perfettamente ostrutto nei mammiferi superiori.

Nell' embrione ancor poco inoltrato le tre vesciche cerebrali e le parti secondarie che derivano da ciascuna, si presentano come tante masse distinte l'una dietro l'altra; ma nei mammiferi gli emisferi si sviluppano presto con tale supremazia su tutto il resto, che essi vanno a ricoprire ed involgere intieramente il lobo del terzo ventricolo, i lobi ottici, ed in parte anche il cervelletto. Nei pesci invece tutte queste parti rimangono sempre distinte I' una dietro l'altra sull' istesso piano; anzi negli infimi di questa classe, come nelle lamprede, il cervello non progredisce oltre la separazione nelle tre vesciche cerebrali (fig. 42). Da questi fatti risulta che nell'organizzazione

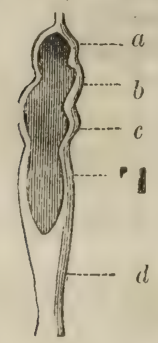

Fis. 42. Sezione verticale del cervello di una lampreda:

du Panizza (*). della massa encefalica le condizioni transitorie nei vertebrati superiori sono invece permanenti in quelli di inferior rango, di modo che si può dire che il cervello dei mammiferi nei suoi primi stadj evolutivi presenta il carattere del cervello dei pesci; e viceversa quest'ultimo si può paragonare ad un cervello di mammifero arrestato nei primordj del suo sviluppo.

$\mathrm{Si}$ arriva ad un risultato analogo osservando l'evoluzione di altri sistemi organici. La corda dorsale, come fu detto più sopra, è l'organo precursore dello scheletro, ed assai precoce, poichè è già for-

(") a. Emisferi (prosencefalo). - b. Lobi ottici (mesencefalo). - c. Cervelletto, e $c^{\prime}$ midollo oblungato (epencefalo). - $d$. Midollo spinale. 
mata poco tempo dopo apparsa la linea primitiva. Immediatamente dopo essa è involta da una guajna cartilaginea da cui si forma il corpo delle vertebre. Sviluppandosi queste, la corda. dorsale stretta e compressa, finisce per scomparire intieramente nei vertebrati superiori: non però nei pesci ove se ne conserva a permanenza un residuo nella sostanza gelatiniforme che riempie gli spazj intervertebrali. Anzi nelle lamprede la corda dorsale si conserva nella sua integrità, contenuta nel suo astuccio cartilagineo, in cui è appena indicata una divisione in vertebre. Infine, nell'ultimo fra i vertebrati, nel branchiostoma (Amphioxus), non vi ha altro rappresentante dello scheletro che la pura e semplice corda dorsale senza la benchè menoma traccia di colonna vertebrale.

La corda dorsale arriva col suo apice anteriore fino in corrispondenza delle capsule uditive dell'embrione. Da questo punto la sua guajna cartilaginea si protende in due gracili appendici che formano un arco chiuso sul davanti. Su queste appendici, dette le braccia del cranio, riposa un'altra formazione cartilaginea affatto indipendente, destinata a proteggere le vesciche cerebrali (fig. 43). $\dot{\mathrm{E}}$

A

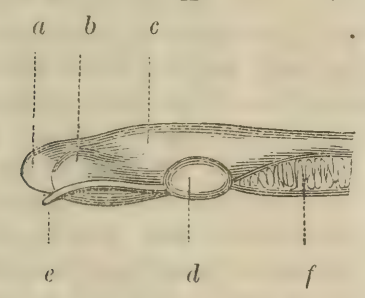

B

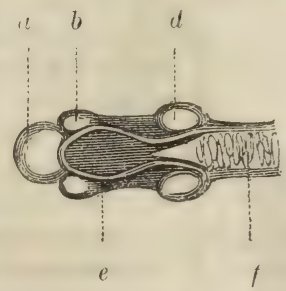

Fig. 43. Cranio della piccola lampreda (Ammocoetes): da C. Vogt. (").

questo il cranio primordiale, il quale scompare col progresso nell' ossificazione, uon però intieramente nei pesci ove ne rimarie a permanenza un residuo, sotto forma di uno strato cartilagineo nell' interno del cranio osseo. In-

(") A. veduto di fianco. B. veduto dalla base.

$a$. Cartilagine labbiale. $-b$. Capsule nasali. $-c$. Capsule cerebrali. d. Capsule uditive. - e. Braccia del cranio. - f. Estremita anteriore della corda dorsale. 
mergendo replicatamente nell' acqua bollente una testa di luccio, si può quindi con facilita staccar ad una ad una le ossa, e scoprire cosi l'anzidetto residuo del cranio primordiale. Nelle lamprede poi, attorno alla massa encefalica, non v' ha che un semplice inviluppo cartilagineo di un sol pezzo, esattamente paragonabile al cranio primordiale degli embrioni dei vertebrati superiori.

Una scoperta di cui sul principio si è molto esagerata l'importanza, è quella, che l'embrione dei vertebrati superiori, dell' uomo stesso ne'suoi primi stadj, cioè appena comparsi i globi oculari e le rescicole uditive, presenta ai lati del collo quattro linguette assai distinte, separate da cinque fenditure (fig. 44). Il celeberrimo fisiologo Rathke

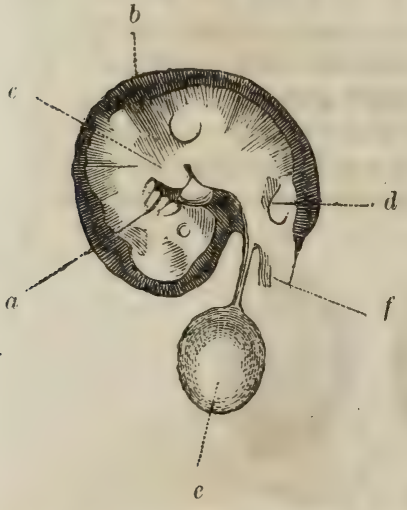

'Fig. 44. Embrione umano di due settimane: da Socmmering (*). ha voluto considerare queste linguette come altrettanti archi branchiali, e tanto più che lungo il margine di ciascuna scorre un vaso sanguigno che parte quasi direttamente dal cuore e va fin sotto la corda dorsale, ove tutti questi vasi confluiscono nell'arteria principale del corpo. Col tempo si è trovato che questi archi branchiali embrionali non sono per nulla gli equivalenti degli archi branchiali dei pesci, ma i rudimenti di alcune parti dello scheletro: essi vanno principalmente a costituire il palato, la mascella inferiore, il corpo dell'osso joido e le sue corna. La fenditura anteriore diventa la cavità dalla bocca.

Si richiami ora la nostra attenzione ad un corollario generale che emana dalle cose anzidette. La formazione dell'embrione nei vertebrati incomincia da due metà simmetriche, in corrispondenza della massa centrale nervosa, dell'asse cerebro-spinale, quindi daHla parte del dorso: l'ultima parte a chiudersi è il ventre.

(") a. Cosi dette branchie. - b. amnios. - $c$. Rudimenti delle estremita anteriori. - I. Idem delle posteriori, $-e$. Vescichetta umbellicale. $-f$. CurIone ombellicale troncato. 
FLNZIONI RIPRODUTTIVE.

Il processo evolutivo degli animali senza vertebre è assai diverso, però anche in questi è soddisfatta la legge generale, che la formazione dell'embrione incomincia in corrispondenza della principal massa nervosa, e di là si estende alle altre parti.

Negli articolati, dopo il solcamento parziale dell' uovo, la formazione di un disco proligero, il suo differenziamento in strato sieroso od anímale e strato mucoso o vegetativo, si vedono ben tosto comparire in due lati simmetrici i primi rudimenti dell'embrione, sotto forma di rialzi disposti in modo da ricordare le piastre vertebrali che vedemmo nell'embrione degli animali superiori. Questi rialzi si convertono successivamente nelle appendici articolate del capo e nelle gambe. $\dot{E}$ la parte ventrale che in 'questi animali si forma per la prima, poichè in questa regione è collocata la catena gangliare che dirama i nervi a tutte le parti del corpo. L'ultima parte a chiudersi ed a completamente organizzarsi è il dorso, ove si accumula la massa del tuorlo, che a poco a poco scompare col progredire dell' organizzazione del nuovo individuo (fig. 45).

A

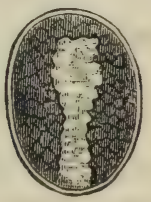

B

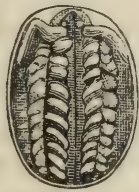

C

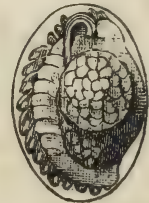

Fig. 45. Embrioni di onisco in corso di sciluppo: Da Rathke (").

E difficile ricondurre a un tipo generale lo sviluppo dei molluschi, attese le grandi differenze che passano fra $i$ diversi tipi compresi in questa grande divisione. E d'uopo intanto sceverarne $\mathrm{i}$ cefalopodi che per molti titoli ed anche per il processo evolutivo dell' embrione, molto si accostano ai vertehrati. Quanto si osserva nei gasteropodi, e può ritenersi come applicabile alla generalità dei molluschi, si riassume principalmente in questo, che dopo il solcamento totale del tuorlo, alcuni lobuli si suddividono $\mathrm{e}$

(') A. Embrione ne' suoi primordi, veduto dalla parte ventrale.

B. Lo stesso più inoltrato nello sviluppo.

C. Lo stesso veduto di fianco, per meglio dimostrare le gambe e le antenne gia pronunciate, ed il tuorlo nella regione dorsale.

DE Fiuppi. Funzioni riproduttive. 
differenziano, e formano uno strato (foglietto animale) che involge per intiero l'ammasso degli altri lobuli di solcamento. Le prime parti a furmarsi sono quelle che spettano

$b$

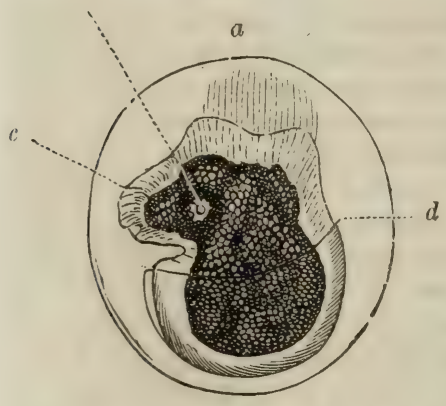

Fig. 46. Embrione di una doride: Da C. Vogt. (*). alla regione cefalica; il velo, innanzi tutto, quindi gli organi uditivi, gli occhi; e di là pure incomincia la formazione del piede (fig. 46). La legge antecedentemente esposta, è soddisfatta anche in questo caso, essendo nei molluschi la principal massa nervosa collocata nella regione cefalica, ove forma il noto cingolo esofageo.

Nei raggiati il processo evolutivo è più semplice: l' embrione si forma da tutte le parti contemporaneamente, non appena è compito il solcamento.

\section{§ 5. Cura de' figli.}

Tutta quella mirabile scena di istinti, di passioni, di godimenti, quella pompa di resti e di colori, che la natura dispiega nelle nozze degli animali, tornerebbe a nulla se non vi succedesse l'opera più tranquilla e secreta di proteggere, difendere, nutrire i frutti di quelle nozze. Senza le pietose cure de' genitori, i neonati non vedrebbero il giorno che per morire subito dopo. I maschi però non prendono in generale che pochissima od anche nissuna parte a queste cure, che formano invece per le madri un dovere imprescindibile, e la più soave compiacenza della vita.

Un'intiera classe di animali, la prima nella serie, è contraddistinta da organi appositi per la nutrizione dei figli dopo la nascita: cioè dalle glandule mammarie che secernono il latte. Queste glandule sono varie in numero, e variamente disposte: or sul petto, or sul ventre, ora

(') $a$. Velo. $-b$. Organi uditivi. $-c$. Piede. $-d$. Conchiglietta embrionale. 
agli inguini. Stanno immediatamente sotto la pelle; ma in alcuni animali, come ne' cetacei e ne' marsupiali, sono anche ricoperte da un sottile strato di fibre inuscolari. I condotti escretori di esse si aprono direttamente all'esterno, all'estremità di una papilla più o meno lunga e sviluppata, che dicesi capezzolo; oppure in una cavita posta entro una glandula stessa, detta seno della mammella, e destinata a servir di ricettacolo per una certa provigione di latte. Tale è appunto il caso delle nostre comuni vacche (fig. 47).

Leglandule mammarie sono possedute anche dai maschi, per altro pochissimo sviluppate e non funzionanti. Non sono però molto rari i casi del contrario; e non ha molto il signor Schlossberger fece un accurato esame del latte spremuto da un caprone.

Il numero de'capezzoli non corrisponde sempre esattamente a quello mammelle; generalmente esso è in relazione colla quantità normale de' prodotii di ogni parto; e quindi, ridotto a due soli nell'uomo, nelle

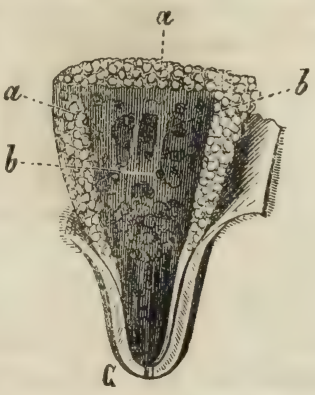

Fig. 47. Porzione di mammella di vacca (*). scimmie, ne' pipistrelli, oltrepassa perfino i dieci in alcuni rosicanti e marsupiali. I soli monotremi non hanno capezzoli.

L'afflusso di sangue all' utero, per i rapporti che si devono stabilire fra questo viscere ed i prodotti del concepimento, determina per consenso un afflusso dell' istesso umore alle mammelle. Gli acini di queste glandule da prima piccoli e contratti, si rigonfiano a poco a poco, stillano pe' condotti un liquido biancastro albuminoso che alla fine della gestazione prende $\mathrm{i}$ caratteri del vero latte. Questo latte, che è un umore bianco, più denso dell'acqua, di sapore e odore particolare e vario secondo le specie, osservato al microscopio si dimostra costituito da una moltitudine immensa di globuli nuotanti in un liquido (globuli proprj del latte), e formati da un inviluppo di materia azotata (caseina), con un contenuto di grasso. Oltre questi globuli v' hanno cellule staccate di epitelio, ed

(") a. Acini secernenti il latte. - b. Cavita dure sboccano i condotti lattiferi. - c. Estremità del capezzolo. 
in alcuni casi abnormi, perfino globuli di sangue, di pus ed anche infusorj.

L'esame chimico del latte ci fa riconoscere, oltre una gran dose d'acqua tenente in soluzione varj sali, soprattutto fosfati (necessarj alla formazione delle ossa de' neonati), una sostanza quadernaria azotata detta caseina; una ternaria non azotata grassa e che forma il butirro; ed un altro composto parimenti non azotato che dicesi lattina, od anche zuccaro di latte pel suo sapore e per la sua facilità a cristallizzare. Ciò nel latte maturo, fresco ed appena munto. Nel primo latte, o colostro, raccolto o poco innanzi, o subito dopo il parto, l'albumina sta in luogo della caseina, nella quale si trasforma più tardi. Ed è noto ciò che avviene nel latte dopo la sua estrazione, abbandonato alla quiete in un vaso. Il grasso si porta alla superficie; la sostanza zuccherina si acidifica, trasformandosi in acido lattico, che produce poi la coagularione della materia caseosa.

Le diverse qualità che presenta il latte nelle varie specie de' nostri quadrupedi domestici, dipendono principalmente dal genere di nutrimento dell'animale; e consistono tanto nel variar delle proporzioni de' componenti ordinarj del latte stesso, come in trasformazioni subite da uno di questi componenti. Così, per esempio, la caseina è più abbondante nel latte de' carnivori che in quello degli erbivori; diminuita invece è la quantità dello zuccaro di latte, e questo non più cristallizzabile. Oltre ciò dere tenersi calcolo dell'aggiunta di qualche leggier traccia di principj particolari; così, per esempio, il latte delle capre deve l'odore ed il gusto suoi proprj ad un acido organico detto acido ircico.

L'istinto guida la nuova creatura a cercare il capezzolo materno ed a succhiare. Ne' marsupiali per altro, che partoriscono i figli cotanto immaturi, e ne' cetacei, l'allattamento sembra passivo per parte de' figli stessi. Lo strato muscolare che abbiamo veduto coprire in questi animali le ghiandole mammarie, spinge mediante la sua contrazione il latte nelle fauci de' neonati.

La durata della secrezione del latte varia secondo le svuotamento periodico e regolare delle mammelle, la prosperità dell' individuo, e l'intervallo dall'uno all'altro concepimento. 
Fuori della classe de' mammiferi non s'incontra più un organo che rappresentando, quanto alle funzioni, la glandula del latte, somministri materiale di nutrimento alla prole. Le madri provvedono allora o recando ai figli deboli ed inetti il cibo ch' esse hanno saputo raccogliere per la campagna, o collocando le uova in mezzo a' magazzini naturali dove gli animaletti appena dischiusi trovino alimento copioso e pronto; ovrero con previdenza ancor più maravigliosa, chiudendo nel ricovero delle uova una provrigione di cibo sempre sufficiente.

$\dot{\mathrm{E}}$ oggetto per tutti di tenera curiosità lo spettacolo degli uccelli che imbeccano i loro piccini. E si è tentati d'accusar la natura del barbaro istinto accordato al cuculo di deporre le uova nei nidi altrui (1), e quello più barbaro ancora del cuculo appena sbucciato, di cacciar dal nido i suoi fratelli spurj, per rimanervi solo ed assoluto, quantunque men legittimo padrone. In alcune famiglie di uccelli, soprattutto dei gallinacei e de' trampolieri, i pulcini appena sgusciati seguono la madre in traccia del nutrimento che essi medesimi raccolgono dal terreno.

Ne' rettili, ne' pesci, ne' molluschi, ne' crostacei, i novelli individui non trovano imbarazzo alcuno a procacciarsi l'alimento, di cui hanno abbondanza all'intorno, nell' istesso mezzo, nelle stesse località dove fanno dimora i genitori. Ma nella grande classe degli insetti, e particolarmente in quegli ordini caratterizzati dalla metamorfosi completa che subiscono le larve molli, inerti, vermiformi, innanzi vestire la forma de' genitori, è dove maggiormente si ammira la sapienza inesauribile della natura, l'istinto preveggente delle madri. Noi vediamo le farfalle depositar costantemente le uova sopra una medesima specie di pianta, delle cui foglie devono nutrirsi le larve appena sbucciate. Le femmine di molti coleotteri insinuano le uova nel legno, scegliendo sempre in una stessa pianta la porzione più ricca di albumina, che è il vero nutrimento delle fu-

(1) Ciò non avviene per vano eapriccio del cuculo; bensi per bisogno e per amor della sua prole. La femmina di questa specie deposita dalle $\mathbf{b}$ alle 6 uova in una stagione: ma a cosi lunghi intervalli l'un dall' altro che essa non potrebhe covar le ultime uova, e nel medesimo tempo procacciar l'alimento ai figli nati dalle prime.

Costumi analoghi, secondo l'osservazione di alcuni viaggiatori, sareblero quelli di un uccello americano, appartenente ad una faniglia ben diversa, e conosciuto solto il nome sistematico di Molothrus pecoris. 
ture larve: sapienza così funesta talvolta alle opere dell'industria umana! Una famiglia intiera di imenotteri, quella degli icneumonidi, è rinomata per l'istinto dellé femmine di deporre le unva sotto la pelle delle larve delle farfalle, che sono poi rose e distrutte da' bachi sbucciati nel lors seno. Altri, ed assai più numerosi di quest'ordine di insetti, costruiscono invece alle loro uova un apposito nido in cui rinchiudono la scorta di cibu alle nasciture larve. Per lo più consiste quella scorta in altri insetti o piccoli ragni previamente uccisi o tramortiti dall'aculeo di cui le femmine di quegli imenotteri sono fornite (V. il Corso Elementare, pag. 263).

Verso altri animali, specialmente delle classi inferiori, la natura fu matrigna. Je femmine o per deficienza di istinto, o per la rita precaria cui sono condannate, sebhene straordinariamente feconde, non possono assicurare a tutti i loro figli i mezzi per lo sviluppo normale. In poco tempo sarebbero sparite queste generazioni dalla faccia della terra, se la sapienza divina non avesse provveduto con altre leggi affatto particolari, ben degne della più alta nostra maraviglia, e delle quali troveremo nel paragrafo seguente una succinta esposizione.

\section{§ 6. Metamorfosi. Polimorfismo. Metagenesi.}

E generalmente noto che in moltissime specie di animali

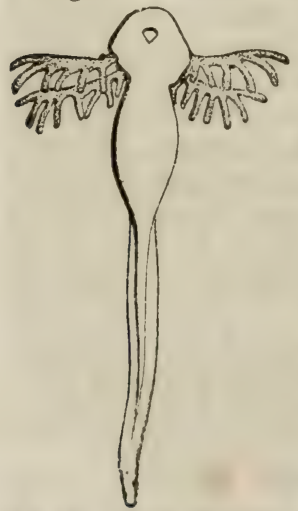

Fir. 4\$. Litica di rana. la giovane prole appena dischiusa dall'uovo ha forme assai diverse da quelle dei genitori, e non le assume che jiù tardi, dopo una serie di cambiamenti. L'esempio il più volgare ci viene offerto da quei piccoli animaletti che nati, dalle rane o dai rospi in primarera, popolano a miriadi le pozzanghere delle nostre campagne (fig. 48). Essi mancano di gamibe, hanno coda, la loro bocca è munita di un piccol rostro, respirano per branchie, si nutrono di alghe e conferve. Giunti in questo stato ad un certo grado di accrescimento, incominciano a svilupparsi le cavità pol. 
monali, ed il sangue che vi affluisce sempre in maggior co. pia vien sottratto alla circolazione delle branchie, le quali per ciò si atrofizzano; contemporaneamente spuntano le estremità, e prima le posteriori poscia le anteriori; e così derivato il sangue dalla circolazione nella coda, questa pure si atrofizza e scompare: infine l'animale che prima chiamavasi girino, ora si chiama rana o rospo, ed è carnivoro. $\mathrm{Si}$ è convenuto di chiamar larve i giovanissimi in. dividui quando hanno forme sensibilmente diverse da quelle che arranno col tempo; ed in istretto senso, quando essi medesimi, trasmutandosi, subendo una metamorfosi, riacquistano le forme precise dei loro genitori; sotto le quali forme soltanto l'animale dicesi perfetto.

Le differenze fra la larva e l'animale perfetto possono essere di vario grado. Non abbandonando la cerchia dei batracj troviamo, per esempio, che le giovani salamandre appena escite dall' uovo, non si distinguono dalle salamandre adulte che per esser munite di branchie provvisorie, avendosi quattro gambe nelle une e nelle altre, ed essendo permanente la coda: tanto che appena può dirsi che in questi animali abbia luogo una metamorfosi.

Chi non conosce la carriera vitale del prezioso insetto che ci dà la seta? Moltissimi altri animali della stessa classe (e ne siano esempio gli scarafaggi, le api, le mosche) presentano nei varj stadj della lor vita differenze dell' istesso grado. Nasce cioè dall'uovo una larva, la quale manca di ali non solo, ma anche di gambe, o ne ha di provvisorie piccole e non articolate, manca di antenne e di occhi faccettati sul capo. Nel lasso di tempo relativamente assai lungo che passa in questo stadio, essa non è ad altro intenta che a mangiare ed a crescere, trovando un nutrimento opportuno e sufficiente nel luogo stesso in cui per provvido istinto la madre ha deposto le uova. Compito questo stadio, la larva si crea o si cerca un rioovero, ed isolandosi dall'antica pelle che le serve di buccia, senza più dar segni apparenti di vita, va trasformandosi a poco a poco in un individuo perfettamente simile ai genitori. Questo stadio transitorio dicesi di ninfa o di crisalide. Infine la buccia si apre e ne esce l'insetto fornito di ali, di gambe articolate, di occhi composti e di antenne, l'insetto che suol dirsi perfetto. Giunto a questo periodo esso non prende che poco o nessun nutrimento; genera, e quindi muore. 
Ma anche negli insetti, come già vedernmo nei batracj, le differenze fra la larva e l' animale perfetto possono ridursi ad assai poche. Così nelle locuste, nelle blatte, nelle pentatome, la piccola larva che nasce direttamente dall'uovo, non si distingue dal suo genitore che per la mancanza di ali : essa è attiva, corre in cerca dell' alimento, cresce, si spoglia diverse volte della pelle; quindi compajono i rudimenti dell'ali, e l'animale è entrato allora in un secondo stadio che può dirsi ancora di ninfa; per ultimo le ali si sviluppano intieramente, e l'insetto è perfetto.

Dal fin qui detto si scorge come la metamorfosi possa essere completa in alcuni animali, incompleta in altri.

Se negli esempi ora riferiti si fa il confronto tra l'organizzazione che ha l'individuo nel primo stadio, con quella che esso acquista nell' ultimo di sua rita, si deve riconoscere che nella metamorfosi, esso è veramente salito da un grado inferiore di organizzazione ad un grado superiore; specialmente se per la determinazione di questi gradi, si calcola lo sviluppo degli organi dei sensi, e dei mezzi di locomozione. Esso ha dunque subíto una melamorfosi progressiva; e questo è il caso generale negli in. setti.

Molti crostacei, miriapodi, aracnidi subiscono una trasformazione di genere analogo in questo senso, che i giovani hanno un minor numero di gambe che non gli adulti. Fra i crostacei però vi hanno specie che presentano una metamorfosi di genere assai diverso; e sono quelle che, giunte all' epoca della propagazione, vivono fisse, od ag̣li scogli del mare, come i cirripedi, o sul corpo di altri animali di cui si fanno parassiti, come i bopiri, le lernee, ecc. In queste specie le larve sono munite di occhi e di arti pel nuoto, ma nell' ultima loro muta perdono i primi intieramente, e tutti od in parte anche i secondi, divengorio inerti, il loro corpo prende una forma del tutto nuova, rigonfiandosi per lo sviluppo degli organi sessuali. In simili casi la larva, in paragone dell' animale a termine, $\dot{e}$ più elevata di grado organico; la metamorfosi che subisce è dunque regressiva. Nei crostacei parassiti, i quali sono unisessuali, deresi poi osservare che questa doviazione dalla primitiva forma è molto maggiore nelle femmine che nei maschi, perchè questi non si fissano come le femmine, e perchè lo sviluppo degli organi generatori è in 
essi, come in generale in tutti gli articolati, più precocc che nelle femmine, sì che lo scopo della metamorfosi è più presto raggiunto.

Indipendentemente dalle diversità di forma, il principale, l'essenziale carattere che distingue la larva dell'animale a termine, risiede negli organi sessuali che sono affatto rudimentali o mancanti nel primo stato, sriluppati e funzionanti nel secondo.

Anche ne' molluschi, toltine i cefalopodi, si può osservar generalmente una metamorfosi; se non che i giovani individui nella prima loro forma restano lungo tempo rinchiusi nell' inviluppo esterno dell'uovo, assai grande e capace, e piuttosto che larve potrebbersi dire embrioni. In tale stato veggonsi continuamente roteare nello spazio limitato di quell' inviluppo, e sempre in direzione costante. La causa di questo moto risiede nella vibrazione inces. sante delle ciglia di cui gran parte del loro corpo è ricoperto.

Ne'gasteropodi gli embrioni, o larve, presentano questo di particolare, che sono sempre muniti di una conchiglietta prov visoria, anche nelle specie che nello stato adulto hanno il corpo nudo; questa conchiglietta ha una struttura assai diversa da quella che avrà la conchiglia permanente, e, a differenza di questa, non tiene all'animale col mezzo di appositi muscoli.

Un altro organo provvisorio che si osserva negli embrioni de' gasteropodi branchiati, consiste in due grandi lobi membranosi che sporgono innanzi alla regione cefalica, e ben presto si vedono forniti di lunghissime ciglia vibranti. Quest'organo è ciò che suol dirsi il velo (fig. 49).

L'embrione dei molluschi acefali lamellibranchi differisce in alcuni casi moltissimo dall' animale perfetto; tanto che $i$ piccoli che si trovano accumulati in si grande quantità nelle branchie esterne delle anodonte femmine, furono da qualcumo considerati come parassiti, piuttosto che figli legittimi del mollusco. Ciò che deve particolarmente osservarsi in questi embrioni, e che è comune probabilmente a tutti gli animali di questa classe, consiste in una ciocca di finissimi filamenti che partono da una glandula particolare del piede, e che furono giustamente paragonati al bisso di cui sono forniti a permanenza i mitili e le pinne (fig. 50). 
Negli anellidi abranchi, come nelle sanguisughe e ge-

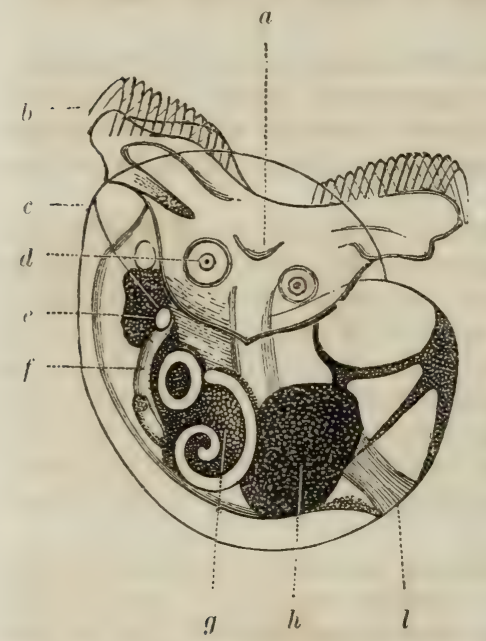

Fig̣. 49. Larra di Doris : da C. Voge (*).

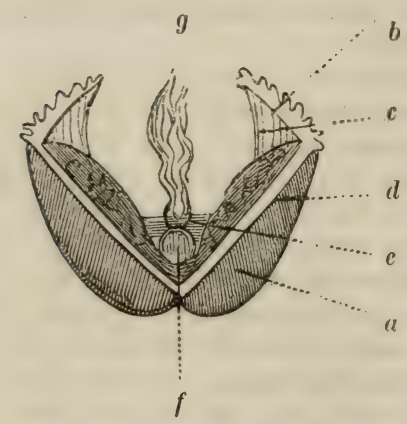

Fig. 50. Larva di Anodonta ("). neri affini, non ha luogo alcuna metamorfosi: invece gli anellidi branchiati prodncono una piccola larva che nuota liberamente col miezzo delle ciglia, le quali, negli embrioni appena sbucciati sorgonoda tutta la periferia del corpo, e quindi a poco a poco si distribuiscono a zone annulari.

Non è raro il trovare in una famiglia, in una classe di animali, alcune specie conservanti a permanenza un carattere che, nella generalità delle altre, è provvisorio, proprio della larva o dell'embrione. L'axolotl dei laghi del Messico, il proteo delle acque sotterranee della Carniola, portano per tutta la vita le branchie di cui invece le salamandre sono munite soltanto allo stadio di larva. Il velo che già vedemmo essere un carattere degli embrioni de' gasteropodi branchiati, rimane permanente nelle tetidi; ed è pure dal velo che si

(') a. Bocea. - b. Velo. - c. Conchighlietta embrionale. - d. ()rgani uditivi. - e. Ano. - 1. Intestino. - \%. Stomaco. - h. Fegato. - I. Fascelto muscolare. (“) ". Guscio bivalve. - b. Ineinetti dentati e mobili. - c. Nuscoli de' medesimi. - 1. Corpo del molluseo - e. Muscolu della valve. - f. Piede. - g. Fioceo di bisso. 
formano in parte almeno i lobi cutanei laterali che caratterizzano i pteropodi. Vedemmo non ha guari, che il bisso è una produzione embrionale nella maggior parte degli acefali lamellibranchi, ma permanente nei mitili e generi affini. La conchiglia degli argonauta, priva di epidermide e senza aderenze muscolari coll' animale, non potrebbe essere paragonata che ad una conchiglia embrionale permanente, quantunque sia propria delle sole femmine, e non si formi se non assai tardi, dopo che il piccolo argonauta è già uscito dall'uovo.

Le ascidie, fra i tunicati, sono fornité allo stato di larva di una grande appendice caudale piatta, mobile, guizzante; e quest'organo è permanente nelle appendicularie (fig. 51, 52).

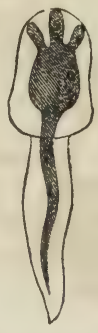

Fig. 51 Larva i'Ascidia. Ma facciam ritorno alle metamorfosi. Da esse fluisce naturalissima e sempre più evidente la conseguenza che in un gran numero di casi l'idea vera e completa della specie non può essere rappresentata da un individuo solo, ma da due o più individui che se ne ripartiscono $\mathrm{i}$ caratteri; e non solo i caratteri esterni, ma perfino gli organi più importanti della vita, e le relative funzioni. Già vediamo negli insetti la larva esser incaricata delle funzioni di nutrizione, l'insetto perfetto di quella della riproduzione. Questo scompartimento di ufficj arriva a tal punto, che in alcune specie, come nelle efemere, l'insetto perfetto ha gli organi digerenti atrofici, e la bocea del tutto inetta a prendere nutrimento. Nelle altre classi d'animali questo che fin d'ora possiam dire polimorfismo della specie, ci offre esempi ancor più stupendi, e non tarderà orcasione di verificarli. Intanto è necessario fissar nella 
mente il poco che ne abbiam detto, onde capire nel se. guito come questa separazione delle funzioni, in individui diversi della medesima specie, possa arrivar al punto da non sapersi più trovar un limite fra organo ed individuo. Le efemere sono certamente nel concetto di ognumo veri individui, ma non perderebbero questo carattere, quando pure suppongasi abolito quel resto che posseggono di apparato digerente, e neppure se perdessero anche gli organi del movimento, e fossero cosi ridotte ad un semplice sacco contenente gli organi sessuali. Or bene questa che è una supposizione per le efemere, diventa una realtà per molti animali delle classi inferiori.

Una medesima specie può anche offrire diverse maniere di propagazione; il che per altro non accade mai negli animali della divisione dei vertebrati. Gli esempi ne sono ancora rarissimi nelle classi degli articolati, ma non per ciò meno interessanti.

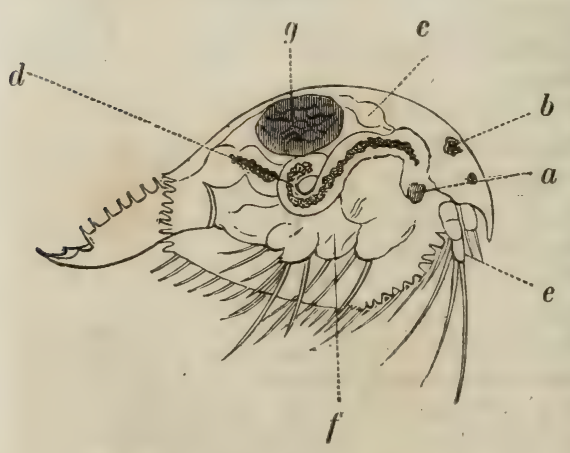

Fig. 53. Linceo (").

Alcuni minuticrostacei, come le dafnie ed i lincei (fig. 53), $b$ producono due sorta di uova assai diverse; quelle d'inverno equelle d'estate.Queste ultime soltanto sono vere uova, le quali restano adunate in gran numero nella cavità ovifera, fino allo schiudimento degli embrioni. Le uova d'inverno, due in numero, più grosse, mancanti di rescichetta germinativa, stanno contenute in un particolare astuccio corneo bivalve, nella cosi detta sella (epinippium), che si stacca dal corpo dell'animale nella muta della pelle alla primavera susseguente (1). Qualche cosa

() a. Maseella. - b. Occhio. - c. Cuore. - d. Intestino. - e. Anteane, - $f$. Gambe. - g. Sella.

(1) Su questa generazione invernale de' erostacei fillopodi sarehbero assai interessanti nuove osservazioni. $\mathbf{E}$ probabile che gli individui presentanti la sella, non abbiano essi medesimi previamente prodotto uova, ma siano il produtto della generazione ovipara estira. 
di analogo ha luogo nei rotiferi che producono d'inverno un unico grosso uovo, e molte più piccole uova nella buona stagione.

La storia mirabile dei gorgoglioni od afidi (fig. 54) è nota da lungo tempo. Dalle uova deposte in autunno da questi insettucci, nascono in primavera delle femmine vivipare, $\mathrm{i}$ cui piccini, cresciuti in breve tempo, sono essi pure vivipari, e cosi prucedendo, si succedono da otto o nove generazioni di fermmine pregnanti e partorienti, senza il concorso di un sol maschio. L'ultima soltanto di questa serie annuale di generazioni pro- Fig. 54. Afide del persico: duce maschi e femmine in giusta mi-

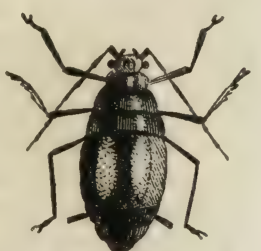
sura, e queste, dopo l'accoppiamento, partoriscono uova che lasciano collate ai ramoscelli delle piante durante tutta la stagion invernale, finchè il tepore della primavera non ne faccia dischiudere la prole vivipara. In questi animali si hanno adunque due diversi modi di generazione, che si alternano regolarmente in individui diversi (1).

Questi esempi ci aprono la strada ad altri ben più com: plicati. Nelle infime classi accade assai sovente che sbucci dall' uovo un animaletto di forme assai diverse da queIle del genitore, cui sarebbe quindi da applicare la denomi-

(1) Questa vicenda di generazioni è stata diversamente interpretata dagli autori. Réaumur volle considerare gli afidi vivipari come ermafroditi Morren pretese invece spiegar la formazione della loro prole, per un'individualizzazione della sostanza della madre, nel modo istesso col quale egli pensa aver origine i vermi intestinali. Owen emise un" opinione assai ingegnosa, secondo la quale gli afidi delle generazioni vivipare non avrebbero gia origine da nuovi germi, ma invece da residui del primitivo vero uovo deposto dalla femmina nella generazione di autunno.

La maggior parte degli autori, senza molto internarsi nella quistione, considerano la generazione degli afidi vivipari come una generazione per semplici germi o spore. Ma qui bisogna riflettere ad una circostanza importante, ed è che negli afidi vivipari i germi de' giovani individui si formano in un apparato organico particolare che equivale perfettamente all'ovario delle femmine ovipare, non distinguendosi da questo che per la mancanza di organi accessorj, quali sono la borsetta seminale e la glandula del glutine. - Gli afidi vivipari sono dunque da considerarsi come vere femmine vergini, le cui uova si sviluppano nell'ovario stesso, per l'effetto remoto dell' accoppiamento avvenuto fra i loro genitori diretti, od avoli o bisavoli od arcavoli. 
nazione generale di larva. Se non che insistendo rell'os. servazione si trova che questo piccolo animaletto non subisce una vera metamorfosi, non giunge miai a possedere organi sessuali, ma tosto o tardi prolifica, o coll' emetter gemme, o collo scindersi, o col produrre spore interne, ed in tal modo dà origine ad un nuovo essere, in cui ricom. pare la forma precisa del primo genitore. - Il naturalista danese Steenstrup, che ebbe pel primo la felice idea di ravvisare il mirabile nesso tra queste diverse forme e generazioni possibili nella sfera della specie, e che furono sempre considerate isolatamente, ha dato alle larve non trasformantesi ma generanti l'intitolazione di nutrici, ormai introdotta stabilmente nel linguaggio scientifico.

La forma più semplice di questo procedimento della natura può rinvenirsi ancora nella classe degli insetti, nella doppia generazione di un piccolo imenottero parassito appartenente alla numerosa famiglia degli icneumonidi pteromalini. Questo insetto depone le sue uora entro quelle di un piccolo coleottero che è il rinchite della vite e del pero; e dall' novo così deposto dal piccolo parassito, non

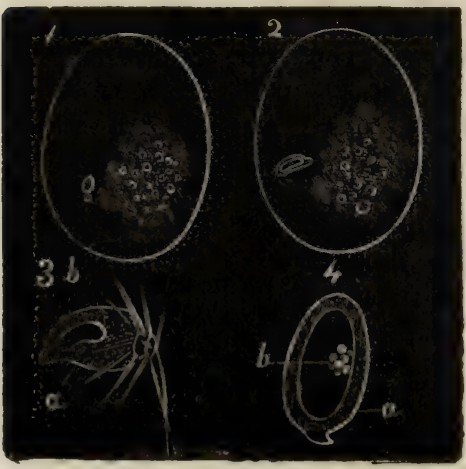

Fig. 5̃. Generazione del Pteromalino nelle uova di rinchite ("). nasce già una larva destinata, come negli altri insetti a trasmutarsi in animale perfetto, ma nasce invece un piccolo animaletto intermediario,munito anteriormente di una specie di rostro e posteriormente di una coda articolata e mobile (fig. 55). Questo primo essere, colla vivacità de' suoi movimenti, distrugge la vitalità dell'uovo del rinchite e ne impedisce lo sviluppo; esso genera poscia nel

(") 1. Uovo di rinchite entro cui si vede la prima larva del parassito. 2. Lo stesso in cui la detta larva è più sviluppata, e già contiene entro di sè il germe della seconda larva. - 3. La prima larva come al N. 1: veluta al microscopio. - 4. La larva come al N. 2. - a. Il corpo della prima larva. - b. Germe della seconda. 
suo interno la vera larva del pteromalino, che dovrà nutrirsi della sostanza di questo uovo. Si hanno cosi due larve: la rrima semplicemente generante, è paragonabile ai sacchetti organizzati e viventi, nei quali vedemmo altrove prodursi i germi dei distomi (pag. 17), essa è quindi una nutrice: la seconda è la vera larva destinata a subir la metamorfosi da prima in ninfa, poscia in insetto perfetto. Il germe di questa larva compare come una vescichetta trasparente nel corpo della nutrice, la quale, collo svilupparsi successivo del germe incluso, si distende, e finisce per diventare un semplice inviluppo della sua prole (1).

La storia genetica degli animali inferiori ci presenta non pochi esempi analoghi, ne' quali un primo essere, nella serie della specie, si limita a produrne un secondu, . che è o diverrà l'animale che si dice perfetto perciò che andrà munito di organi sessuali; e si ha in tal caso non moltiplicazione, ma semplice rinnovamento dell' individuo (E'chini, Asterie). In altri casi invece una sola larva generante, o nutrice, dà origine ad un gran numero d'individui perfetti (alcuni vermi) : infine una nutrice procrea una famiglia d'altre nutrici, ciascuna delle quali alla sua volta produrrà uno o più individui dell'ultima generazione (elminti trematodi, acalefi).

Questo fatto fisiologico più o meno complesso fu chiamato da Steenstrup delle generazioni alternanti, perchè, se è riconosciuto che una medesima specie di viventi pui moltiplicarsi con diversi processi genitici, è riconosciut() altresi che questi processi non hanno mai luogo contem. poraneamente in un medesimo individuo, ma si succedono con ordine alterno, in individui diversi discendenti gli uni

(1) Questo fallo curioso da me scoperto non è anciora ricevuto colla fede che si merita, eppure potrebbe essere verificato colla massima facilita. Io lo credo anzi una manifestazione di un processo generale a tutti gli icneumonidi, ed inavvertito fin qui per la sola circostanza che finora non si sono osservate che larve di ieneumonidi troppo sviluppate. Fin d'ora sembra probabile che il sacco membranoso trovato da Ratzuburg includente la giovane larva negli Anomalon, e di cui egli non sa darsi una ragione, altro non sia che il residuo della nutrice.

Sarebbe solamente da porsi in questione il modo di interpretare il fatto stesso; se cioe debba vedersi in esso an esempio di generazione germipara, oppure se non sia il caso di far qui l'applicazione dell'ipotesi di Uwren mentovata nella nota antecedente. 
dagli altri (1). Lo stesso significato ha un altro nome la cui etimologia è evidente per sè: quello di metagenesi, il quale ci sembra esprimere convenientemente l'idea cui si riferisce.

Queste premesse verranno meglio in chiaro con una serie di fatti particolari, ai quali passiamo senz'altro.

Come già fu detto a pag. 9, O. F. Müller area osservato in un verme di mare della famiglia delle nereidi, la formazione di un nuovo individuo all' ultimo segmento dell'estremità caudale, e la consecutiva sua separazione. De Quatrefages ebbe a convalidare questa osservazione, ma scoperse nel medesimo tempo che l'individuo produttore di questa gemma terminale non ha alcuna traccia di organi sessuali, ed invece sviluppatissimo l'apparato nutritivo; mentre nel nuovo individuo questo apparato è in. tieramente atrofico, e la cavità viscerale non contiene che gli organi della generazione. In altro genere affine (Myrianide) Milne Edwards ha verificato la stessa cosa, colla differenza che il primo individuo, larva generante, o nutrice, produce una catena d'altri individui forniti di organi sessuali. E inutile l'aggiungere che dalle uora di questi rinascono poi le nutrici gemmipare.

Una delle più belle scoperte della zoologia moderna è senza dubbio quella che risguarda le metamorfosi e la generazione degli echinodermi, fatte conoscere da G. Müller in una serie di stupendi lavori.

Ciò che può dirsi di comune a tutte le specie di questa classe si è, che dall' uovo ha origine primieramente un embrione infusoriforme, ricoperto di ciglia vibratili, e che

(1) Alcuni casi sembrano opporsi alla generalita di questa legge. Koekliker ha trovato in una medusa (Stomobrachium) un soleo divisorio unitamente a vere e distinte uova in corrispondenza di alcuni raggi vascolari. Schultze ha parimenti veduto in una turbellaria (Microstomum) il sotoo divisorio di due individui apparentemente nati per scissione di un solo, coesistere cogli organi sessuali sviluppati negli individui stessi, uno dei quali è maschio, l'altro femmina. Nella Sarsia prolifera, secondo Busch, si danno embrioni nati per gemme alla base dei filament, e nel medesimo tempo organi sessuali attorno al canale alimentare.

Ma le due turbellarie di Schultze, lungi dall esser nate da un solo individuo per scissione, potrebhero con maygior probabilità considerarsi cumb due individui in istato di conjugazione: e quanto agli altri due fatti nsservati da Koelliker e da Busch, v' ha omai luogo a credere che il solcu in un caso, la grmmazione in un altro, siano due fatti compiuti che non si ripetono dopo che sono comparsi gli organi sessuali. 
ben tosto questo embrione si trasforma in una larva, la quale, nella conformazione generale del corpo, non presenta ancora il tipo raggiato, ma invece un tipo bilaterale più o meno evidente (1). Ma in alcune specie questa larra, per quanto dissimile dall'adulto, si va a poco a poco trasformando in questo, prendendo sempre più il tipo raggiato; in altre specie l'individuo di questo tipo non risulta dalla metamorfosi della larva, ma è da questa, che più larva non è, ma veramente nutrice, generato per gemmazione.

Così notevoli differenze non corrispondono affatto a gruppi naturali di questa classe; di modo che, per esempio, mentre ha luogo semplice metamorfosi nelle oloturie, e metagenesi negli echini, troviamo nelle asterie esempi 'dell' uno e dell' altro processo.

La larva di alcune asterie (echinastri) è di forma ovale, e posteriormente presenta una o più sporgenze, colle quali aderisce al corpo della madre: a poco a poco si forma nel suo interno una cavità che sarà la cavità viscerale della futura asteria; ed entro questa una seconda cavità a pareti proprie, che è la futura cavità digerente della stessa. Sono questi i primi passi ad una completa organizzazione in asteria.

Le ofiure, che formano un cospicuo genere nella medesima famiglia, presentano un ben diverso modo di sviluppo. L'embrione uniformemente cigliato, si trasforma in una larva, o meglio nutrice, della lunghezza di $1 / 2$ linea all' incirca, trasparente, di forma difficile a descriversi, ma che puossi delineare all' ingrosso come piramidale, con prolungamenti ineguali ai quattro angoli della base, nel cui centro sta la bocca, che introduce ad un tubo intestinale. Un complicato scheletro interno provvisorio, non male paragonabile ad un cavalletto da pittore, costituito da finissimi bastoncini calcarei insieme congiunti e saldati, sostiene le parti molli, continuandosi fin entro i prolungamenti anzidetti, i quali sono contornati da ciglia vibranti (2). In tale stato l'animale, lungi dal trascinarsi stentatamente sul fondo del mare, come fanno le asterie,

(1) Fatta eccezione dell'Ophiolepis squamata che presenta subito il tipo raggiato.

(2) Sotto questa forma la nutrice delle ofiure fu primamente descritta dallo stesso G. Müller come un genere apposito Pluteus.

DE FilipPr. Funzioni riproduttive. 
nuota in tutta libertà, innalzandosi anche verso la su. perficie delle acque. Dopo breve tempo compajono attorno alla hocca alcuni bottoni o gemme, che si sviluppano sempre più, e si dispongono fra loro come per costituire un corpo unico, entro il quale si forma un altro complicato scheletro calcareo (fig. 56). Questo corpo di nuova produzione, nel suo progressivo accrescimento, sporge sempre più dal corpo della nutrice, di cui si appropria il canale alimentare, e ben presto si dà a riconoscere pel disco della giovane ofiura (fig. 57). Mano mano poi questa procede

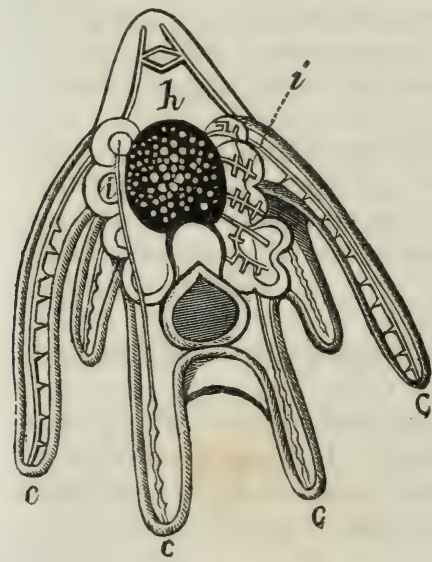

Fig. 56. Nutrice di ofura: da G. Muller (").

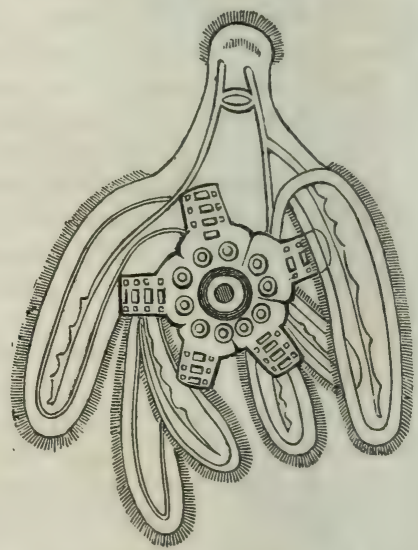

Fig. 57. Nutrice portante la piccola ofiura gia formata: da G. Muller.

nel compimento della sua organizzazione, la nutrice che l'ha generata cessa di vivere e si scompone.

Affatto analogo è il modo di sviluppo degli echinidi, fatta astrazione di una grande varietà nella forma e proporzione delle singole parti, e nella distribuzione degli organi vibranti alla superficie del corpo.

In altre specie (asterie propriamente dette), la larva generante o nutrice, di forma alquanto diversa dalla descritta,

(") c. c. Braccia della larva. - $h$. Stomaco. $-i$. Principio di formazion della giovane ofiura col suo proprio scheletro calcareo. 
si distingue per due sporgenze a guisa di natatoje, per la mancanza di uno scheletro calcareo provvisorio, e specialmente per sopravvivere al distacco dell' asteria, ignorandosi ancora cosa avvenga di lei nel seguito; se tosto muoja, ? se invece possa riprodurre stomaco ed intestino, e quindi altre asterie (1).

Le larve giovanissime delle oloturie si distinguono per una forma singolare che ricorda quella di certi scudi gentilizj di stile barocco, con due lembi contornati di ciglia vibranti, e disposti con varie inflessioni ai lati del corpo (2). A poco a poco queste inflessioni si modificano per modo che le frangie si dispongono circolarmente; e questo è il primo grado verso la trasformazione completa in oloturia.

Negli echinodermi la nutrice si limita a produrre un unico individuo, il quale poi, cresciuto e fatto adulto, mol. tiplica la sua specie col generare un gran numero di uova, che si svilupperanno in altrettante nutrici. Per altri animali il caso è inverso: l'individuo moltiplicatore è la nutrice, e l'individuo da considerarsi come a termine, perchè munito di organi sessuali, non dà che un solo prodotto.

Ne abbiamo un esempio nelle bifore o salpe (fig. 58), nellt

A

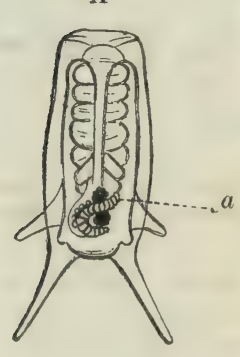
quali appunto Chamisso scopri pel primo il grande fatto fisiologico delle generazioni alternanti, che rimasto nell'oscure per quasi trent'anni, emerge ora in tutta la sua importanza, e ci obbliga a rinno-

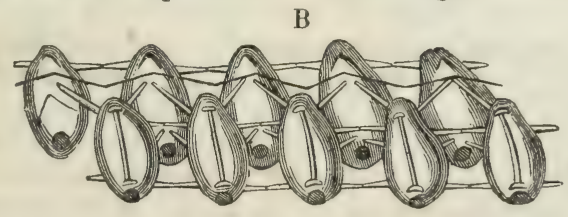

Fig. 3̈8. Bifora democratica (Forskal) (").

var per intero la storia degli animali inferiori. Ogni spe-

(1) Le nutrici di asteria sotto questa forma furono descritte da Sars col nome generico di Bipinnaria.

(2) Queste larve per la prima volta incontrate da G. Müller, furono descritte col nome di Auricularia.

(") A. Individuo nello stadio d'isolamento. - a. Catena di feti.

B. Individui nello stadio d'aggregazione. 
cie di salpa vive sotto la duplice condizione di individui liberi, e di individui aggregati, diversi gli uni dagli altri per molti caratteri. I primi, che rappresentano lo stadio di nutrice, sono agami, e producono, per gemmazione su di uno stolone interno, una catena di individui aggregati: ciascuno di questi alla sua volta produce un unico uovo, che si sviluppa nel ventre della madre, e dà origine ad una salpa isolata che rincomincia la moltiplicazione per gemme.

La metagenesi si verifica e più complicata e mirabile nei polipi idrari (1), e negli acalefi. Già ci è noto che la comune idra d'acqua dolce, la quale si moltiplica per gemme, produce pure uova: ma l'ordine di successione di questi due processi riproduttivi non è arbitrario. Intanto si osserva costantemente che l'idra germogliante non presenta giammai nell'istesso tempo organi sessuali; e per contrario che l'idra in determinate stagioni emette, ancora per gemmazione, da 1 a 4 capsule ovifere, od ovarj semplicissimi estemporanei, contenenti ciascuno un solo uovo relativamente assai grande; ma in tal caso non produce più gemme comuni. Quando poi le uova sono mature esse si separano dal corpo materno, e l'idra cessa di esistere e si scompone. Le giovani idre nate da queste uova, rincominciano la generazione per gemme (2).

In altri polipi idrari aggregati, che vivono nelle acque del mare, spuntano come per svolta od ernia del canale nutritizio comune, capsule ovifere del tutto analoghe; se non che invece di esser formate da un tessuto omogeneo e compatto, presentano già quattro canaletti disposti come i raggi di un ombrello, e che sono caratteristici delle meduse. $\dot{E}$ appunto ciò che si osserva in alcurıe campanularie (fig. 59) e nelle sertularie. Queste nuove produzioni sono considerate da alcuni naturalisti come semplici organi sessuali femminei del polipajo, da altri invece come vere meduse, le quali producono uova, prima ancora che si compia la loro organizzazione. Questa maniera di redere è pienamente giustificata dal fatto, che altri polipi idrari

(1) Cioè polipi, la cui cavita gastrica non provveduta di parete propria, e scavata nella sostanza medesima del corpo.

(2) Non si è ancora ricercato se le idre ovipare siano le stesse che nell'eta più giovane abbiano prodotto gemme, oppure individui novelli. Quest'ultimo caso sembra il più probabile. 
aggregati, come altre specie di campanularie e le sincorine, producono nell'istesso modo vere incontrastabili meduse, le quali si distaccano dal polipajo, e si fanno libere e nuotanti nell'acqua, prima ancora che in esse si sviluppino le uova (fig. 60 e 61). Queste nuove produzioni dei polipi idrari, nel seno delle quali tosto o tardi si producono uova, sono organi, sono individui? La risposta a questa quistione può essere imbarazzan te. Dalle capsule sessuali delleidre, che sono semplici organi, alle meduse generate dalle sincorine, che sono veri in-

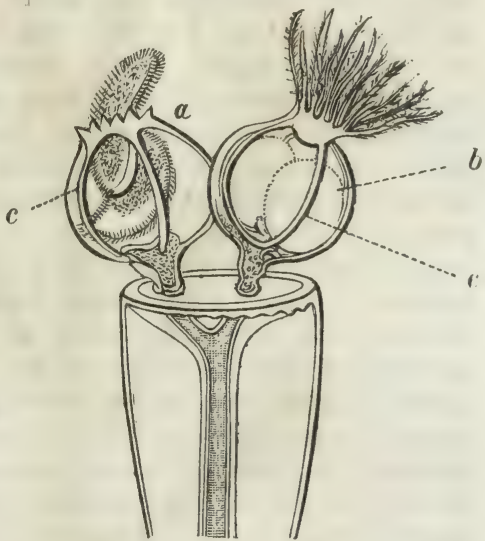

Fig. 59. Porzione di una

campanularia (C. geniculata): da Löven ("). dividui, la transizione è affatto naturale coll'intermedio di alcune campanularie, le cui capsule sessuali si potrebbero quasi indifferentemente prendere tanto per organi medusiformi, come per meduse fisse. Ripetiamo che questa seconda maniera di vedere è quella che ha maggior fondamento, e che per conseguenza i cosi detti organi sessuali de' polipi idrari sono da considerarsi come meduse piứ 0 meno abortive e fisse.

Quanto ora abbiamo detto riguarda in special modo le capsule ovifere, ma è applicabile egualmente alle capsule. seminifere, le quali però non giungono mai a presentare l'organizzazione delle meduse, e ciò per la ragione sovente ridetta del precoce e rapido sviluppo degli organi maschili che accorcia la carriera evolutiva dell'individuo che li porta.

L'uovo fecondato di questi individui medusiformi, fissi - liberi che siano, dà origine ad un embrione che per le ciglia vibranti di cui è tutto sparso, si può benissimo pa-

(*) Questa figura rappresenta la parte superiore di un individuo munito dei cosi detti organi femminei maturi e gia esciti dalla capsula, ma ancora aderenti pel loro peduncolo. I quattro canaletti che veggonsi in $c$, li caratterizzano come meduse. - $b$. Due uova. - $a$. Due embrioni. 
ragonare ad un infusorio. Ben tosto le ciglia scompajono;

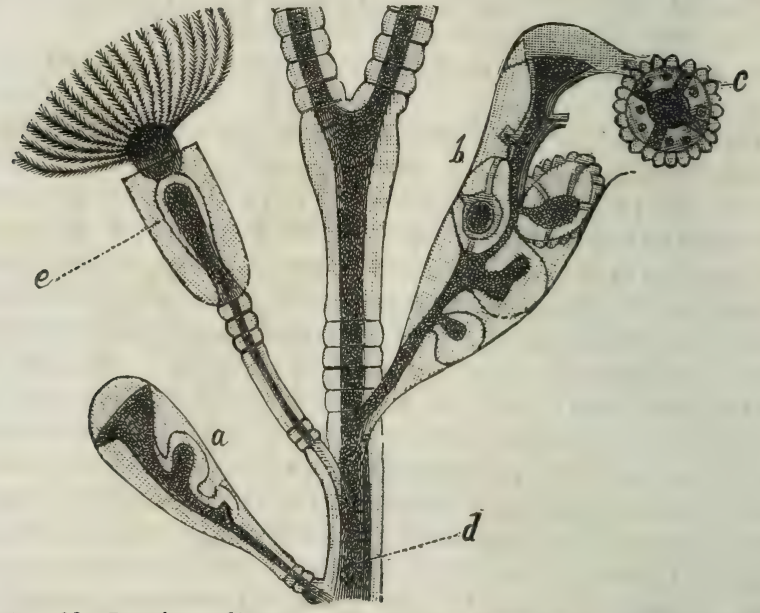

Fig. 60. Porzione di un cespite di campanularia: da Desor (").
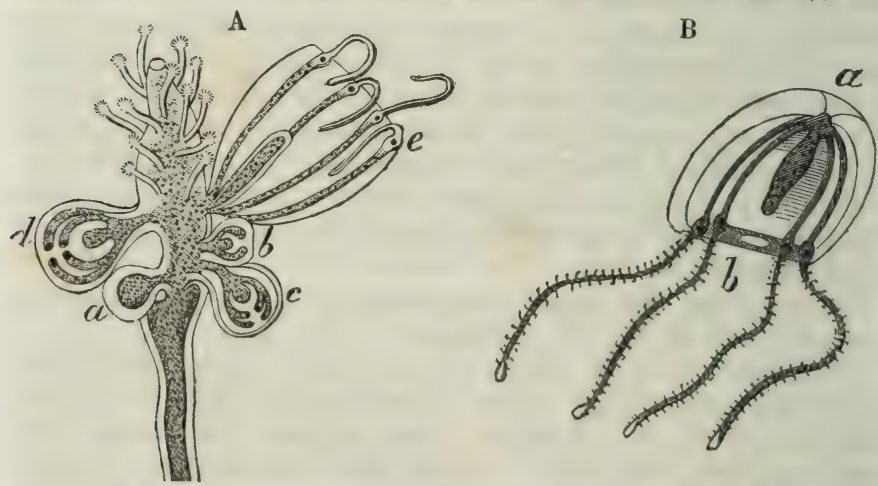

Fig. 61. Una sincorina generante meduse: da Desor ("*).

(") a. Un individuo riproduttore, con gemma in corso di formazione. - b. Un individuo simile in cui le gemme sono gia sviluppate in meduse, una delle quali in $c$ e gia staccata e libera. $-d$. Serbatojo conune del fluido nutritizio. - $e$. Un individuo nutriente colla sua corona di tentaculi.

(“) A. Un polipo (sincorina) $-a$. $-e$. Sue gemme a vario grado di sviluppo in meduse.

B. Una medusa gia staccata e nuolante. $-a$. Sorta di ombellico pel quale la medusa aderiva in origine al polipo. $-b$. Bucca. 
l'embrione si fissa, si incava ed acquista una cavità gastrica, al cui margine non tardano a comparire i tentacoli; e così si trasforma in polipo, ossia nella nutrice che deve generare per gemmazione le meduse produttrici d: uova.

Nei casi ora riferiti ad esempio, primi ad essere riconosciuti dai naturalisti, e descritti come specie particolari e distinte, furono gli individui polipiformi, i quali perciò si dissero generatori di meduse. Una serie analoga di vicende si ripete in altri animali della stessa classe, con questa differenza soltanto, che primi ad essere conosciuti e descritti furono invece gli individui ovipari medusiformi, i quali vennero perciò considerati come generatori di polipi. In una bellissima specie di medusa ad ombrello, la Medusa capillata, gli embrioni si trasformano in polipi, nel modo che abbiamo detto. Ogni polipo non tarda a procreare per gemme laterali una numerosa progenie di altri individui simili, i quali invece di vivere aggregati, come nelle campanularie, si liberano dal corpo materno per crescere e germogliare separatamente. Giunti questi individui polipiformi ad un determinato sviluppo, incomincia la loro moltiplicazione per scissione. Compare da prima un solco circolare alla base della corona dei tentacoli, poscia varj altri successivi; e per tal modo si formano varj segmenti, ognuno de' quali diviene sul posto un animale che non tarda ad offrire i caratteri della primitira medusa (1). Questi nuovi individui disposti su di un asse comune, formano come una pila d'animali (2); ma infine l'uno dopo l'altro si distaccano e divengono nuotanti, per crescere e svilupparsi sotto la nuova forma che hanno acquistata, e riprodurre quali le uova, quali il liquido fecondatore (fig. 62).

Rientrano sotto la stessa legge quegli animali che formarono fin qui, ancora nella classe degli acalefi, un ordine distinto detto dei sifonofori. Essi portano alla sommità un galleggiante, costituito o da un disco cartilagineo con cel-

(1) Alcuni autori interpretano diversamente questo modo di formazione degli individui medusiformi; e piuttosto li fanno derivare da una successione di gemme terminali.

(2) Questo aggregato di giovani meduse fu primamente descritto da Sars sotto il nome generico di Strobila. Più tardi questo medesimo autore ne riconobbe la vera genesi, e si acquistó il merito di aver scoperto pel primo questo complicato processo di generazione nelle meduse. 
lule aeree (velelle, porpite), o da una semplice vescica

$a$

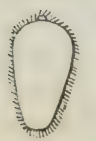

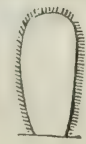

$b$

$c$
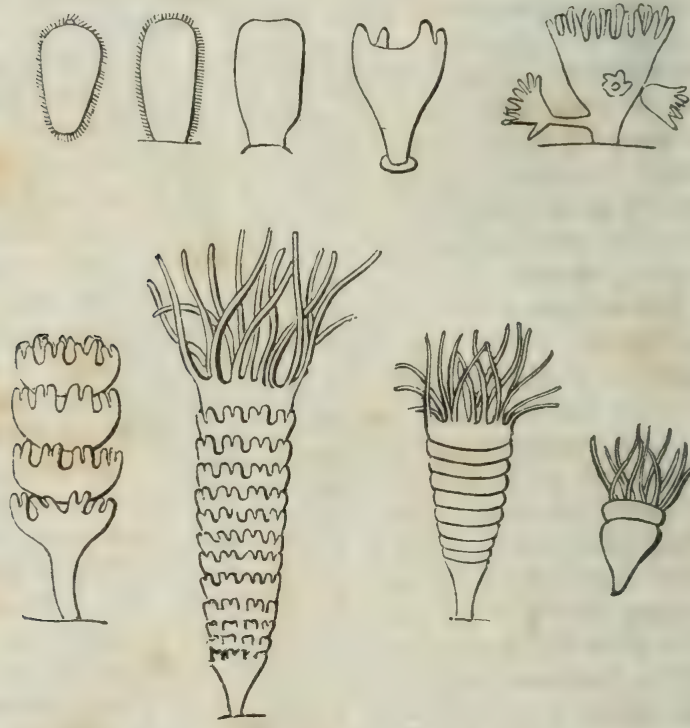

y

$f$
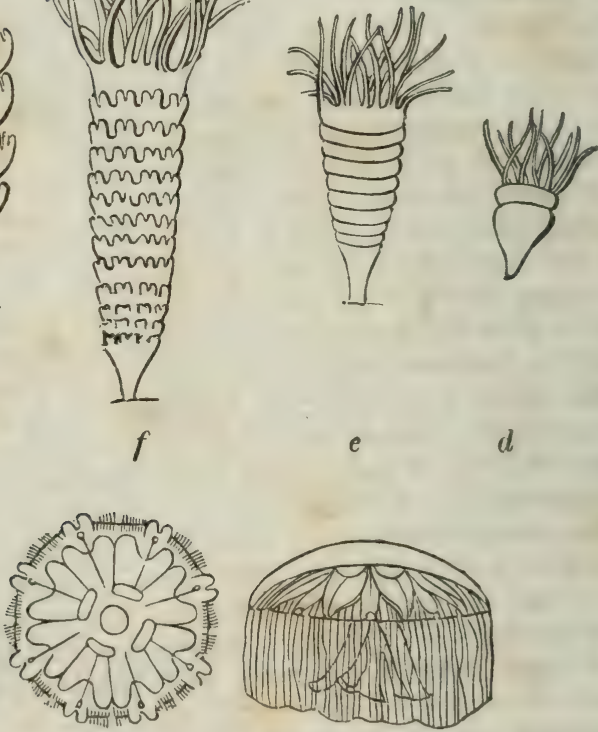

$h$

$i$

Fig. 62. Generazione della Medusa capillata: da Sars (`).

(") $a$. Due embrioni infusoriformi. - $b$. Gli stessi gia trasformantisi in polipo. - $c$. Polipo che altri ne produce per gemme laterali. - $d-y$. Diversi stadj suceessivi della generazione di meduse da un polipo. - $h$. Una ginvane Medusa capillata veduta per di sotto. - $i$. La stessa di profilo. 
piena di aria (fisofore, fisalie), ed al quale sono sospese le parti veramente attive nelle diverse funzioni della vita, come gli organi della locomozione, quelli della digestione, quelli della generazione. Tutti questi organi, varj in nu. mero, sono fra loro variamente disposti ne' diversi generi distinti dai naturalisti, ma per lo più si trovano lungo il decorso di uno stelo comune, sottile, molle, flessibile, cavo e ricettante il fluido nutritizio. Il polimorfisino si manifesta negli animali di quest'ordine nel modo più maraviglioso; poichè quelli che non ha guari abbiam detto organi, sono veramente altrettanti individui nati per gemmazione dal tronco che li porta, ed aventi gli uni i caratteri più o meno evidenti di meduse, gli altri quelli di semplici polipi idrari (fig. 63). Ciascuno poi ha un' organizzazione sua propria, ed è incaricato di una funzione speciale che torna al ben essere dell'intiera colonia. Vi hanno infatti campanelle contrattili che sono gli individui locomotori, i quali per la presenza dei quattro canaletti raggiati nella grossezza delle loro pareti, accennano già alla forma più elevata che è quella di medusa: v' hanno polipi con una bocca ed uno stomaco, ed alla base strumenti complicati per la pesca della loro preda; e questi sono gli individui mangianti: v' hanno infine altri polipi astomi che producono alla loro base le gemme sessuali, e questi sono gli individui riproduttori. Queste gemme presentano più o meno evidente il tipo medusario; e divengono anzi in alcuni, come nelle velelle, vere e genuine meduse che si distaccano per vivere di vita propria, ed a suo tempo produrre o uova o fluido seminale. Quali poi siano le fasi evolutive dell' uovo in questi animali, come da esso venga ripristinata una nuova colonia, non è ancor conosciuto. Questo soltanto possiam dire, che il numero degli individui è tanto più limitato quanto più giovane è la colonia; che nuovi individui si vanno successivamente formando in prossimità della vescica aerea, quindi sono respinti per dar luogo alla formazione di nuove gemme, così che gli individui più sviluppati sono quelli più distanti dalla vescica aerea.

Ma come vedemmo delle idre che riproducono sempre tanto per gemme che per uova la stessa forma, cosi dobbiamo accennare ora esservi meduse (Sarsia prolifera), le quali producono per gemme, al margine dell'ombrello, al- 
tre piccole meduse; e ad epoca più inoltrata una seconda
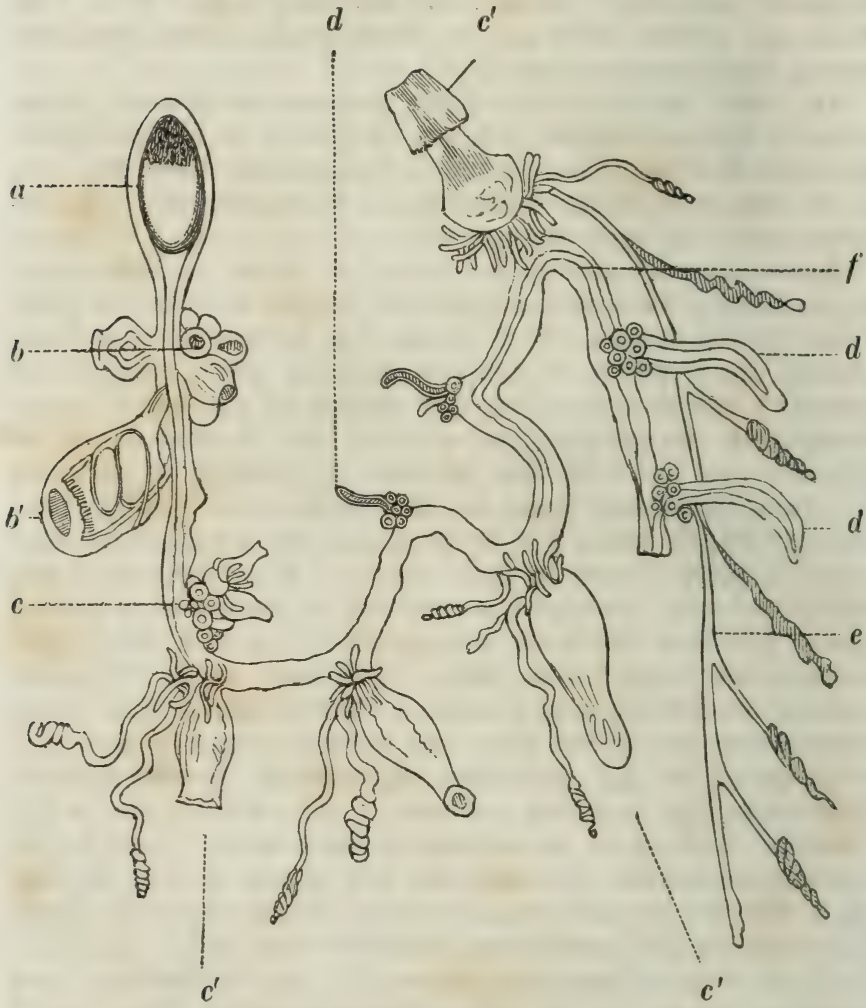

Fig. 63. Una sifonofora (Agalma rubra) : da C. Vogt. (")

generazione per uova, dalle quali con tutia probabilità nasceranno direttamente altre meduse. Nel che ci conferma la scoperta fatta da G. Müller di una medusa (Aeginopsis

(") $a$. Vescica natatoria. - b. Ammasso di giovani individui. - $b$ '. Uno di questi individui sviluppato. $-c$. Ammasso di giovani individui (polipi) rutritivi. - $c^{\prime}$. Individui riproduttori producenti per gemmazione alla loro base capsule ovifere (Meduse). - $\boldsymbol{d}$. Individui (polipi) riproduttori astomi. $-e$. Filo per la pesca. $-f$. Tronco comune. 
mediterranea), in cui le larve hanno già il tipo medusario, e presentano cosi l'esempio di una specie in cui la trasformazione dell'embrione in medusa ha luogo senza lo stadio intermedio di polipo.

Da tutti questi fatti C. Vogt, cui siamo debitori di un classico lavoro intorno a questo argomento, ha conchiuso giustamente che i polipi idrari, le meduse discofore, e le sifonofore, devono costituire una sola classe, che egli ha chiamato delle idro-meduse (1).

La storia genetica degli elminti, o vermi intestinali, che in ragione delle tenebre onde fu sempre avvolta, ha dato adito alle più strane e discordanti congetture, fu intieramente rinuovata dalle scoperte fatte in questi ultimi anni. Ormai è dimostrato che non v'ha una sola specie di questi vermi, la quale percorra tutte le fasi di sua vita in un ospite solo: che tutte trasmigrano e passano in generale i primi stadj come parassiti di animali delle classi inferiori, l' ultimo periodo invece, quello che è contraddistinto dallo sviluppo degli organi sessuali, nel corpo de' vertebrati. In questi animali le uova o gli embrioni degli elminti possono circolare col sangue, e penetrare in ogni organo del corpo; ma nella cavità intestinale principalmente trovano essi le condizioni favorevoli al loro completo sviluppo. Fuorviati e trattenuti in altri organi essi rimangono in uno stato imperfetto, o per lo meno sterili per un tempo indefinito, e per lo più ravvolti in un particolare inviluppo, o come suol dirsi in una cistide. Da questa condizione passano rapidamente a quella di animali perfetti quardo mutino sede, e vengano trasferiti coll'alimento nell' intestino di animali superiori.

I nematoidi (ascaridi, strongili) non subiscono metamorfosi alcuna, e la sola differenza fra i giovani e gli adulti consiste nella mancanza o presenza degli organi sessuali. Invece nei cestoidi e nei trematodi ogni specie è rappresentata da individui di forma, struttura, proprietà fisiologica e sede assai diversa. Incominciamo dai cestoidi.

Le tenie, comunissime nel tubo intestinale dei vertebrati, ed anche dell' uomo, ove ricevono il nome affatto improprio di vermi solitarj, constano di un capo e di

(1) Recherches sur les animaux inférieur's de la Mediterranée. Premier mémoire. Genève $185 \%$. 
una serie di articoli o segmenti, ohe noi considerammo già come altrettanti individui; ed infatti essi possono separarsi in alcuni casi, e vivere per un certo tempo allo stato di isolamento. Gli scolici (Scolex) quali si incontrano nella cavità polmonale dei lumaconi, non differiscono in nulla da un capo di tenia; le proglottidi (Proglottis) che si trovaro nell'intestino di varj animali, sono in tutto paragonabili ad articoli isolati di tenia. Ora è chiaro di quali membri debba comporsi uno di questi aggregati comunemente chiamati tenie. Il primo individuo della serie, il capo, è uno scolice, che non ha organi sessuali e che genera per una successione di gemme tutta la serie degli altri, che sono proglottidi, ed in ognuno dei quali si trovano riuniti e funzionanti gli organi de' due sessi (1). Le uova sono tanto più numerose e mature quanto più le proglottidi sono di antica formazione, e discoste dallo scolice per l'interposizione di una lunga serie di altri individui simili, sempre più giovani.

Nella pluralità dei casi l'embrione si forma dall'uovo nel corpo stesso delle proglottidi. Esso consta di una sostanza omogenea e non presenta organi di sorta, tranne 6 uncinetti appajati, che ne' movimenti che fa, stando ancora rinchiuso nella membrana dell' uovo, veggonsi soventi cambiar direzione (fig. 64). In tale stato le uova vengono emesse, e tosto o tardi se non

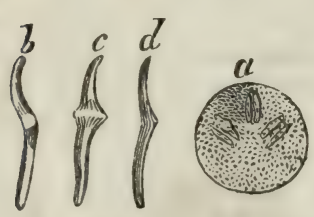
per tutte, almeno per alcune, giunge l'istante di penetrare, $\mathrm{mi}$ ste a qualche sostanza alimentare, nell' intestino d'altri animale. L'uovo allora si dischiude.

L'embrione non si trasforma direttamente in scolice, ma si Fig. 64. Embrione di tenia ("). incava nella sua parte centrale, e dal fondo di questo ricettacolo in cui esso convertesi, produce una gemma che si organizza ben tosto nel vero scolice ( fig. 65). Più tardi questo si svincola dal suo ricettacolo, e secondo la dimora in cui

(1) Van Beneden chiama strobila questo aggregato di individui costituente una tenia nell'antico significato di questa parola.

(") a. Liembrione ancora rinchiuso nella membrana dell'uovo, $-b-d$. Uncini isolati e veduti ad un maggior ingrandimento. 
sarà per fissarsi, subirà diversi destini. Nel tubo intestinale de'vertebrati, e specialniente delle classi superiori, il ricettacolo dello scolice si scompone e viene digegerito, e lo scolice stesso incomincia a produrre per gemmazione incessante una serie talvolta lunghissima di proglottidi. Si avrà così uno di quegli aggregati che i naturalisti chiamarono fin qui tenie. Quando le uova o gli embrioni ingojati coll' alimento possono attraversare le tonache dell' intestino, e circolando col sangue vanno a fissarsi o nelle pieghe del mesen- di un lumacone: da Siebold(*). terio, o più lungi ancora, nel fegato, nei polmoni, nel tessuto sottocutaneo, nel cervello, ciascuno di essi produce ancora uno scolice, ma questo non genera la serie delle proglottidi, o sole poche e sterili, ed invece il suo ricettacolo si prolunga in un'appendice caudale vescicolosa portante ancora i sei uncinetti embrionali dislocati (fig. 66). Quest'appendice caudale si riempie di un fluido sieroso, si distende, e si trasforma in una cistide acquosa, in uno di que' corpi che si dicono idatidi. In tale stato l'animale non diventa più una tenia, nel linguaggio antico, ma un cisticerco (fig. 67). Il majale in causa della sua polifagia va esposto più d'ogni altro animale a tranguggiare uova di tenia, e deve a questa circostanza il nu-

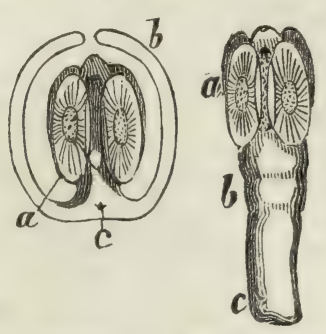

Fig. 65̃. Scolici di tenia della cavita polmonale

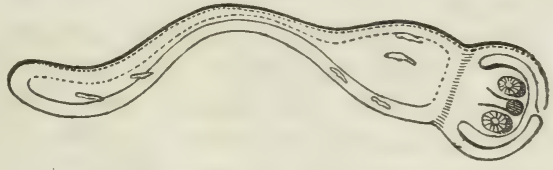

Fig. 66. Scolice della larva del tenebrione della farina: da Stein.

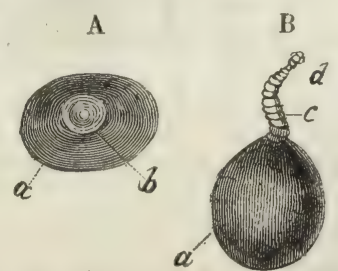

Fig.67. Cisticerco della cellulosa da Siebold (").

(*) A. Uno scolice ancora racchiuso nel suo ricettacolo.

B. Lo stesso gia svolto. $-a$. Testa. $-b$. Ricettacolo. $-c$. Uncinetti embrionali residui.

(**) A. Visto per di sopra.

B. Visto di profilo. - $a$. La vescica. - $b$. Il corpo del verme ritratto.

- c. Lo stesso corpo svolto. - d. Parte anteriore o capo del verme. 
mero incalcolabile de' cisticerci che si sviluppano talvolta nel suo tessuto pinguedinoso sottocutaneo, a danno del lardo, e costituiscono quell'affezione conosciuta col nome di ladreria o gragnuola.

Se invece gli stessi embrioni di tenie, circolando nel sangue, vanno a fissarsi nel cervello de' ruminanti, vi si svilupperanno in modo particolare. Dal ricettacolo che si fa grande e capace, spuntano non un solo scolice, ma più scolici; ed avrà origine ura cistide acquosa portante alla sua superficie molte cosi dette teste di tenia: e ne risulterà il cenuro, causa frequente del capostorno, del marasmo e della morte delle pecore.

Altre volte l'embrione di tenia fissato nel parenchima de' visceri del basso ventre, si trasforma non in un semplice ricettacolo, ma in una vera vescica piena d'acqua, ed entro questa si producono per gemme numerosi scolici, che si staccano dalla parete e cadono nel vano della vescica; e cosi ha origine l'echinococco, frequente ne' nostri grossi mammiferi domestici, non raro anche nella specie umana, e cagione di gravi disturbi all' economia vivente.

Facciasi dunque attenzione a questa serie di generazioni negli elminti cestoidi: si ha da principio un embrione, il quale produce per gemme uno o di raro più scolici, vere larve generanti o nutrici: queste riproducono ancora per gemme una serie di proglottidi: le proglottidi infine generano i primitivi embrioni (1).

I trematodi (monostomi, distomi, anfistomi, ecc.) sono essi pure ermafroditi (eccettuata fin qui una sola specie)

(1) Le recentissime esperienze di Küchenmeister e di Siebold hanno dimostrato all'ultima evidenza la genesi delle tenie da scolici ingojati. Il cisticerco che si trova nel fegato dei ratti, fatto mangiare ai gatti si converte nella tenia crascicolle. Il cisticerco del majale, quello del coniglio, il cenuro cerebrale, amministrati ai cani, danno luogo allo sviluppo di una medesima specie di tenia, dalla quale non si può specificamente distinguere quella dell' uomo. Sono anche riescite esperienze in senso inverso. - Il prof. Leuckart di Giessen ha fatto sviluppare artificialmente il cisticerco nei ratti, facendo loro mangiare la tenia crascicolle del gatto. Il prof. Haubner di Dresda, produsse l'artificiale sviluppo del cenuro in un branco di pecore, facendo ad esse mangiare, miste al foraggio, una quantita di embrioni della tenia serrata nel cane. Vedi a quest'unpo l'interessante opera di Siebold: Ueber die Band, und Blasenwurmer. Lipsia 1834.

Più recentemente Van Beneden e Leuckart produssero la gragnuola in alcuni majali, propinando a questi la tenia ( $T$, solium) dell'uomo. 
come le proglottidi; e le loro uova, che in molte specie si dischiudono già nel ventre materno, danno origine ad embrioni affatto diversi da quelli de' cestoidi; mancano essi degli uncinetti, che vedemmo in questi, ed hanno il corpo rivestito di ciglia vibratili. In tale stato molto rassomigliano a certi infusorj, come leucofridi e borsarie, che si incontrano soventi liberi nell' acqua.

Questi embrioni non si trasformano in individui simili al genitore, ma diventano o producono un altro essere, una nutrice, che procrea per germi o spore la vera prole in cui tosto o tardi ricompajono i caratteri dei primitivi trematodi. Il processo genetico è qui ancor più complicato che nei cestoidi, poichè mentre gli scolici non si moltiplicano e non possono provenire che direttamente da embrioni, le nutrici de' trematodi, veri equivalenti degli scolici, si riproducono eziandio come esseri indipendenti; hanno quindi una doppia origine, e procreano una doppia prole, cioè la prole loro propria, e quella del trematode stipite.

Queste nutrici si presentano sotto due forme. Le une come semplici sacchetti con pareti sottilissime, inerti, od appena debolmente contrattili: le altre come veri esseri organizzati, con una faringe, un esofago, una cavità digerente, vasi, e dotati di movimenti assai vivaci. La prole molto numerosa si forma da germi liberi nella cavità del corpo, nel modo che fu detto a pagina 17; e quando è sviluppata, il che d'ordinario avviene entro il corpo stesso della nutrice, presenta già i caratteri morfologici del trematode adulto, dal quale si distingue per mancare di organi sessuali, ed essere invece dotata di organi provvisorj, quali sono una coda contrattile e guizzante, e non raro anche due occhi rudimentali. Sotto questo stato, che è un vero stato di larva, i giovani trematodi furono considerati come animali completi ed indipendenti, e se ne compose il genere Cercaria. Le stesse nutrici organizzate furono da principio descritte come costituenti un genere particolare di elminti, col nome di redie, chiamandosi più particolarmente sporocisti le nutrici semplici, prive di organi interni.

I trematodi adulti, fatte pochissime eccezioni, si rinvengono soltanto nel tubo intestinale dei vertebrati, o nelle sue dipendenze, soventi in gran numero: le loro nutrici, 
per lo contrario, ed in conseguenza anche le larve, si sviluppano esclusivamente, in numero ancor maggiore, nel corpo dei molluschi, e specialmente nel loro fegato, di cui le nutrici aventi la forma di redie mangiano la sostanza.

Da questi cenni generali è già abbozzato il ciclo evo. lutivo de'trematodi. Ora convien aggiungere che in riguardo alle forme della nutrice e delle larve, e del modo di trasmigrazione di queste, si possono suddistinguere due principali tipi.

L'embrione infusoriforme di molte specie di distomi, penetrato nel corpo di una prefissa specie di mollusco, perde le sue ciglia, e si converte direttamente in un sacco membranoso, in una sporociste, che diventa pregnante di molti germi di distomi, e questi rapidamente si sviluppano in altrettante larve, ossia cercarie (fig. 68), le quali

A

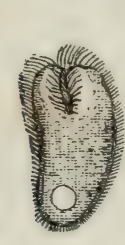

B

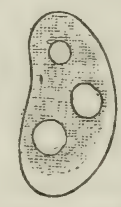

C

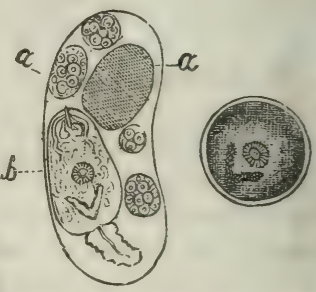

Fig. 68. Embrioni, sporocisti, e larve del Distoma inaculosum (').

come carattere particolare presentano, nella parte dorsale della loro ventosa anteriore, un piccolo dardo. Gli embrioni prima che si trasmutino in sporocisti, o le sporocisti stesse, si possono moltiplicare per scissione; e questo spiega come da un numero relativamente piccolo di primitivi embrioni di distoma possano provenire quegli ammassi innumerevoli di sporocisti che si incontrano talvolta nei molluschi. Le cercarie giunte ad un certo grado di sviluppo, abbandonano la sporociste materna, e quindi anche il molluseo

(") A. Embrione che nasce direttamente dall'uovo del distoma.

B. Sporociste in cui l'embrione A si è trasformato: con germi di cercarie.

C. Spororiste con germi di cercaria $a$, ed una cerearia armata $b$.

D. Cercaria passata allo stadio di distoma incistidato. 
che le ha fino allora ospitate, guizzano per qualche tempo nell'acqua, e trovato un altro ospite che loro convenga, per lo più qualche larva d'insetto, mediante il dardo di cui sono armate vi penetrano, nel quale atto perdono la coda, e quindi pure lo stesso dardo; ed in questa nuoril dimora si incistidano prontamente. Il nuovo ospite che si sono scelte non tarda ad esser preda di altri animali voraci: e per questo veicolo i giovani distomi incistidati arrivano nell' intestino di qualche animale vertebrato, ivi si svolgono, si sviluppano, diventano capaci a generare, emettono uova che vengono quindi evacuate colle feci del nuovo ospite. Una cosi fatta serie genetica si può constatare nel distoma delle rondini (D. maculosum) (fig. 68 e 69),

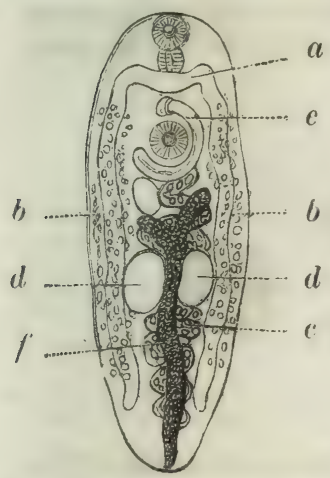
che allo stato di larva è parassito di una specie di paludina ( $P$. impura), d'onde passa per trasmigrazione attiva nelle larve di perla e di efemera, e poscia di nuovo, per trasmigrazione passiva, rientra nel corpo delle rondini, che predano e mangiano le perle e le efemere per. fette e volanti liberamente nell'aria.

In altre specie di trematodi l'em.

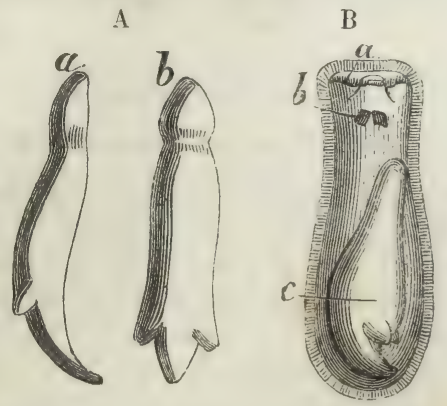

Fig.69.Distoma maculosum(*).

brione, di organizzaziune più complicata, poichè va fornito di un sistema vascolare, e talvolta anche di un rudimento di occhi (fig. 70), genera nel suo interno una nutrice avente la forma di redia, cioè munita di un

Fig. 70. Embrione e nutrice di un Monostomum : da Siebold (*).

(") $a$. Principio dell'intestino. $-b$. Ovario. $-c$. Ovidutto. $-d$. Testicoli. - e. Cirro (pene). $-t$. Organo escretore.

(") A. Due nutrici isolate. $-a$. di profilo. $-b$. di fronte.

B. Un embrione avente nell'interno la nutrice tigliata. - a. surchiatojo. $-b$. Occhi, $-c$. La nutrice.

De Furppr. Funzioxi riproduttice. 
apparato digerente e di vasi con ciglia vibratili. (V. pag. 17, fig. 10-B). Le nutrici, fatte libere nel corpo del mollusco, generano, come le sporocisti, per germi liberi interni una doppia figliuolanza, cioè altre nutrici e larve, ossia cercarie. Queste non presentano giammai il dardo di cui vanno munite invece le cercarie nate in semplici sporocisti, e sovente hanno occhi rudimentali con una lente ed un pigmento nero (fig. 7le 72):

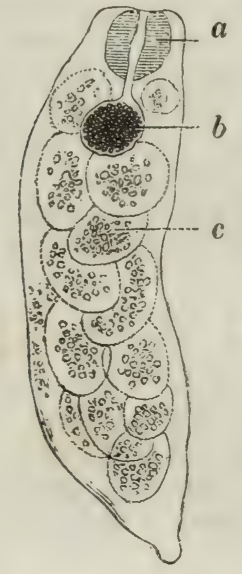

Fig. 71. Sporociste organizzata o redia dell anfistoma delle rane (").

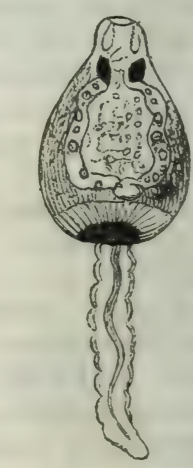

Fig. 72. Cercaria ossia larva dell'anfistoma delle rane.

giunte poi a sufficiente sviluppo, lasciano la loro nutrice; rimangono per qualche tempo libere nel mollusco, poscia, o nel corpo stesso di questo, o più di soventi fuori nell'acqua ambiente, si raccolgono a palla, segregano a strati una sostanza densa mucosa, e cosi incistidate possono conservarsi per lungo tempo, finchèil caso non le porti nell'intestino di un vertebrato, ove le cistidi si aprono, ed i trematodi inclusi raggiungono rapidamente il termine dalla loro carriera vitale, e ricominciano la generazione per uova. Questo ciclo fu a quest'ora positivamente verificato in varie specie, come nel monostomo degli uccelli acquatici, che allo stato di larva o di cercaria è parassito del grande planorbe ( $P l$. corneus); nell'anfistoma delle rane e delle

(1) a. Faringe muscolosa. - b. Stomaco. - c. Germi di anfistuma. 
salamandre, che passa lo stadio di cercaria nei piccoli planorbi ( $\boldsymbol{P l}$. nitidus e vortex); nel distoma echinato degli uccelli che vive come cercaria nei grossi limnei (L. stagnalis e palustris) (1).

La metagenesi infine, di cui redemmo tanti e maravigliosi esempi, ha luogo anche negli infusorj, ma in questi animali è più difficile seguire la successione delle generazioni, ond'è che diffettiamo ancora di una storia veramente completa anche di una sola specie. Le belle osservazioni di Stein hanno però fatto fare un gran passo anche in questo argomento speciale: ed intanto basti qui il richiamare come in un'intiera famiglia di infusorj, le specie si presentino sotto due forme alternanti, di vorticelle e di acinete, ciascuna delle quali si distingue anche pel modo di propagazione, e per la forma de' nuovi prodotti.

Tutti questi fatti, venuti in piena luce soltanto in que. st' ultimo decennio, ci mettono nella necessità di rinnovare intieramente la classificazione e la storia degli ani. mali inferiori, essendo evidente che un numero grandissimo di specie dovranno sparire dai cataloghi sistematici, come su null'altro fondate che su caratteri individuali, talvolta diversissini, che una sola specie può presentare nella sua serie genetica.

\section{§ 7. Cenerazione spontanea.}

L'apparizione inaspettata di esseri viventi, in casi ed in circostanze che ne rendono, almeno al volgo, misteriosa la vera provenienza, ha servito di fondamento ad un'ipotesi antichissima, secondo la quale sarebbe ammesso che di simili esseri possano formarsi dal semplice fortuito concorso de'loro elementi costitutivi, senza la necessaria opera di un progenitore. Contribuí non poco al favore di questa teoria il vedere generarsi animali dalla apparente dissoluzione di altri organismi, dalla fermentazione lenta di sostanze organiche. Non sembrò sufficiente il vedere fra questi due fenomeni una relazione qualunque, ma si volle che uno dipendesse strettamente dall'altro: che i principj sprigionantisi

(1) $\mathbf{E}$ bene avvertire che in alcune specie i grovani individui nati nelle sporocisti o nella redies sono privi di coda, quindi non si presentano rom. cercarie. 
colla fermentazione, trovandosi allo stato nascente, teridano con particolar energia a combinarsi di nuoro, ed a generare altri corpi organici.

I più discreti campioni di questa teoria limitano la possibilità di un'origine primitiva e spontanea, o come direbbesi di getto, ai semplicissimi fra gli esseri viventi, ammettendo come proprietà naturale e costante di certi composti il presentarsi sotto forma di globuli o di cellule, nella stessa guisa che altri si presentano sotto quella di cristalli; ed ammettendo altresi che tosto formata una cellula, per necessaria condizione della sina struttura, divenga strumento di alcuno fra que' fenomeni che si considerano come manifestazioni della vita: fra i quali primo e più costante e più palese, un movimento.

Ma la quistione così circoscritta è intieramente cambiata, e si riduce piuttosto a stabilire: quali manifestazioni si richieggano, perchè globuli o cellule od altri corpuscoli sospesi e moventisi nell'acqua, debbano considerarsi come veri individui organizzati e viventi. Ora è ben sicuro non bastare a tal giudizio il moto per quanto vario ed illudente in cui possano essere trascinati simili corpuscoli. Si rifletta soltanto a quel fenomeno fisico detto movimento molecolare o browniano, che presentano cosi evidente varj corpuscoli sospesi nell'acqua, ai quali nessuno sarebbe tentato attribuir la natura di esseri viventi (1). Molti globuli che infatti si producono in soluzioni acquose di sostanze organiche oscillano, si agitano, nell' istesso modo: ma il roler per ciò solo considerarli come monadi viventi, è in vero un precipitare il giudizio. Ben altro si richiede a caratterizzare la vita.

Lo stato attuale della chimica, inoltre, non è favorerole all'idea fondamentale di questa teoria; essendo ormai riconosciuto che i composti organici complessi, ne'loro processi di scomposizione, a libero contatto dell'aria, lungi dal ristabilire altri composti organici complessi, tendono inrece a risolversi in più semplici combinazioni inorganiche.

(1) Come per cause puramente fisiche possano prodursi movimenti del Intli) analoghi ad alcuni che si osservano in corpi viventi, risulta in partieolar morlo dalle curiose esperienze di E. E. Weber sui fenomeni che paIesano i granuli di sostanze resinose (per esempio di gomma golla) sospesi in un miseuglio di acqua ed alcool sotto certe condizioni (Vedi Bullettino Acllir Reale Aceademia di Sassonia. Classe Fisico-Matem. 1854). 
Sarebbe opera lunga e vana il passare a rassegna i singoli fatti, ai quali si è voluto appoggiare la teoria della generazione spontanea. Già sono trascorsi due secoli da che Redi con una serie d'ingegnosi esperimenti ridusse al loro reale valore alcuni di questi fatti, facendo vedere come i bacherozzoli delle frutta e delle carni, non si producano dalla fermentazione della materia che li annida, ma da uova che diverse specie di insetti vi hanno previamente deposte. Egli ha cosi additato il vero metodo per la dilucidazione di altri fatti analoghi rimasti oscuri, e sui quali solamente potrebbe ancora agitarsi qualche discussione al giorno d'oggi.

Due generi di fenomeni prestano deboli armi agli ultimi e più tenaci sostenitori della generazione spontanea, e sono la formazione de'vermi intestinali, e quella degli infusorj.

E. generalmente conosciuto che ogni essere vivente pui ricettare e nutrire ne' suoi visceri più specie di altri esseri viventi. I vertebrati in special modo ospitano nel loro canale alimentare diverse specie di parassiti, rappresentati dalle tre più comuni forme degli ascaridi, de' distomi, " delle tenie. Anche per queste specie, viventi in cavità che hanno libera comunicazione coll'esterno, sembra difficile od impossibile la provenienza da' germi introdotti, perciocchè esse non s'incontrano fuori di quelle regioni e di quegli ospiti.

Le difficoltà crescono pei rermi che si dissero trovati nei feti ancora rinchiusi nell'utero materno, e per quelle specie che tanto di frequente si incontrano nella polpa stessa de' visceri, come per gli echinococchi, pe' cisticerci, pe'cenuri; poichè tali vermi non producono mai uova, ed ammesso ancora che le producano, non si saprebbe trovare la via per la quale queste uova possano essere portate nell'intimo tessuto di visceri chiusi.

Si è anche invocata la circostanza che gli entozoi si trorano appunto in un focolajo di operazioni chimico-vitali, in mezzo a gran copia di materiali plastici, dai quali si potrebbero facilmente produrre nuovi organismi: mentre non si saprebbe credere come quei vermi, pervenuti dal di fuori nell'intestino de' loro ospiti, possano resistere all'azione de' sughi digerenti.

Nel paragrafo antecedente già abbiamo esposto alcuni fatti che rischiarano non pochi misteri della generazione 
degli entozoi. Già redemmo come i cenuri, gli echinocchi, i cisticerci siano scolici di tenie, derivino perciò da uora di tenie. Che tali uova possano essere assorbite e tradotte in circolazione, non è menomamente da dubitarsi, quando è noto che vengono facilmente assorbiti nell'intestino anche particelle solide di sostanze inorganiche, siccome fu da alcuni fisiologi dimostrato col pulviscolo di carbone. Aggiungeremo a questa considerazione il fatto importantissimo, che nelle pecore affette dal cenuro si trovano molti embrioni di tenie ne'vasi delle meningi (1); nè alcuno penserà mai che questi embrioni siansi formati spontaneamente in quelli stessi rasi, come fu supposto, e sempre senza fondamento, per le filarie che si trovano cosi soventi nel sangue di vari animali.

La formazione di tenie complete dalle accennate tre forme di scolici introdotte nell'intestino ne' vertebrati, malgrado, anzi col farore de'sughi digerenti, è parimenti dimrostrata da facili e decisive sperienze, nè più suscettibili di dubbio alcuno.

Infine deve pur accordarsi molto valore al rapporto trovato dalla frequenza della tenia nell'uomo col diverso genere di nutrimerito, e con certi particolari professioni. In Europa sono particolarmente affette da questo parassita coloro che fanno molto uso di carni crude anche salate ed affumicate, e specialmente poi i macellai ed i pizzicagnoli. Sembrano invece andarne immuni quelli che, vincolati a certe discipline religiose, si astengono affatto dall' uso delle carni. Nell'Abissinia, ove la base del nutrimento ordinario consiste principalmente di carni crude, la tenia è si frequente che si considera come in uro stato fuori del normale ]'individuo che ne va esente. La ragione di questi rapporti non può esser doruta ad altro se non alla facilitá colla quale le uova della tenia dell'uomo possono passare coll'alimento nel corpo de' nostri comuni animali da macello, per quivi convertirsi in scolici, e sotto questa forma rientrare nell'intestino umano (2).

(1) Questa osservazione ḋ dovuta a Numan e Schiroeder Van der Kolk.

(2) Recentemente il Dottor Küchenmeister pote dimostrar sperimentalmente la derivazione della tenia dell uomo dai cistieerei presi dal lardo del majale, ammisistrati at una fonna condannata al patibolo, in varic riprese pochi giomi e fin poche ore innanzi l'esecuzione della sentenza capitale (Ammales des Seiences naturelles 4. Serie, 3 vol., pag. 377 ). 
Quanto agli entozoi della famiglia de' trematodi (distomi, monostomi, anfistomi), gioverà qui richiamare come giungano essi a completo sviluppo nell'intestino de'vertebrati, pervenendovi allo stato di larve incistidate: che gli embrioni nati poscia dalle uova, passano nel corpo de'molluschi, ove si sviluppano gli esseri produttori (nutrici) delle anzidette larve, le quali, per trasmigrazione passiva od attiva, rientrano nell'intestino de' vertebrati.

Più oscura è la storia de' nematoidi (ascaridi, strongili, ecc.), non soggetti a vera metamorfosi. Ma la frequenza colla quale si incontrano nelle acque, come anche in alcune sostanze alimentari (per esempio negli stessi cereali), di quei vermi filiformi agami che soglionsi indicare colla vaga denominazione di vibrioni, anguillule, filarie; il non incontrar giamınai fuori dal corpo de'vertebrati questi vermi muniti di organi sessuali, sono circostanze che tracciano già il programma di un'ipotesi assai razionale, quando assolutamente se ne voglia una.

Dobbiamo confessare, è vero, che fino ad oggi non si conosce la storia genetica completa, l'intiera successione delle metamorfosi e delle trasmigrazioni, se non di pochissime specie: che di molte non si colloscono che alcuni stadj, e di un numero ancora maggiore che stadj isolati(1). Ma i fatti chiari e precisi che abbiamo riferiti, il valore incontrastabile delle più evidenti analogie, ci obbligano a considerare come sciolta la parte teorica generale del problema. Che se realmente sussistono molte difficoltà pratiche per singoli casi, queste non sono che temporanee, e vamno esse pure giornalmente sciogliendosi, e in nessun caso autorizzano o solamente permettono che si ricorra ad una teoria cui manca l'appoggio del benchè menomo fatto positivo, e che è in tanta opposizione colle leggi eterne che regolano il creato (2).

Se passiamo ora agli infusorj, troveremo che anche da questo lato manca ogni solidita di fondamento alla ipotesi della generazione spontanea.

(1) Una delle più ovvie specie di entozoi, la cui storia é completamente all'oscuro, e che merita per molti rispetti la speciale attenzione de' naturalisti, è la Fasciola epatica che infesta le pecore.

(2) Per una completa trattazione di questo argomento delle metagenesi e trasmigrazioni degli entozoi, rimando il lettore alla gia citata opera dell'egregio mio amico il Professore De Siebold di Monaco, tradotta recentemente negli Annales des Sciences naturelles (4. ${ }^{\mathrm{e}}$ Série, Vol. 5). 
Come punto di partenza si ha il fatto conosciutissimo, che se abbandonasi all'influenza della luce solare un bicchiero di acqua, dopo breve tempo questo è popolato da una moltitudine di esseri organici che prima non vi esistevano. Se in luogo di pura acqua s'adopera un'infusione vegetale, per esempio di fieno, quegli esseri organici vi si svilupperanno più rapidamente, ed in assai mag. gior copia e varietà.

Per aver diritto a sostenere che tali esseri organici si sono prodotti dalla pura e semplice combinazione dei loro elementi costitutivi, bisogna esser sicuri della completa esclusione di ogni sorta di germi organici dall'esperimento.

Ora quando si roglia concedere che la previa ebullizione dell'acqua adoperata a questo sperimento basti a distruggere la vitalità de'corpuscoli organici che vi poteano essere contenuti, resta a vedersi se debba farsi un' egual concessione per l' aria che all'esperimento medesimo ha preso tanta e sì necessaria parte.

Sono già note da molto tempo le osservazioni fatte prima da Moscati, e poscia da Boussirngault, delle quali risulta contenersi nell'aria miasmatica delle paludi una sostanza organica azotata. Varj fatti comprovano inoltre che sempre e dovunque, nella grande massa dell' atmosfera trovansi invisibilmente sospesi corpuscoli organici. E a questi, e precisamente alla loro carbonizzazione nell'acido solforico concentrato, che si deve l'annerimento di questo acido lasciato a contatto coll'aria. Dall'acido solforico così annerito si possono ottenere arrche minutissimi cristalli di solfato di potassa, la cui base alcalina non può esser data che dagli stessi corpuscoli organici dell' atınosfera. L'aria che trovasi a contatto con un corpo rovente, esala in distinto odore di sostanza organica bruciata.

Sotto particolari circostanze il pulviscolo estremamente diradato che sta sospeso nell'atmosfera, si condensa in una polvere meteorica, che il vento travolve e lascia quindi precipitare nella terra. Ehrenberg che ha esaminato varie li queste polveri cadute in diverse epoche ed in localiti liverse, le ha trovate quasi per intiero composte di esseri organici perfettamente determinabili (1).

(1) Vedi varie comunicazioni fatte all'Aceademia di Berlino, ma specialmente l'opera apposita Die Passat Staube, ecc. 
Non appena uno di tali esseri sia caduto in condizioni propizie, incomincia e si compie rapidamente il suo sviluppo, e cosi diventa stipite di nuove generazioni. Lo spazio di 24 ore è già sufficiente perchè da un solo germe possano provenire milioni di individui. L' acqua pura, esposta alla luce solare, non presenta infusorj se non dopo il lasso di alcuni giorni, perchè l'impreteribile legge che regola l'armonia e l'equilibrio de'due regni organici, che vincola l'esistenza degli animali a quella delle piante, esige che lo sviluppo di microscopici semplicissimi vegetali preceda e prepari quello degli infusorj. Che se all'acqua viene aggiunta appositamente una certa quantità di succo o di decozione di una pianta erbacea, lo sviluppo degli infusorj sarà tanto più pronto.

Queste induzioni da risultati sperimentali sono suscettibili di una controprova che viene tutta a loro conferma. Quando il liquido destinato a diventar nido di infusori sia stato previamente esposto ad un'alta temperatura, capace a distruggervi la vitalità di ogni germe organico, I' aria che deve per necessità concorrere nell' esperimento siasi fatta passare previamente per un tubo rovente, non avrà più luogo in tal caso la formazione di alcun essere organico. Si è veduto di più che se il liquido che ha servito alla esperienza contiene una sostanza suscettibile di subire un processo di fermentazione, anche questo processo non avrà compimento (1).

La stretta connessione tra la fermentazione delle sostanzt. organiche e lo sviluppo in esse di minuti organismi ha condotto alcuni chimici a supporre tra questi due fenomeni una dipendenza inversa da quella che è nel concetto li alcuni naturalisti, cioè non a far provenire la nuova formazione di esseri viventi dallo scomporsi della materia. organica morta, ma a considerare questa scomposizione coine prorocata da quelli esseri. Ciò che è causa per gli uni è effetto per gli altri. Questa opinione prese lavore dall'osservazione di Schwann, che il lievito di birra ammasso di vegetali microscopici; e che può ottenersi la fermentizione dello zuccaro coll'aggiungervi, in luogo del lievito ordinario, cellule regetali fresche e viventi.

Quale sia il modo d'azione dell'aria sulle sostanze fer-

(1) Vedi a questo proposito le rierre di IIelmholtz negli Arehirj di Viiller, 1813, pag. 453 . 
mentabili è ancora un problema. Generalmeute si crede che la fermentazione sia determinata da un processo di ossidazione: se ne attribuisce quindi la causa all'ossigene dell'aria. Ma che ciò veramente sia, è lecito il dubitare, quando si pensa che la composizione normale dell'aria, o ineglio la proporzione de' suoi elemienti gasosi, non sono per nulla alterate dal passaggio per un tubo rovente, pel quale perde l'aria la proprietà di determinare la fermentazione. Lo stesso ossigene nascente, svolto dalla decomposizione dell' acqua col mezzo della pila, e dotato di si energico potere ossidante, si dimostra per sè solo inattivo(1). Ma nel caso nostro riesce di molto interesse il fatto che per altra circostanza può l'aria perdere la virtù di proinovere la fermentazione di alcune sostanze organiche: ed e. quando sia stata previamente filtrata attraverso il cotone (2). Siccome per questa filtrazione non viene per nulla alterato il miscuglio gasoso che essenzialmente costituisce l'aria, cosi non si saprebbe dar ragione del fatto, se non attribuendolo al privarsi essa per tal maniera de' corpuscoli organici che tiene sospesi (3).

Alcuni naturalisti hanno immaginato un altro processo di generazione spontanea, ed ammettono che particelle staccate dall'organismo possano individualizzarsi e svilupparsi in altrettanti organismi completi indipendenti, e dotati di vita propria. Si è supposto, per esempio, che $\mathrm{i}$ vermi intestinali nascano da villi dell' intestino staccati e indivi-

(1) Vedi Helmholtz op. cit.

(2) Vedi Schrüder e De Dusch. Annales de Chimie et Physique. T. 41, 1854, pag. 189.

(3) Lo studio de'corpuscoli organici dell'atmosfera è di si grande importanza, che non deve bastare l'averne constatata l'esistenza co' mezzi che abbiamo indicati. I processi suggeriti a quest' uopo dal signor Baudrimont (Comptes rendus, ece., 183\%, 2. ${ }^{\circ}$ semestre), sono troppo imperfetti. Io preferirei i seguenti :

1. ${ }^{\circ}$ Far passar tranquillamente, ma pel lasso di vari giorni, col mezzo di un aspiratore, dell'aria per un tubo di vetro pieno di cotone, o meglio di amianto: esporre quindi o il cotone o l'amianto in circostanze opportune perché abbiano a svilupparsi i corpuscoli organici che potesse aver raccolto nel servire da filtro.

2." Raccogliere le prime stille di una pioggia temporalesea suceedente a lunga siccita, e farvi parimenti sviluppare i corpuscoli organici che vi fossero contenuti.

S'intende da sé che onde queste sperienze riescano concludenti è d'uopo renderle comparative, non solo variando i materiali dalle esperienze mede. sime, ma anche istituendo queste in circostanze diverse di tempo e di luogo. 
dualizzati: il che sarebbe creare vincoli di paternità fra un animale e i suoi parassiti. La fisiologia nell' attuale suo stato ha fatto inesorabile giustizia di questo, come di tante altre fantasticherie sorte da osservazioni erronee interpretate col prisma di teorie preconcette.

Concludiamo che se la teoria della generazione spontanea fosse conforme alla rerità, essa avrebbe trovato col progredire delle nostre cognizioni, col perfezionamento dei nostri mezzi di ricerca, un sempre più valido appoggio dai fatti: le è toccata invece una sorte affatto opposta, ciò che è sufficiente a farla respingere, malgrado il fascino che essa può esercitare sulla fantasia de' giorani studiosi, e malgrado l'autorità di ingegni distinti che le hanno dato, ne tempi passati, un passaggern splendore. Ex mihiln nihil. Omne vivum ex ovo. 



\section{N D I C E}

\$1. Della fecondita degli animali. . . . . . . . . pag. 1

2. Della generazione agamica . . . . . . . . . . (5)

a) Per scissione . . . . . . . . . . . . . . . " is:

b) Per gemme . . . . . . . . . . . . . . . . . . . . . 8

c) Per spore . . . . . . . . . . . . . . . . . 11

3. Della generazione sessuale. . . . . . . . . . . " 17

a) Apparato maschile . . . . . . . . . " " is i

b) Apparato femmineo . . . . . . . . . . . " 21

c) Caratteri esterni del sesso . . . . . . . . . . . . . " 2?

d) Ermafroditi . . . . . . . . . . . . . 333

e) Neutri . . . . . . . . . . . . . . . . . . . 39

f) Fecondazione dell'uovo . . . . . . . . . . . 41

g) Epoca degli amori . . . . . . . . . . . . . . 4't

1. Ibridi . . . . . . . . . . . . " 46

Sviluppo dell'uoro e formazione dell'embrione (1) . . . " 48

ə. Cura de' figli . . . . . . . . . . . . . . . . " 66

6. Metamorfosi. Polimorfismo. Netagenesi . . . . . 79

7. Generazione spontanea . . . . . . . . . . . . . 99

(1) Per errore fu ommesso di contrassegnare come distinto questo paragrafo. 



\section{ERRORI DI STAUPA DA CORREGGERSI.}

A puy. 56 lin. 8 in luogo di alimentari leggasi elementari.

90 La spiegazione della figura 63 si rifaccia nel segucute mode.

(') a. Vescica natatoria. - b. Ammasso di giovani individui locumuturi. - $b^{\prime}$. Uno di questi individui sviluppato - $c$. Ammasso di tiovant individui (polipi) nuirienti. - $c^{\prime}$. Di tali individui conpletemente sviluppati. - $d$. Individui riproduttori (polipi astomi), produente alla loro base capsule ovifere (meduse). - P. Fito per lat pessa. f. Tronco comune. 






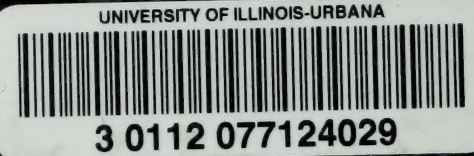

ac
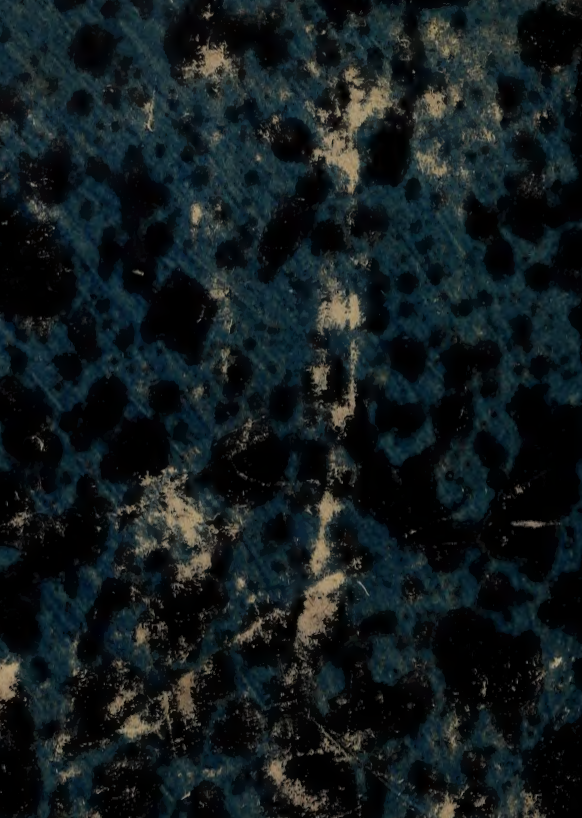

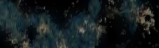
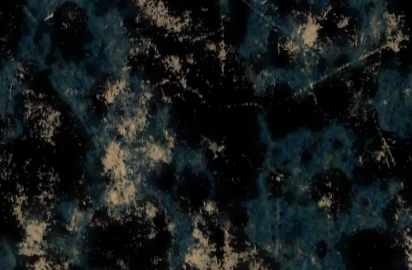

2.

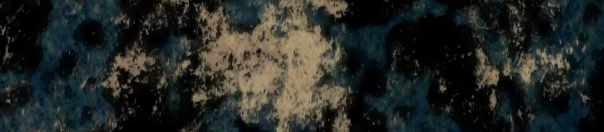
Nets

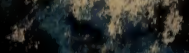

